\title{
Evaluation of Nitrification Kinetics for a 2.0 MGD IFAS Process Demonstration
}

\author{
Wesley Allan Thomas
}

Thesis submitted to the faculty of Virginia Polytechnic Institute and State University in partial fulfillment of the requirements for the degree of

\section{MASTER OF SCIENCE}

in

\section{ENVIRONMENTAL ENGINEERING}

Charles B. Bott

Gregory Boardman

John Novak

March 30, 2009

Blacksburg, Virginia

Keywords: IFAS; Nitrification; Biofilm; NOB; AOB 


\title{
Evaluation of Nitrification Kinetics for a 2.0 MGD IFAS Process Demonstration
}

\author{
Wesley Allan Thomas
}

\begin{abstract}
The James River Treatment Plant (JRTP) operated a 2 MGD Integrated Fixed Film Activated Sludge (IFAS) demonstration process from November 2007 to April 2009 to explore IFAS performance and investigate IFAS technology as an option for a full scale plant upgrade in response to stricter nutrient discharge limits in the James River Basin. During the study, nitrification kinetics for both ammonia and nitrite oxidizing bacteria and plastic biofilm carrier biomass content were monitored on a near-weekly basis comparing the IFAS media, the IFAS process mixed liquor, and mixed liquor from the full-scale activated sludge process. Carrier biomass content is variable with respect to temperature and process SRT and relates to the localization of nitrification activity in the IFAS basin. Similar to trends observed for carrier biomass content (Regmi, 2008), ammonia oxidizing bacteria (AOB) and nitrite oxidizing bacteria (NOB) activity also shifted from the fixed film to the suspended phase as water temperatures increased and vice versa as the temperature decreased. The data suggest that AOB activity occurs on the surface of the biofilm carriers, while NOB activity remains deeper in the biofilm. During the highest temperatures observed in the IFAS tank, AOB activity on the media contributed as little as $30 \%$ of the total nitrification activity in the basin, and after temperatures dropped below $20^{\circ} \mathrm{C}$, AOB activity in the fixed film phase made up $75 \%$ of the total activity in the IFAS basin. During the warmest period of the summer, the media still retained more than $60 \%$ of the total NOB activity, and more than $90 \%$ of the total NOB activity during the period of coldest water temperature. This trend also points out that some AOB and NOB activity remained in the mixed liquor, even during the coldest periods. The retention of nitrification activity in the
\end{abstract}


mixed liquor indicates that the constant sloughing of biomass off of the carriers allowed for autotrophic activity, even during washout conditions. Carrier biomass content and nitrification rates on the IFAS media remained constant along the length of the basin, indicating that the IFAS tank is will mixed with respect to biomass growth, although there was a concentration gradient for soluble species $\left(\mathrm{NH}_{4}-\mathrm{N}, \mathrm{NO}_{2}-\mathrm{N}, \mathrm{NO}_{3}-\mathrm{N}\right)$. In addition to the weekly nitrification rate measurements, experiments were also conducted to determine how operational inputs such as dissolved oxygen (DO) and mixing affect the nitrification rates. Mixing intensity had a clear impact on nitrification rates by increasing the velocity gradient in the bulk liquid and decreasing the mass transfer boundary layer mass transfer resistance. At higher mixing intensities, advection through the mass transfer boundary layer increased making substrate more available to the biofilm. The affect of mixing was much more profound at low DO, whereas increased mixing had less effect on nitrification rates at higher bulk liquid DO. DO also affected nitrification rates, such that as DO increased it penetrated deeper into the biofilm increasing the nitrification rate in a linear fashion until the biofilm became saturated. Another aspect of the research was modeling effective half saturation effects for AOB and NOB activity in the fixed film phase. The modeling work demonstrated that $\mathrm{K}_{\mathrm{S}}$ for $\mathrm{AOB}$ activity on the media was similar to accepted suspended growth $\mathrm{K}_{\mathrm{S}}$ values, while $\mathrm{K}_{\mathrm{S}}$ for $\mathrm{NOB}$ activity on the media was considerably higher than suspended growth $\mathrm{K}_{\mathrm{S}}$. This trend indicates that nitrite was not as bioavailable in the biofilm and resists diffusion into the deeper part of the biofilm where NOB activity takes place. $\mathrm{K}_{\mathrm{O}}$ for both $\mathrm{AOB}$ and $\mathrm{NOB}$ activity in the biofilm was higher than typical suspended growth values because of boundary layer and biofilm diffusion resistances. In addition, the presence of readily degradable organics did not significantly affect nitrification rates on the media, but did reduce nitrification rates in the mixed liquor. That, combined with 
low chemical oxygen demand (COD) uptake rates indicates that little heterotrophic activity is occurring on the media. 


\section{Acknowledgements}

I would like to sincerely thank Dr. Charles Bott, my Thesis advisor, for his guidance and support over the past years. Charles played a key role in influencing me to pursue graduate studies and have provided valuable insight to every aspect of my graduate work.

Funding for this project was provided by the Hampton Roads Sanitation District. Their support for this research is greatly appreciated. I would like to offer a special thanks to David Waltrip, Bob Rutherford, Rick Baumler, Danny Barker, Jesse DeLuna, all of the HRSD employees at the James River Treatment Plant, and all of the scientists that assisted with the research.

I would like to acknowledge Dr. Gregory Boardman and Dr. John Novak for serving on my committee and offering support and comments on my research.

I also express appreciation for Dr. Gary Schafran, Dr. Margaret Muholland, and Puskar Regmi at ODU for their contribution to the research work and allowing the use of facilities crucial to the success of the project.

In addition, I would like to offer my thanks to Ameet Pinto for helping with the molecular work done in conjunction with the nitrification kinetics work.

I would also like to extend my appreciation to Jim McQuarrie at Ch2MHill for his support and guidance with my research work.

Finally, I want to thank Rich Jones at ENVIROSIM for his help and participation with the research and modeling work associated with the research effort. 


\section{Table of Contents}

1 INTRODUCTION.......................................................................................................................................... 1

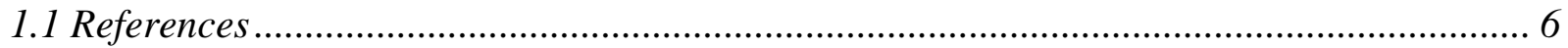

2 TECHNICAL LITERATURE REVIEWED.............................................................................. 7

2.1 Suspended Growth Nitrification .................................................................................... 7

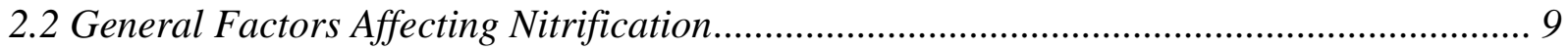

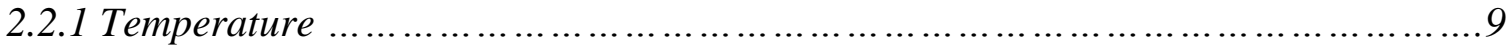

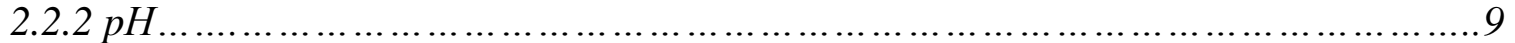

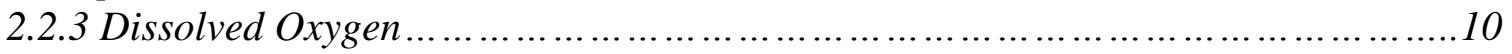

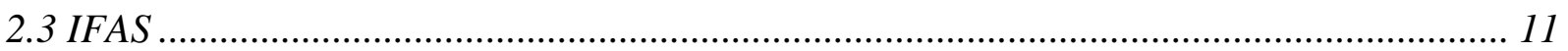

2.3.1 Process Description ............................................................. 11

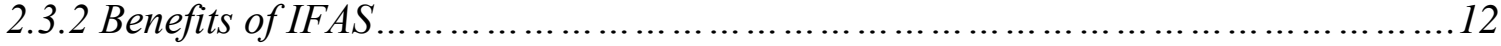

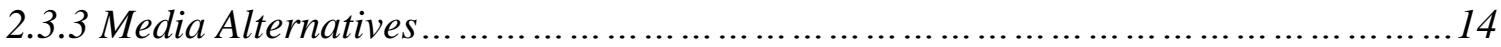

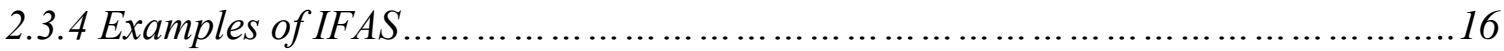

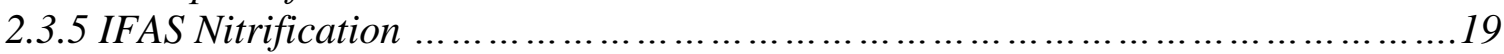

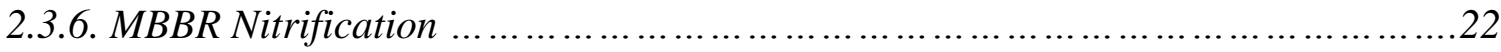

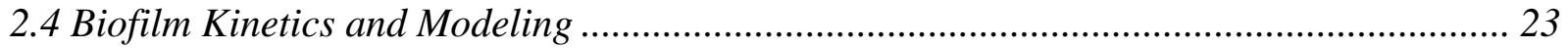

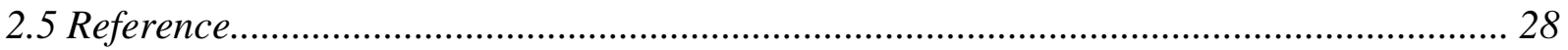

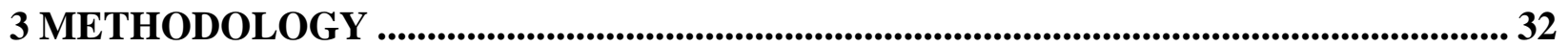

3.1 Bench Scale Reactor Construction ........................................................................... 32

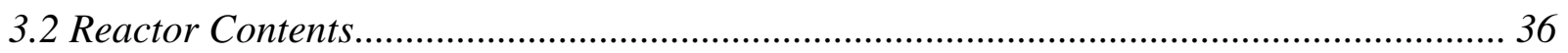

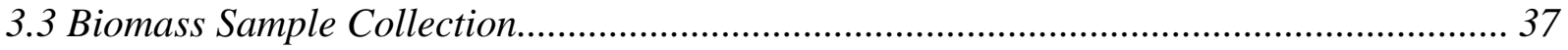

3.3.1 Nitrification Rate Testing .................................................... 37

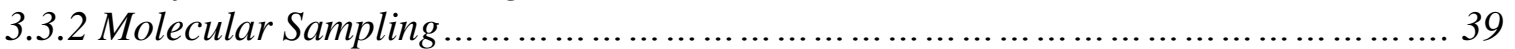

3.3.3 Carrier Biomass Content Measurements ...........................................41

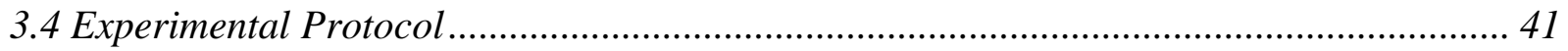

3.4.1 Nitrification Rate Testing ................................................... 41

3.4.2 IFAS Performance Testing - Campaigns ....................................... 42

3.4.2.1 Half-Saturation Coefficient Evaluation (low $\mathrm{NH}_{4}{ }^{+}-\mathrm{N}$ and $\left.\mathrm{NO}_{2}-\mathrm{N}\right) \ldots \ldots . .42$

3.4.2.2 DO and Mixing .......................................................42

3.4.2.3 Affect of COD addition on Nitrification Rates .............................43

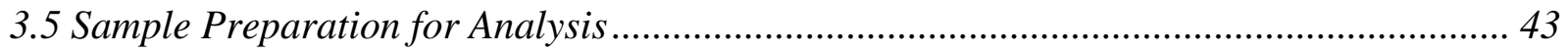

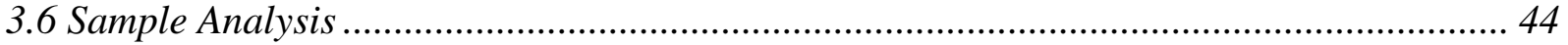

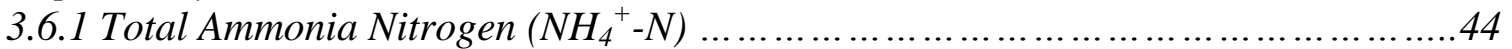

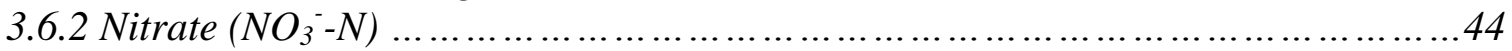

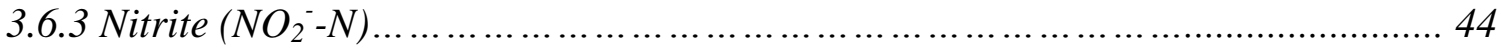

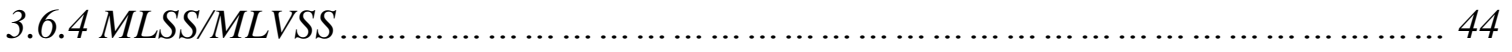


3.7 Reference

4 MANUSCRIPT 1: IFAS NITRIFICAITON KINETICS......................................................... 46

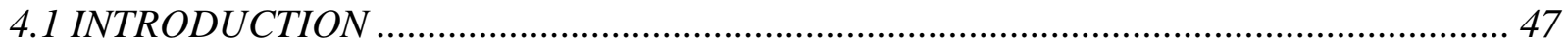

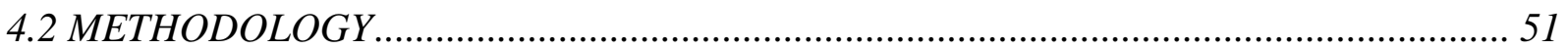

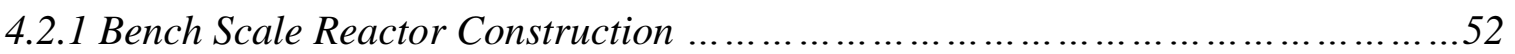

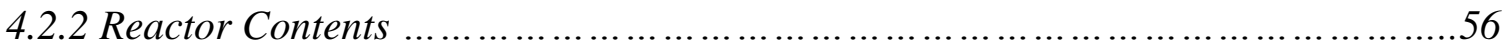

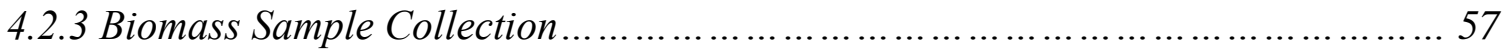

4.2.3.1 Nitrification Rate Testing ….............................................5 57

4.2.3.2 Carrier Biomass Content Measurements ...................................59

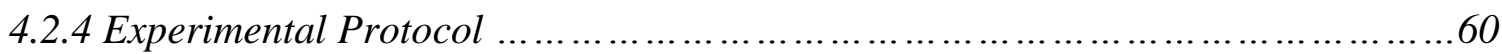

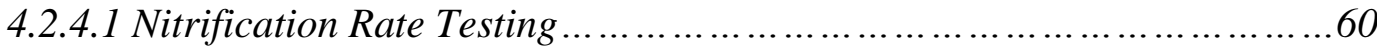

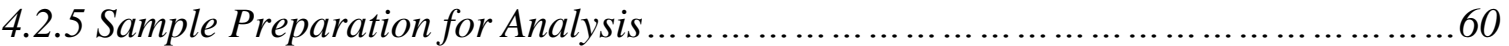

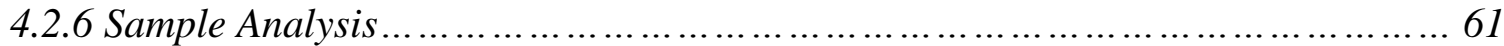

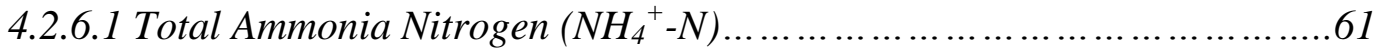

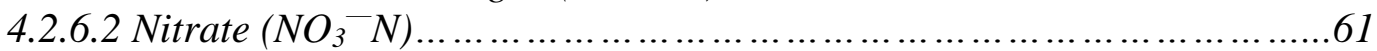

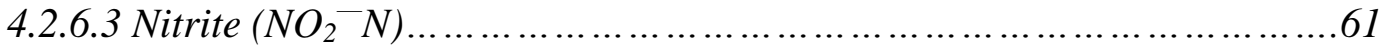

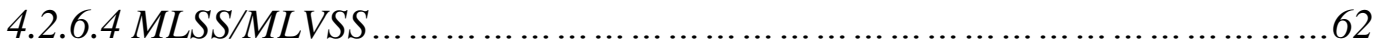

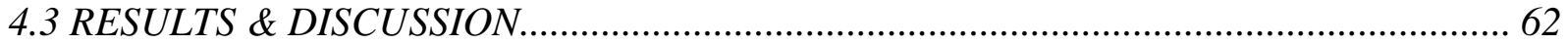

4.3.1 Plant Operation and Performance Data ............................................62

4.3.2 Temperature and Biomass Measurements ...........................................6.65

4.3.3 Typical Nitrification Rate Test Results …….....................................68

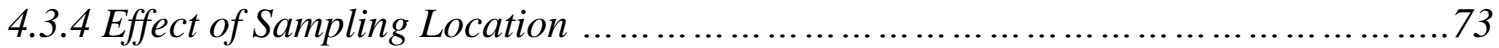

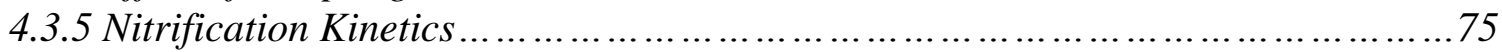

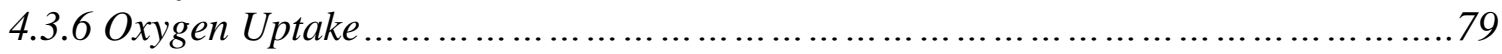

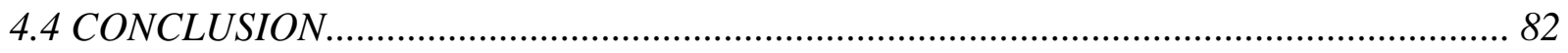

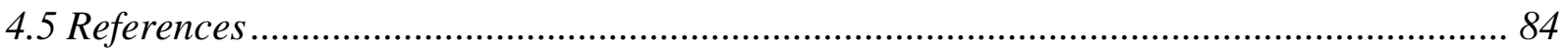

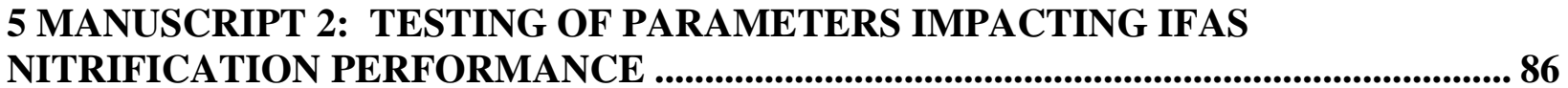

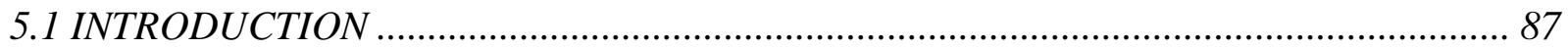

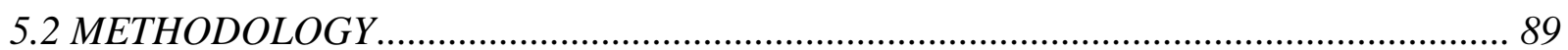

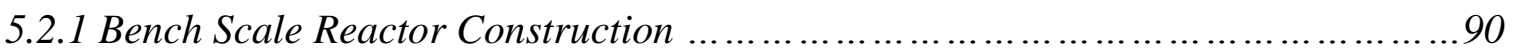

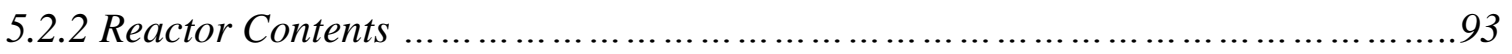

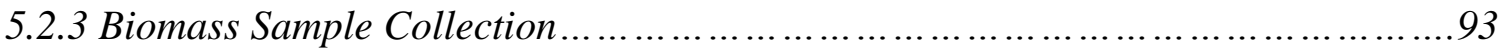

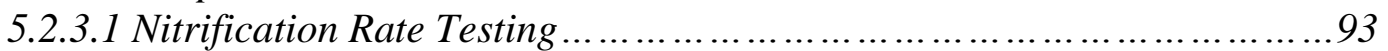

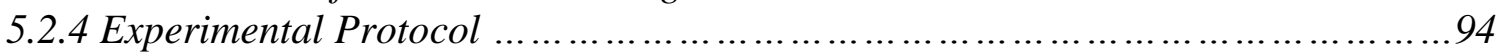

5.2.4.1 Half-Saturation Coefficient Evaluation (low $\mathrm{NH}_{4}{ }^{+}-\mathrm{N}$ and $\mathrm{NO}_{2}-\mathrm{N}$ ) .......94

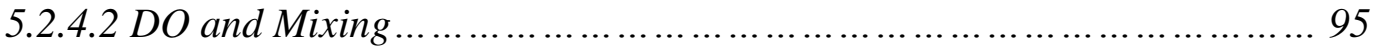

5.2.4.3 Affect of COD addition on Nitrification Rates ................................ 95

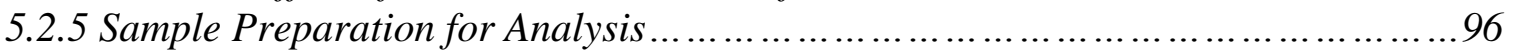

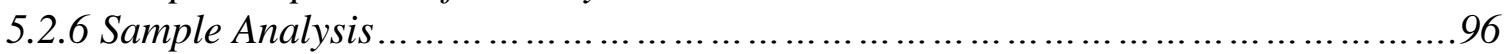

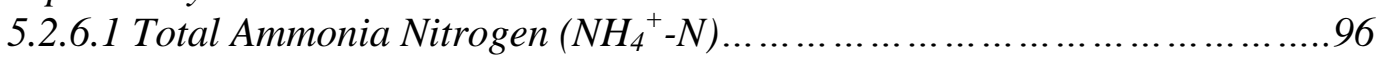

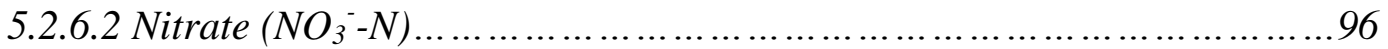




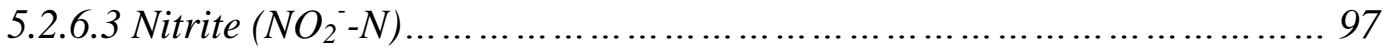

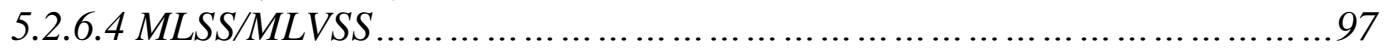

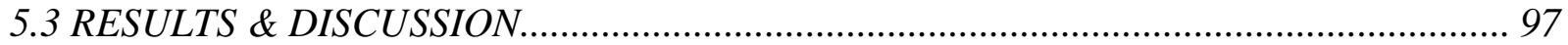

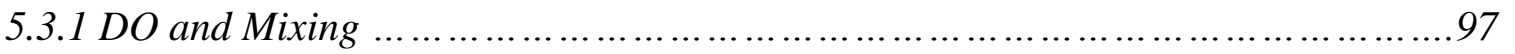

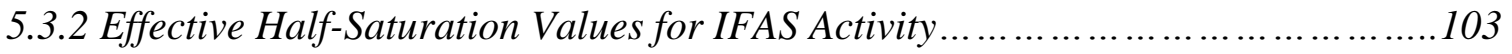

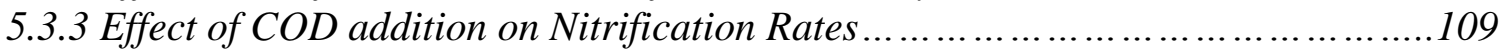

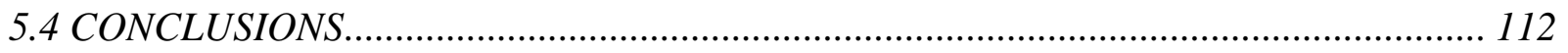

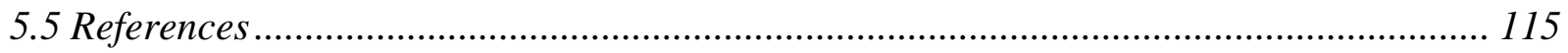

6 ENGINEERING SIGNIFICANCE ...................................................................................... 117

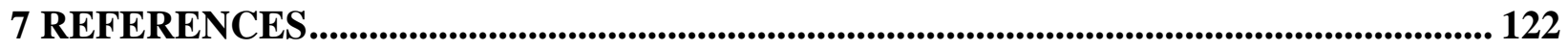

8 APPENDICES ...................................................................................................................................... 126

8.1 Appendix A. Nitrification Rate Testing Results.......................................................... 126

8.2 Appendix B. Sampling Location Results .................................................................. 128

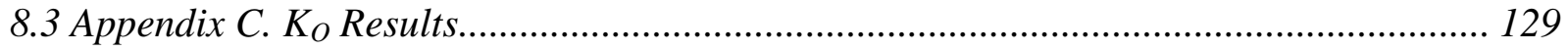

8.4 Appendix D. Mixing and DO Results............................................................... 131

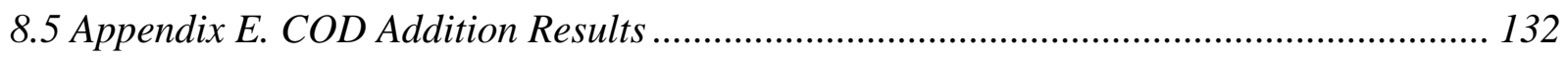




\section{List of Tables}

Table 3-1. G value range for various mixing speeds and temperatures.......................35

Table 4-1. G value range for various mixing speeds and temperatures.......................55

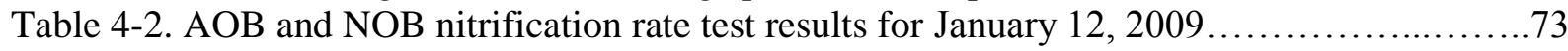

Table 5-1. $\mathrm{K}_{\mathrm{O}}, \mathrm{K}_{\mathrm{S}}$, and $\mu_{\max }$ Data for Mixed Liquor........................................ 103

Table 5-2. Diffusion coefficients for Nitrite, Ammonium, and Oxygen at $25{ }^{\circ} \mathrm{C} \ldots \ldots \ldots \ldots . . . . .105$

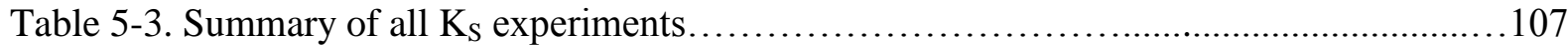

\section{List of Figures}

Figure 1-1. Process Flow Diagram of IFAS Demonstration...................................4

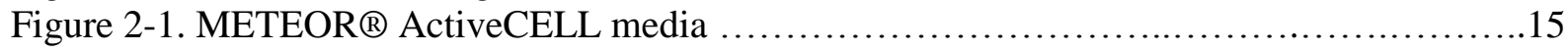

Figure 2-2. Siemens AGAR® media ...................................................... 15

Figure 2-3. Anox Kaldnes K3 Media ............................................... 15

Figure 2-4. Diagram of substrate concentration through water film and biofilm ...................24

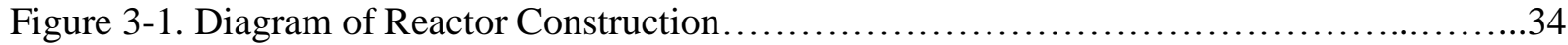

Figure 3-2. G Value Measurements for IFAS Mixed Liquor................................ 35

Figure 3-3. G Value Measurements for IFAS Media...........................................

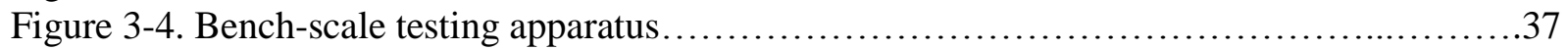

Figure 4-1. Process Flow Diagram of IFAS Demonstration...................................49

Figure 4-2. Diagram of Reactor Construction..........................................54

Figure 4-3. G Value Measurements for IFAS Mixed Liquor..................................55

Figure 4-4. G Value Measurements for IFAS Media.......................................56

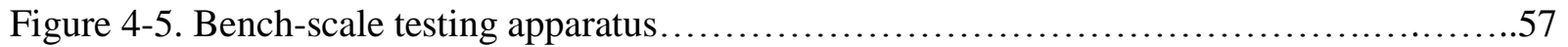

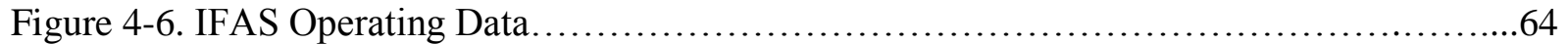

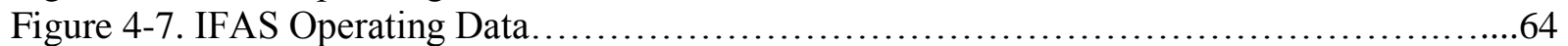

Figure 4-8. Recorded Temperatures for All Four Bench Scale Reactors........................66

Figure 4-9. Biomass Measurements on the Carriers vs. Temperature.............................68

Figure 4-10. Velocity Gradient in the IFAS tank .......................................69

Figure 4-11. AOB and NOB nitrification rate test results for January 12, 2009.................71

Figure 4-12. Nitrification Rates vs. Sampling Location................................. 74

Figure 4-13. AOB and NOB Nitrification Rates and Percent Total Activity..............................77

Figure 4-14. AOB and NOB Nitrification Rates........................................ 78

Figure 4-15. Carrier Nitrification rates Normalized to biomass content.........................79

Figure 4-16. Measured OUR vs. Predicted OUR ............................................ 81

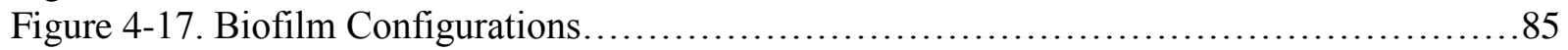

Figure 5-1. Diagram of Reactor Construction........................................ 93

Figure $5-2$. Velocity Gradient in the IFAS tank ...................................... 99

Figure 5-3. DO and Mixing Affects on Carriers................................................ 102

Figure 5-4. DO and Mixing Affects on Mixed Liquor................................... 103

Figure 5-5. Representative Model Fitting for Ks and Ko effects- June 24, 2008 ............ 105

Figure 5-6. AOB and NOB Carrier Nitrification rates vs. DO ............................... 109

Figure 5-7. AOB and NOB Nitrification Rates on the IFAS Mixed Liquor vs. DO..............110

Figure 5-8. COD Uptake Rates for IFAS Mixed Liquor and Media..........................111

Figure 5-9. Effects of COD addition on Nitrification Rates on the IFAS Media.................112

Figure 5-10. Biofilm Configurations............................................... 116

Figure $6-1$. Biofilm Configurations ................................................ 122 


\section{List of Abbreviations}

AOB-Ammonia Oxidizing Bacteria

BNR-Biological Nutrient Removal

$\mathrm{BOD}_{5}-5$ day Biochemical Oxygen Demand

COD-Chemical Oxygen Demand

DO-Dissolved Oxygen

FISH-Fluorescent In-Situ Hybridization

G- Velocity Gradient

HRSD-Hampton Roads Sanitation District

IFAS-Integrated Fixed Film Activated Sludge

JRTP-James River Treatment Plant

$\mathrm{K}_{\mathrm{O}}$-Dissolved Oxygen Half Saturation Coefficient

$\mathrm{K}_{\mathrm{S}}$-Substrate Half Saturation Coefficient

MBBR-Moving Bed Biofilm Reactor

MGD-Million Gallons Per Day

MLSS-Mixed Liquor Suspended Solids

NOB-Nitrite Oxidizing bacteria

PFD-Process Flow Diagram

QPCR-Quantitative Polymerase Chain Reaction

SLR-Solids Loading Rate

SND- Simultaneous Nitrification/Denitrification

SOR-Surface Overflow Rate

SRT-Solids Residence Time

SVI-Sludge Volume Index

TN-Total Nitrogen

TSS-Total Suspended Solids

WPCP-Water Pollution Control Plant

WTF-Water Treatment Facility

WWTP-Wastewater Treatment Plant

$\mu_{\max }$-Maximum Specific Growth Rate 


\section{INTRODUCTION}

Stringent nitrogen limitations have been and will continue to be implemented for a number of wastewater utilities discharging into salt water estuaries in the United States. Nitrogen limits are becoming stricter to address a number of issues related to discharging nutrients, namely surface water eutrophication, as well as ammonia toxicity. The need to control algae blooms in the Chesapeake Bay is not a novel issue, but as Bay health continues to decline, strict nitrogen limits from point sources are necessary to revitalize the Bay ecosystem. Many of the treatment plants for which nitrogen removal is being considered are currently designed primarily for biochemical oxygen demand $\left(\mathrm{BOD}_{5}\right)$ and total suspended solids (TSS) removal, although some plants achieve warm weather nitrification, and others must fully nitrify yearround to meet ammonia limitations. Many of these plants do not have land available for an expansion using conventional biological nutrient removal (BNR) activated sludge processes and will need to explore alternative technologies in order to meet more stringent discharge limits.

One of these emerging technologies is Integrated Fixed Film Activated Sludge (IFAS) with plastic, free-moving media. IFAS technology offers a number of benefits for plants having to upgrade for stricter nutrient limits. IFAS allows plants to retro-fit and upgrade their existing plant without significant new construction, which lowers capital costs and does not require additional plant footprint area. IFAS also enables plants designed for partial nitrification, or plants needing to expand to meet a growing demand, to achieve complete, year round nitrification despite limiting cold temperature conditions with smaller aeration tanks and without increasing the solids load to secondary clarifiers (Johnson et al. 2004; Yerrell et al. 2001). 
In 2005, new regulations were implemented as part of the Chesapeake Bay 2000 Agreement which require Hampton Roads Sanitation District (HRSD) wastewater treatment plants (WWTPs) discharging to the James River Basin to reduce the aggregate mass discharge of total nitrogen (TN) to 6,000,000 lbs/year (Water Quality Management Planning Regulation). HRSD staff concluded that biological nutrient removal with IFAS should be employed at the 16.7 MGD James River Treatment Plant (JRTP) as a cost effective strategy to help achieve this aggregate goal, decreasing effluent TN at this facility to approximately $12 \mathrm{mg} / \mathrm{L}$ (annual average).

However, IFAS remains a relatively new approach for boosting nitrogen removal performance, and there are still a number of fundamental and applied aspects of this technology that are not clearly understood. Process kinetics are not well defined with respect to variables including dissolved oxygen (DO), mixing intensity/regime, temperature, and localization of AOB and NOB activity. IFAS models that combine an IWA-style activated sludge model with a fundamental non-empirical biofilm model (considering external mass transfer and multicomponent biofilm diffusion) have been developed, but calibrated with limited full-scale experience. HRSD elected to conduct a demonstration-scale IFAS study at JRTP to evaluate the performance of this process and to develop design criteria before implementation on a wider scale. For this demonstration project, an existing single, fully-aerobic conventional aeration basin with dedicated secondary clarification, which was previously operated to achieve nitrification during warm weather months only, was converted to a 1.86 MGD (2.22 MGD max month) IFAS train in an MLE configuration with a 50\% fill of AnoxKaldnes plastic biofilm carriers in the aerobic zone only (K3 with a specific surface area of $500 \mathrm{~m}^{2} / \mathrm{m}^{3}$ ). 
Figure 1-1 represents a process flow diagram (PFD) of the IFAS demonstration tank at the JRTP. The demonstration is set up in the MLE fashion as shown below. The tank has two internal mixed liquor recycle pumps that were operated to not only return mixed liquor to the IFAS tank, but also to manage the distribution of media in the tank. For much of the duration of the demonstration study, the majority of internal mixed liquor recycle was performed by IMLR pump 1 to ensure that media concentrations in the IFAS tank were roughly homogeneous and to prevent media accumulation near the screens. During plant operation, the flows through IMLR pump 1 and IMLR pump 2 varied, but averaged as about 275\% through IMLR pump 1 and 130\% through IMLR pump 2. Operating the two IMLR pumps in this fashion created some concern with substrate short circuiting through IMLR pump 1, but after performing tracer testing, it was determined that an insignificant amount of substrate recycle was occurring and that nitrate recirculation to the anoxic zone was occurring. R1, R2, and R3 are all anoxic zones, and zone $\mathrm{R} 4$ is the tank volume dedicated to IFAS. The smaller R5 zone is also aerobic, but does not contain any IFAS media. For most of the duration of the demonstration the plant performed Garrett wasting except for December 2008, when the plant also wasted some sludge from the secondary clarifier. The WAS stream was also used to seed the full scale plant that was not operated for complete nitrification. This seeding allowed nitrifiers to be present in the full scale plant and enabled the full scale plant to achieve nitrification throughout the year. 


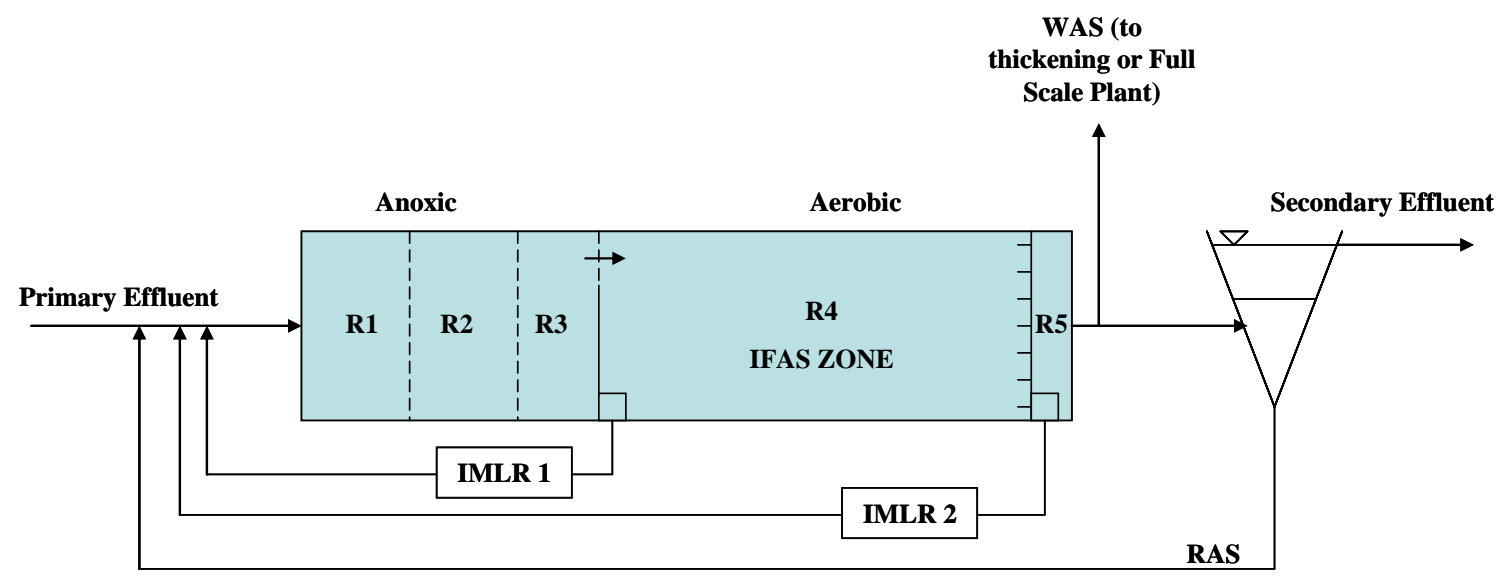

Figure 1-1. Process Flow Diagram of IFAS Demonstration

The IFAS process was targeted to achieve complete, year-round nitrification at an operating solids residence time (SRT) well below the washout value for nitrifiers during cold weather periods, suggesting that AOB and NOB must colonize the IFAS carriers (McQuarrie et al. 2004). In addition, the IFAS process has been demonstrated to achieve complete nitrification, even at temperatures as low as $8{ }^{\circ} \mathrm{C}$ (Hubbell et al. 2003). Not only does the IFAS process offer the potential for year round nitrification, the technology has demonstrated much higher nitrification kinetics than can be achieved in a conventional activated sludge process (Ross et al. 2004). Furthermore, sloughing of nitrifiers from the IFAS carriers would be expected to “temporarily bioaugment” suspended biomass operating below washout SRT, providing additional nitrification capacity (Choi et al. 2007).

The goal of this research was to measure nitrification rates for both ammonia oxidizing bacteria (AOB) and nitrite oxidizing bacteria (NOB) in both suspended growth and fixed film phases from the IFAS demonstration tank at the James River Wastewater Treatment Plant (JRWWTP), in Newport News, Virginia to achieve a number of objectives. The specific research objectives for this project were: 
- Compare nitrification rates measured from January 2008 through January 2009 to find a clear relationship between warm and cold weather conditions on nitrification rates on both the IFAS carriers and IFAS mixed liquor, and compare these rates to mixed liquor from the full scale unmodified aeration basins at the JRTP

- Determine localization of AOB and NOB activity in both phases of the IFAS process

- Achieve a better understanding of IFAS process kinetics

- Evaluate the impact of mixing on nitrification rates

- Measuring half saturation effects on the media to better understand mass transport issues for ammonia, nitrite, and oxygen and calibrate existing models to optimize modeling of the IFAS process and other biofilm processes

- Measure the effect of COD addition on nitrification rates in the mixed liquor and on the carriers

Other experimentation was conducted in conjunction with this testing to achieve additional goals related to evaluating the IFAS process including:

- Periodic nitrogen species profiling in the IFAS basin

- Weekly biomass measurements on the IFAS media (carrier biomass content)

- Florescent In Situ Hybridization (FISH) and quantitative polymeric chain reaction (QPCR) on both the suspended portion and fixed portion of biomass in the IFAS tank sampled at regular intervals throughout the nitrification rate testing (data not yet available; Pinto et al; 2009)

- Tracer testing in the IFAS basin to determine mixing regime and whether short circuiting of nutrients is occurring due to internal mixed liquor recycle placement (HRSD, 2008)

- Normal process sampling was performed by HRSD to manage process performance and optimize TN removal in the IFAS basin (HRSD, 2008) 


\subsection{References}

Choi, N., Phillips, H., Johnson, T.L., Butler, R., Lauro, T. Pilot Testing Of MBBR And IFAS Treatment Processes For Nitrification And Denitrification At The Mamaroneck WWTP. Proceedings of the $80^{\text {th }}$ WEFTEC- National Conference of the Water Environment Federation, San Diego, CA. 80: October 13-17, 2007.

Hubbell, S., McDowell, C. Cold Temperature BNR Using Integrated Fixed-Film Activated Sludge (IFAS) Hybrid Technology. Proceedings of the $76^{\text {th }}$ WEFTEC- National Conference of the Water Environment Federation. Los Angeles, CA, October 12-15, 2003.

Johnson, T., McQuarrie, J., Shaw, A. Integrated Fixed-Film Activated Sludge (IFAS): The New Choice For Nitrogen Removal Upgrades In The United States. Proceedings of the $77^{\text {th }}$ WEFTEC- National Conference of the Water Environment Federation. New Orleans, LA, October 2-6, 2004.

McQuarrie, J., Rutt, K., Seda, J., Haegh, M. Observations From The First Year of Full-Scale Operation - The IFAS/BNR Process At The Broomfield Wastewater Reclamation Facility, Broomfield, $C O$. Proceedings of the $77^{\text {th }}$ WEFTEC- National Conference of the Water Environment Federation. New Orleans, LA, October 2-6, 2004.

Ross, D., Fernandes, W., Briggs, T., Kim, N., Booth, G., Neely, D., Welp, J. Integrated Fixed Film Activated Sludge (IFAS) At The Lakeview WWTP: The Real Implementation Issues.

Proceedings of the $77^{\text {th }}$ WEFTEC- National Conference of the Water Environment Federation. New Orleans, LA, October 2-6, 2004.

Water Quality Management Planning Regulation. Chapter 720. 9 VAC 25-820-70.

Yerrell, K., Gobbie, M., Dold, P., Jones, R., Sickerdick, L. Full-Scale Demonstration Of A FreeMoving Media IFAS Process For Enhancing Nitrification Performance. Proceedings of the $74^{\text {th }}$ WEFTEC- National Conference of the Water Environment Federation. Atlanta, GA, October 13$17,2001$. 


\section{TECHNICAL LITERATURE REVIEWED}

\subsection{Suspended Growth Nitrification}

Nitrification is the process of oxidizing ammonia $\left(\mathrm{NH}_{4}{ }^{+}-\mathrm{N}\right)$ to nitrite $\left(\mathrm{NO}_{2}{ }^{-} \mathrm{N}\right)$ and then to nitrate $\left(\mathrm{NO}_{3}{ }^{-} \mathrm{N}\right)$. This biochemical process is important for a number of reasons, and as nutrient limits continue to become more stringent, the demand for better technology will be critical to the wastewater treatment field. Nitrification is a two step process that is performed by two different genera of Gram-negative bacteria. Ammonia oxidizing bacteria (AOB) accomplish the first part of the process by oxidizing ammonia to nitrite, and nitrite oxidizing bacteria (NOB) work to complete the reaction and convert nitrite to nitrate. The bacteria Nitrosomonas is most commonly associated with ammonia oxidation, although many other genera of autotrophic bacteria have been identified as AOBs (Metcalf \& Eddy, 2003; Onnis-Hayden et al. 2007). The following reaction describes the ammonia oxidation reaction: $\mathrm{NH}_{4}{ }^{+}+1.5 \mathrm{O}_{2} \rightarrow \mathrm{NO}_{2}{ }^{-}+\mathrm{H}_{2} \mathrm{O}+$ $2 \mathrm{H}^{+}$. This reaction indicates that the production of hydrogen ions is a byproduct of the reaction and, as a result, the consumption of alkalinity is associated with ammonia oxidation. The nitrite oxidizing process is performed by a different set of autotrophic bacteria, most notably in activated sludge cultures Nitrospira, though many other nitrite oxidizing genera are known (Metcalf \& Eddy, 2003; Onnis-Hayden et al. 2007). The chemical reaction describing the oxidation of nitrite to nitrate is the following: $\mathrm{NO}_{2}{ }^{-}+0.5 \mathrm{O}_{2} \rightarrow \mathrm{NO}_{3}{ }^{-}$. This reaction does not indicate a consumption of alkalinity, as is the case for ammonia oxidation.

Nitrification occurs in two different forms in wastewater treatment plants. It can be accomplished in suspended growth processes with long SRTs or in attached growth applications. By using an attached growth process, the nitrification capability of the plant is no longer a 
function of the SRT, like for suspended growth, and plants can operate at SRTs designed for BOD removal and rely on the attached growth parts of the biological processes to achieve nitrification. Suspended growth describes a free floating floc of bacteria suspended in the bulk liquid it is in contact with, while attached growth refers to biomass that is attached to some media support in the form of a biofilm. In the latter case, the biomass is immobile on the media.

Much work has been completed to quantify growth kinetics and Monod half saturation effects of nitrifiers in suspended growth applications. Envirosim (2008) suggests that AOB populations in activated sludge have a $\mathrm{K}_{\mathrm{S}}$ of $0.7 \mathrm{mg} / \mathrm{L}-\mathrm{N}$ and a maximum specific growth rate $\left(\mu_{\max }\right)$ of 0.9 day $^{-1}$. Environsim (2008) also suggests that NOB populations in activated sludge have a $\mathrm{K}_{\mathrm{S}}$ of $0.05 \mathrm{mg} / \mathrm{L}-\mathrm{N}$ and a $\mu_{\max }$ of 0.7 day $^{-1}$. Other kinetic parameters for AOB populations that have been suggested are a $\mu_{\max }$ of 0.77 day $^{-1}$ and $\mathrm{K}_{\mathrm{S}}$ of $1 \mathrm{mg} / \mathrm{L}-\mathrm{N}$ with kinetic parameters for NOB populations as $\mu_{\max }$ of 0.82 day $^{-1}$ and $\mathrm{K}_{\mathrm{S}}$ of $1.3 \mathrm{mg} / \mathrm{L}-\mathrm{N}$ (Grady et al. 1999). These two sources do not agree about whether AOB or NOB populations are faster growing. This is most likely because Grady et al. (1999) is using Nitrobacter as the primary NOB organism. While this organism was widely accepted for a long time as the primary NOB, it is now apparent that Nitrospira, a slower growing NOB, is the primary NOB (Onnis-Hayden et al. 2007). This essentially means that $\mathrm{AOB}$ populations are faster growing organisms that are not quite as sensitive to washout as NOB populations. Sen et al. (2007) reports that $\mathrm{K}_{\mathrm{S}}$ for nitrifiers growing in a biofilm is as high as $2.1 \mathrm{mg} / \mathrm{L}-\mathrm{N}$. The $\mathrm{K}_{\mathrm{S}}$ values for AOB from all sources is about the same meaning that $\mathrm{AOB}$ populations have a reasonable affinity for ammonia, but the $\mathrm{K}_{\mathrm{S}}$ values given for NOB populations differs in the literature. A lower $\mathrm{K}_{\mathrm{S}}$ value indicates very high affinity for nitrite, while a higher $\mathrm{K}_{\mathrm{S}}$ suggests only a moderate affinity. 


\subsection{General Factors Affecting Nitrification}

The different mechanisms for nitrification in attached growth processes mean that external factors such as $\mathrm{pH}$, temperature, mixing and $\mathrm{DO}$ affect the nitrification capabilities of the biomass in a way different from a more traditional suspended growth application.

\section{$\underline{\text { 2.2.1 Temperature }}$}

The role of temperature on the nitrification process when biofilms are involved is a bit more complex than suspended growth processes, specifically because of the influence of temperature on boundary layer and biofilm mass transfer. Temperature, in a suspended growth application, affects the specific growth rate of the nitrifying bacteria, which limits the ability to nitrify in a wastewater treatment plant and requires a lengthy SRT in order to ensure that these nitrifiers are able to grow in the system and not washed out (Hubbell et al. 2003). For submerged biofilm systems like IFAS, temperature affects diffusion rates through the boundary layer and biofilm for both DO and substrate. Because of these factors, the Arrhenius equation that is typically used to make temperature corrections to different growth parameters in the Monod equation is not alone sufficient for adjusting growth kinetic coefficients.

\section{$\underline{2.2 .2 \mathrm{pH}}$}

$\mathrm{pH}$ plays a role in the ability to nitrify for both $\mathrm{AOB}$ and NOB populations in both fixed film and suspended growth environments. Overall, $\mathrm{pH}$ ranging between 7.2 and 9 has been demonstrated to be the best for nitrification (Chen et al. 2002). Other evidence suggests that relationship between $\mathrm{pH}$ and nitrification can be described as a bell-shaped curve for both $\mathrm{AOB}$ and NOB populations (Park et al. 2007). This bell shaped curve indicates that the optimal pH for 
AOB activity is $8.2 \pm 0.3$ and $7.9 \pm 0.4$ for NOB populations. The work by Park et al. (2007) work also indicates that $\mathrm{NOB}$ populations are much more sensitive to $\mathrm{pH}$ changes than $\mathrm{AOB}$ populations, resulting in a narrower bell-shaped curve.

\subsubsection{Dissolved Oxygen}

Dissolved oxygen is also a crucial parameter for consideration in nitrification for both suspended and attached growth bacteria. Oxidation of ammonia and nitrite to nitrate requires a significant amount of oxygen in both attached growth and suspended growth applications.

However, maintaining higher DO concentrations is required in an attached growth application, mainly because of the requirement of transferring the oxygen through the boundary layer and the biofilm. Oxygen diffusion through the biofilm occurs in the same fashion as substrate diffusion, and despite higher DO concentrations in the bulk liquid, DO drops rapidly inside the biofilm and may become a limiting factor in the nitrification process (Chen et al. 2005). $\mathrm{K}_{\mathrm{O}}$ values for both AOB and NOB populations have been well documented in the past. Envirosim (2008) suggests that $\mathrm{AOB}$ populations in activated sludge have a $\mathrm{K}_{\mathrm{O}}$ of $0.25 \mathrm{mg} / \mathrm{L}-\mathrm{O}_{2}$ and that $\mathrm{NOB}$ populations in activated sludge have a $\mathrm{K}_{\mathrm{O}}$ of $0.5 \mathrm{mg} / \mathrm{L}-\mathrm{O}_{2}$. Peng et al. (2006) suggests a range of $\mathrm{K}_{\mathrm{O}}$ values for both AOB and NOB populations of 0.2-0.4 mg/L- $\mathrm{O}_{2}$ and 1.2-1.5 mg/L $\mathrm{O}_{2}$, respectively. Another $\mathrm{K}_{\mathrm{O}}$ value for $\mathrm{AOB}$ populations that has been suggested is $0.5 \mathrm{mg} / \mathrm{L}-\mathrm{O}_{2}$ with a $\mathrm{K}_{\mathrm{O}}$ value for NOB populations of $0.68 \mathrm{mg} / \mathrm{L}-\mathrm{O}_{2}$ (Grady et al. 1999). It is well accepted that AOB populations have a higher affinity for oxygen than NOB, and this is the basis for centrate treatment processes such as SHARON and DEMON. This suggests that changes in operating DO will affect NOB activity in mixed liquor more than AOB activity. 


\subsection{IFAS}

\section{$\underline{\text { 2.3.1 Process Description }}$}

The IFAS process is comprised of a fixed film media, free moving or stationary, combined with activated sludge. By allowing the fixed film phase to retain biomass in the basin, the IFAS process can be operated at low SRTs and still achieve nitrification. By retaining biomass in the fixed film, the IFAS process can still achieve full nitrification, even in cold temperatures, because the nitrifiers in the basin can grow in the fixed film that has an effective SRT controlled by the steady-state sloughing of biomass from the media. This is expected to be much longer than that required for nitrifier growth even at very cold temperatures. The addition of a fixed film media to an existing activated sludge process effectively increases the biomass in the aeration basin without placing any additional load on the secondary clarifier (Johnson et al. 2004). By maintaining a low SRT in the IFAS basin, the process has also been credited with better settling sludge with lower SVIs compared with conventional activated sludge processes (McQuarrie et al. 2004).

The IFAS process has the potential to provide year round complete nitrification for plants originally designed only for $\mathrm{BOD}_{5}$ removal or partial nitrification, assuming the oxygen demands and tank design requirements (e.g. media retention screens) can be accommodated. This is made possible by allowing autotrophs to grow in the fixed film phase while the activated sludge process is still operated for $\mathrm{BOD}_{5}$ removal.

The volume, or percent fill, of plastic free-floating media varies for different plants, depending on the plant's treatment goals, and treatment capacity. Typically, IFAS tanks hold anywhere between 30-60\% fill by volume (Johnson et al. 2004). It is not uncommon for the 
IFAS tank to be designed for a certain fill, but to operate at a lower media concentration until the additional media is needed at a higher future flow rates (McQuarrie et al. 2004).

\subsubsection{Benefits of IFAS}

Upgrading wastewater treatment plants to achieve complete nitrification with conventional activated sludge requires more tank volume and longer SRTs. A number of benefits to the IFAS process exist. Nitrification can be limited at a wastewater treatment facility by low temperatures, clarifier solids loading capacity, and insufficient tank volume to achieve winter time nitrification (Randall et al. 2006). By adding a fixed film phase to activated sludge, nitrification performance can be enhanced at low temperatures without expansions made to the basin or secondary clarifier (Randall et al. 1996). By modifying existing tanks, it is possible to implement IFAS into a wastewater treatment plant without new construction, greatly decreasing the capital cost of the retrofit (Ross et al. 2004). Hubbell et al. (2003) investigated IFAS performance in Soda Springs, CA where difficult terrain and land availability made any attempt to expand the footprint of the existing package wastewater treatment plants impossible. In this case, the IFAS process proved to be a cost effective and successful alternative to plant expansion and enabled the local municipality to meet new and stricter nutrient discharge limits. In the Annapolis WRF demonstration, the IFAS process using Ringlace media achieved much higher nitrification rates than the control activated sludge per unit volume when the ammonia concentrations were high enough to maintain a substantial nitrifier population (Randall et al. 1996). Randall et al. (1996) also notes that the greatest improvement of nitrification capacity when compared to conventional activated sludge occurred at lower temperatures. 
Johnson et al. (2004) notes that the IFAS process is also operated in the same way as conventional activated sludge processes by controlling DO and process SRT and requires the same amount of operator attention as a conventional activated sludge process. In many cases, an IFAS upgrade requires less aerobic volume, resulting in the creation of an anoxic zone preceding the aerobic zone with media to allow for more TN removal (Hubbell et al. 2004).

The main concern for plants expanding to accommodate larger flows, or better nitrification, is the slow growth rate of the autotrophic nitrifiers. These organisms require a much longer SRT then heterotrophic bacteria in activated sludge and are at risk of being washed out of an aeration basin at low temperatures, or if the SRT is too short for the nitrifiers to establish a presence in the mixed liquor (Grady et al. 1999, Jackson et al. 2007)). Related to this issue is the MLSS concentration in an aeration tank and the load the biomass places on the secondary clarifiers. Typically, mixed liquor concentrations range between $2500-3500 \mathrm{mg} / \mathrm{L}$ and secondary clarifiers can then be designed around solids overflow rates (SOR) and solids loading rates (SLR) within a set range (Grady et al. 1999). By maintaining low process SRT and lower MLSS concentrations in the aeration basins, IFAS does not cause secondary clarifiers to become overloaded because the additional biomass remains in the IFAS tank. (Johnson et al. 2004; Yerrell et al. 2001) Secondary clarifier loading rates associated with the IFAS process are remarkably lower than conventional activated sludge processes (Ross et al. 2004).

IFAS may also be credited with better sludge settling. Effluent TSS concentrations from the Broomfield wastewater treatment plant demonstrated lower solids concentrations than previously measured when only activated sludge was used to treat the wastewater McQuarrie et al. 2004)). SVI measurements of the suspended growth sludge in the IFAS tank was also lower than most of the previously measured and recorded SVIs at the same plant using only activated 
sludge (McQuarrie et al. 2004). Ross et al. (2004) also reported improved sludge settleability compared to conventional activated sludge during an IFAS demonstration study at the Lakeview WWTP in Ontario.

\section{$\underline{\text { 2.3.3 Media Alternatives }}$}

IFAS technology appears in many forms, and a variety of media is available to choose from. The different types of media include networks of string or rope that are suspended in the water (sometimes known as rope or ring lace systems), free-floating sponges (e.g. Linpor), and hard plastic media (Johnson et al. 2004). Each of these media technologies has advantages and disadvantages. One difference is the biomass retention on a string system or free-floating sponge and a hard plastic media. A thicker biofilm is able to grow on the string systems and freefloating sponges, which may provide an anoxic zone within the biofilm and promote denitrification, while biomass on the outside of the biofilm is responsible for most of the nitrification. Hard plastic media, on the other hand, readily slough excess biomass while being mixed in the IFAS tank, maintaining a more constant biomass concentration on the media, which can be controlled by adjusting mixing intensity and DO concentrations in the tank (Johnson et al. 2004). The hard plastic media comes in a number of varieties manufactured by different companies, but they all work to achieve the same goal. The different types of hard plastic media can be seen below in Figures 2-1, 2-2, and 2-3. Each of these hard plastic media varieties has a specific surface available for any given volume of media and has a variety of shapes and sizes to accommodate biomass growth. 


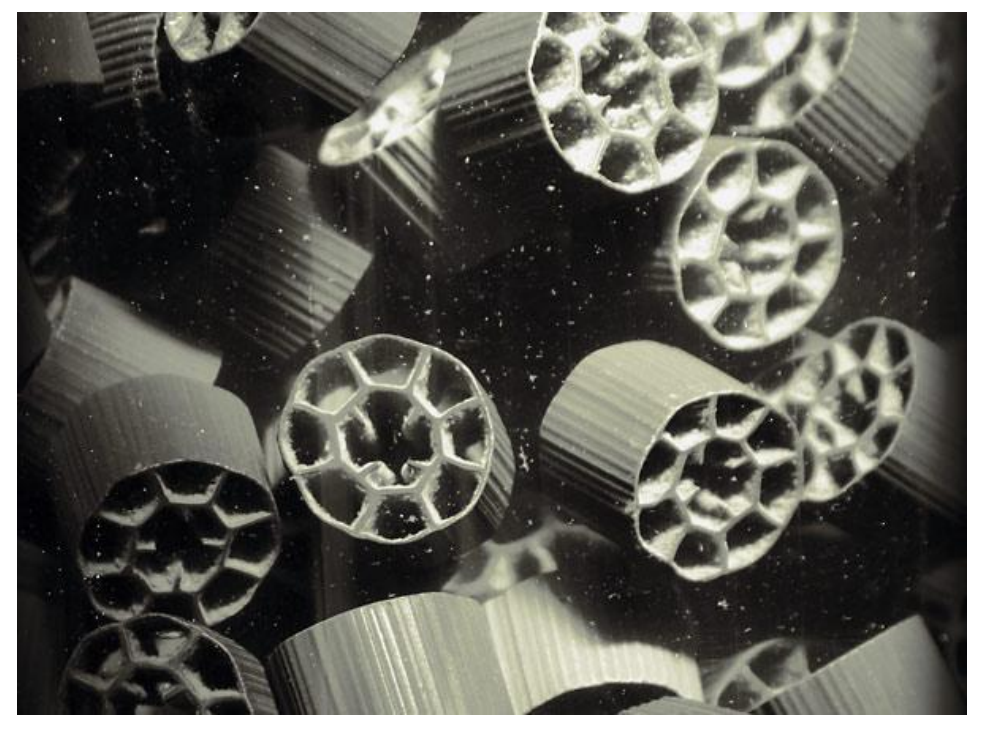

Figure 2-1. METEOR® ActiveCELL media $\left(\sim 515 \mathrm{~m}^{2} / \mathrm{m}^{3}\right)$

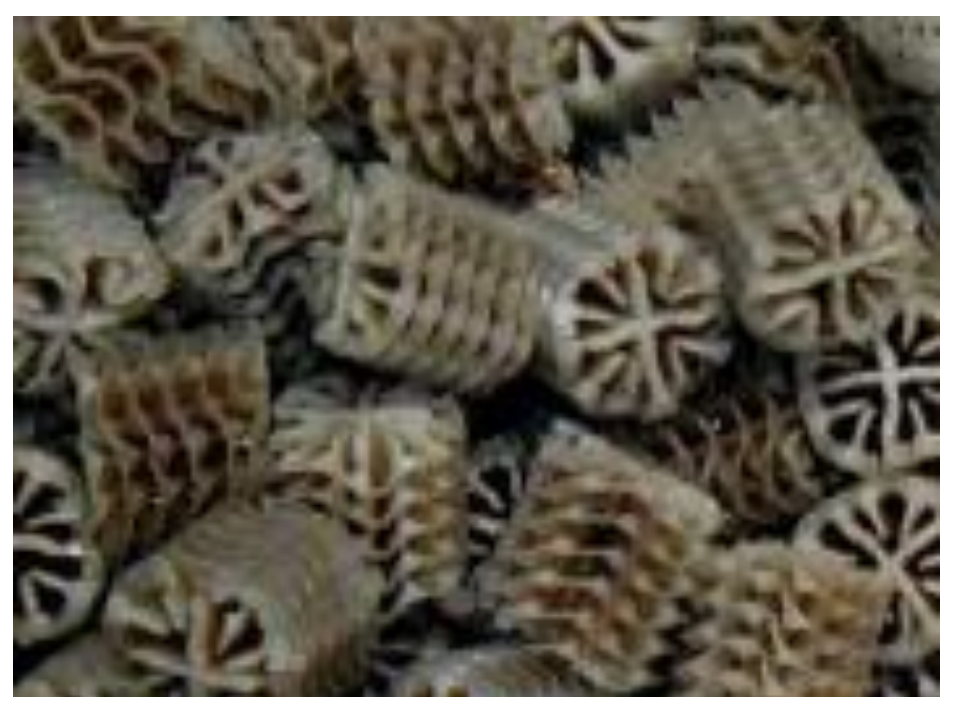

Figure 2-2. Siemens AGAR® media $\left(\sim 800 \mathrm{~m}^{2} / \mathrm{m}^{3}\right)$

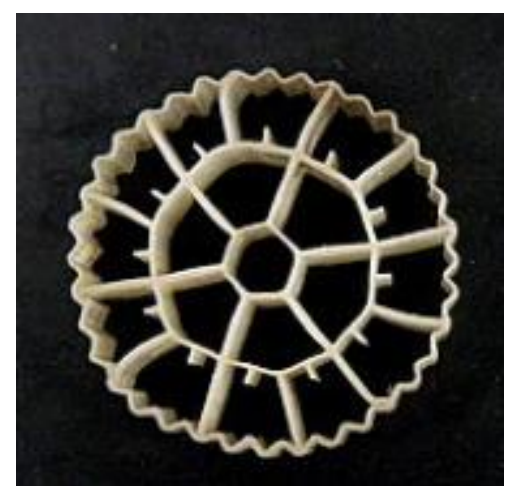

Figure 2-3. Anox Kaldnes K3 Media $\left(\sim 500 \mathrm{~m}^{2} / \mathrm{m}^{3}\right)$ 


\section{$\underline{\text { 2.3.4 Examples of IFAS }}$}

A number of IFAS demonstrations and full scale upgrades have already taken place. Some of the most notable demonstrations that have been conducted in the past are as follows:

- Broomfield, CO WWTP: The Broomfield WWTP was forced to expand plant capacity from 5.4 MGD to $8 \mathrm{MGD}$ in conjunction with new and more stringent effluent quality standards. The plant underwent an extensive upgrade with IFAS using AnoxKaldnes plastic media. The IFAS process demonstrated a significant improvement in ammonia removal and added stability to the plants ability to meet low ammonia concentrations. In addition to enhanced nitrification performance, the plant also reported improvements in the solids settleability (McQuarrie et al. 2004)

- Mamaroneck, NY WWTP: The Mamaroneck WWTP is a 20.6 MGD plant that also did an extensive IFAS and MBBR demonstration with AccuWeb modules. The Mamaroneck plant has been able to maintain TN concentrations under $10 \mathrm{mg} / \mathrm{L}-\mathrm{N}$. The IFAS tank at the Mamaroneck Plant did suffer some red worm predation on the IFAS modules, limiting their nitrification performance at times. The plant then pilot tested an IFAS configuration with AnoxKaldnes K1 media at a 30\% fill. This pilot study demonstrated that the addition of IFAS media greatly enhanced nitrification kinetics (Onnis-Hayden et al. 2007))

- The Colony, TX WWTP: The Colony WWTP is operating at a 2.4 MGD flowrate that required an upgrade to meet new effluent ammonia standards of $3 \mathrm{mg} / \mathrm{L}-\mathrm{N}$. The plant used BioWeb media to accommodate the existing fine bubble diffusers. The IFAS system allowed The Colony WWTP to meet the new treatment limits and saved the plant a substantial amount of money in construction costs (Jackson et al. 2007)) 
- Windsor Locks, CT WPCA: The Windsor Locks WPCA installed the AccuWeb IFAS configuration to achieve lower effluent TN stipulated in the plant's new discharge permits. The WPCA has an average flow of 1.43 MGD that used the IFAS configuration to fully nitrify and to reduce basin volume requirements that might otherwise have required new construction. The result was a much improved nitrification capacity and ultimately lower effluent TN (Hubbell et al. 2004)

- Donner Summit Public Utility District, CA The Donner Summit plant is a small plant servicing a small ski community in Soda Springs, CA. The plant experiences extremely cold wastewater temperatures (reaching as low as $4^{\circ} \mathrm{C}$ ) and needed to upgrade to a BNR process to meet new effluent nitrate standards. The plant used AccuWeb modules in their IFAS process which allowed them to fully nitrify, even in temperatures as low as $5{ }^{\circ} \mathrm{C}$ and was able to achieve as much as $3 \mathrm{x}$ the ammonia oxidation as a conventional activated sludge process (Hubbell et al. 2003)

- Christies Beach WWTP, Australia: The Christies Beach WWTP, a 2 MGD, operated a full scale demonstration study of IFAS with free floating media for 8 months to see if the existing plant could be retro-fit to fully nitrify and remove $80 \%$ of TN. During this study, a significant amount of work was focused on DO requirements for IFAS systems. It was determined that the IFAS process would be sufficient to meet the effluent quality standards for the plant (Yerrell et al. 2001)

- Norman Cole JR. WPCP, VA: The Norman Cole WPCP conducted a pilot scale study to see if the IFAS process or MBBR process was able to meet their $3 \mathrm{mg} / \mathrm{L}-\mathrm{N}$ TN effluent requirements and to see the effect of using multiple stages on effluent $\mathrm{NO}_{\mathrm{X}}$ concentrations. The plant implemented the technology as a last pass IFAS setup at the end of the aerobic 
process to help set up for the denitrification process. The plant used AnoxKaldnes K1 plastic media at a $30 \%$ fill fraction. The IFAS process was able to meet the $2 \mathrm{mg} / \mathrm{L}-\mathrm{N} \mathrm{NO}$ effluent quality standards and achieved $\mathrm{NO}_{\mathrm{X}}$ concentrations as low as $0.86 \mathrm{mg} / \mathrm{L}-\mathrm{N}$ during a short period of stable operating conditions (Motsch et al. 2007)

- Water Treatment Facility (WTF), WI: Here a full scale cold weather performance test of the IFAS rope media process was conducted at a 1.5 MGD. The purpose of the study was to test to see if the IFAS process could allow them to meet effluent quality standards in cold weather without having to construct additional aeration tanks. The study suffered from a number of upsets, but ultimately IFAS did improve nitrification capacity. (Nelson et al. 2007)

- Lakeview, Ontario WWTP: The Lakeview Plant (103,57 gal/d) conducted a full scale demonstration study on the IFAS process using Hydroxyl media with a flow of 14,000 m3/d to test the ability to achieve year round complete nitrification to meet new effluent quality standards. The plant consistently achieved nitrification at low MLSS concentrations, the process was more stable under varying mixed liquor concentrations, and the mixed liquor exhibited better settling characteristics (Ross et al. 2004)

- Westerly, RI WWTF: The Westerly WWTF is a 3.3 MGD plant that upgraded to an IFAS process to meet effluent TN requirements. The plant used LINPOR ${ }^{\mathrm{TM}}$ media for the IFA configuration. The plant met their limit shortly after a short startup period and has allowed the plant to achieve effluent $\mathrm{TN}$ of $5 \mathrm{mg} / \mathrm{L}-\mathrm{N}$ and has experienced a significant improvement on the sludge SVI (Masterson et al. 2004)

- Chesterfield County, VA BNR Program: The Chesterfield County BNR program was put in place in response to new effluent quality standards and explored IFAS as an option to meet these effluent standards. They underwent a pilot study using ActiveCell ${ }^{\mathrm{TM}}$ plastic media at a 
$50 \%$ fill. The pilot was able to fully nitrify and reach effluent ammonia concentrations as low a $0.29 \mathrm{mg} / \mathrm{L}-\mathrm{N}$ (Kaldate et al. 2008)

- The Annapolis, MD WRF: In response to pending TN effluent standards of $10 \mathrm{mg} / \mathrm{L}$, the Annapolis WRF, the plant modified one of its 10 MGD aeration tanks into a single stage anoxic-aerobic operation with Ringlace media added to the aerobic portion. The study showed that the IFAS section of the plant had a much higher nitrification rate than the control train, except when the IFAS process was ammonia limited. The demonstration showed that nitrification rates per unit volume were greatly enhanced by the addition of IFAS media and that at lower temperatures, the greater the improvement in the TN removal capacity compared to the control activated sludge process (Randall et al. 1996)

\subsubsection{IFAS Nitrification}

The distribution of these microorganisms on the media is difficult to accurately determine, but is related to the specific growth rates for both the AOB and NOB populations in the biofilm. In a biofilm, the organism with the higher maximum specific growth rate will be more abundant on the surface of the biofilm and the other species will remain within the biofilm and rely more on diffusion of substrate and oxygen into the biofilm (Grady et al. 1999). This is because faster growing organisms and will slough faster than slower growing organisms. Location in the biofilm also deals with half saturation coefficients and generally how high the affinity for the substrate is to the biomass. Thus, substrate includes oxygen, and organisms that are oxygen limited will tend to grow in the surface of the biofilm where substrate does not have to diffuse as far before it becomes bioavailable. According to the default parameters used by Envirosim (2008), AOB populations have a $\mu_{\max }$ of $0.9 \mathrm{~d}^{-1}$, while NOB populations have a $\mu_{\max }$ 
of $0.7 \mathrm{~d}^{-1}$, indicating that AOB populations would flourish at the surface of the biofilm, while NOB populations would exist deeper in the biofilm closer to the fixed surface.

Nitrification rate testing from the IFAS demonstration study at the Lakeview WWTP showed that the nitrification capacity of the IFAS process was higher than with a conventional activated sludge configuration by demonstrating that IFAS nitrification kinetics were higher than kinetics achieved with a conventional activated sludge process operating for nitrification (Ross et al. 2004). IFAS has demonstrated excellent ammonia oxidation year round, under a wide range of temperature variations in a number of case studies where the process has already been implemented. At the Broomfield wastewater treatment plant in Broomfield, $\mathrm{CO}$, the IFAS exhibited higher and more consistent removal efficiency than activated sludge (McQuarrie et al. 2004). McQuarrie et al. (2004) also reports that effluent ammonia concentrations for the Broomfield WWTP were consistently under $1 \mathrm{mg} / \mathrm{L}-\mathrm{N}$ when the IFAS process had been implemented, where pre-IFAS effluent ammonia ranged much higher, up to $12 \mathrm{mg} / \mathrm{L}-\mathrm{N}$. Hubbell et al. (2004) also reported a significant improvement of ammonia removal capacity of an IFAS upgrade demonstration compared with conventional activated sludge. At the Donner Summit Public Utility District IFAS upgrade, significant ammonia oxidation was reported, even with influent wastewater temperatures as low as $8^{\circ} \mathrm{C}$ (Hubbell et al. 2004). Nitrification rates measured for the two stage IFAS configuration at the Broomfield, CO. WWTP for mixed liquor, media only, and media with mixed liquor to evaluate process kinetics, and the results demonstrate that nitrification rates increased on the carriers in the first stage where ammonia concentrations were higher (Onnis-Hayden et al. 2007). According to the work done by OnnisHayden et al. (2007), AOB nitrification rates of $5.04 \mathrm{~g} / \mathrm{m}^{2} /$ day were observed at temperatures of $20{ }^{\circ} \mathrm{C}$ at the Mamaroneck WWTP demonstration. This same study also demonstrated that 
nitrification rates in the second stage were evenly split between the mixed liquor and the media. In both stages the study indicated that little to no nitrite accumulation occurred in the nitrification rate testing on the carriers, while the mixed liquor in both stages tended to accumulate nitrite during ammonia oxidation. This trend suggests that significant NOB activity was localized on the carriers for both stages of IFAS at the Broomfield WWTP. A molecular analysis using florescent in-situ hybridization (FISH) at the Broomfield WWTP indicated that AOB activity at the IFAS plant was dominated by Nitrosomonas populations, while NOB activity was dominated by Nitrospira (Onnis-Hayden et al. 2007). Another full scale demonstration conducted in the Christies Beach WWTP in South Australia demonstrated that by adding IFAS media to a conventional activated sludge plant essentially doubled the nitrification rates at the wastewater treatment plant, where IFAS nitrate production was measured at $0.19 \mathrm{mg} / \mathrm{L} / \mathrm{min}$ and activated sludge nitrate production rate was $0.088 \mathrm{mg} / \mathrm{L} / \mathrm{min}$ (Yerrell et al. 2001). Pilot testing of the IFAS process was also conducted at the Mamaroneck WWTP, which experienced about 90\% ammonia removal by mass and also experienced about $90 \%$ removal of total nitrogen by mass with a post anoxic zone (Johnson et al. 2007). In addition to the Mamaroneck demonstration, the Norman Cole Demonstration in Fairfax County, VA was able to meet the $2.0 \mathrm{mg} / \mathrm{L}$ effluent NOX-N standard in $18.5-20^{\circ} \mathrm{C}$ wastewater with an average of 0.86 of a short stable period of operation in a last pass IFAS configuration (Motsch et al. 2007). This indicates that the demonstration was able to achieve complete ammonia oxidation with the IFAS process.

The effect of DO on the overall nitrification rate achieved with a biofilm is well-known. Despite this little work has been done to quantify the $\mathrm{K}_{\mathrm{O}}$ effects on nitrification rate in the IFAS setting. Yerrell et al. (2001) examines $\mathrm{K}_{\mathrm{O}}$ effects of both mixed liquor alone and for media combined with mixed liquor. According to this study, $\mathrm{K}_{\mathrm{O}}$ for media and mixed liquor was 
determined to be $0.5 \mathrm{mg} / \mathrm{L}$, a value matching accepted $\mathrm{K}_{\mathrm{O}}$ values for nitrifying bacteria in mixed liquor. Based on this research, it appears that higher DO concentrations are necessary to operate the IFAS process than for conventional activated sludge processes. In another case, Sen et al. (2007) reports that Ko for nitrifiers in a biofilm is $4 \mathrm{mg} / \mathrm{L}$ at $25^{\circ} \mathrm{C}$.

\subsubsection{MBBR Nitrification}

Moving Bed Biofilm Reactors (MBBR) are another biofilm process that uses fixed film media for nitrogen removal, but in this case, no internal recycle is used, resulting in no mixed liquor. Because no mixed liquor is present, only the excess biomass resulting from sloughing off of the carriers needs to be removed from the effluent stream (Odegaard et al.) In this case, a filter is a viable option for solids removal from MBBR effluent instead of using clarifiers, and solids loading is much lower for MBBRs. The MBBR process works well for nitrification if the readily degradable organic material in the wastewater has been removed (Odegaard et al.). Unlike the IFAS process, that incorporates activated sludge, the presence of degradable COD in the wastewater stream will select for heterotrophic growth instead of autotrophic growth resulting in diminished nitrification performance, so some pretreatment is required for nitrification. Similarly to the IFAS process, nitrification rates depend on bulk liquid DO, and nitrification performance is linearly related to DO in the MBBR process because MBBRs are a biofilm process (Rusten et al. 1996).

A demonstration performed at the Nordre Follo WWTP in Norway recorded between 85\%-100\% removal efficiency for influent ammonia using a MBBR (Rusten et al. 1995). Rusten et al. (1995) also reports nitrification rates in excess of 1.4-1.6 $\mathrm{gNH}_{4}-\mathrm{N} / \mathrm{m}^{2} /$ day using the $\mathrm{MBBR}$ process at temperatures ranging from $8{ }^{\circ} \mathrm{C}$ to $15.6^{\circ} \mathrm{C}$. At the lowest temperatures, removal 
efficiency dropped below $85 \%$ at high ammonia loading conditions, but remained well above 50\% (Rusten et al. 1995). Rusten et al. (1995) also notes that nitrification rates depend on the autotrophic fraction on the biofilm, influent soluble organics, and DO diffusion into the biofilm.

Studies on MBBRs and nitrification demonstrate a linear relationship between nitrification rate and bulk liquid DO up to $10 \mathrm{mg} / \mathrm{L}$, but the impact of mixing has not been defined (AEsoy et al.). In addition, bulk liquid DO can be used in the MBBR process to counter any influent COD that may be in the wastewater stream and by increasing DO with pure oxygen to high concentrations, nitrification rates can be maximized, even in the presence of organics (AEsoy et al.). AEsoy et al. also demonstrated that nitrification rates in MBBRs are also related to the influent ammonia load placed on the process. The relationship is not linear, and levels off at higher ammonia loading conditions.

\subsection{Biofilm Kinetics and Modeling}

Attached growth processes using biofilms offer advantages over suspended growth applications for wastewater treatment. Biofilms are bacteria held to a solid surface with the same extracellular material traditionally identified to hold flocs of bacteria together in suspended growth wastewater treatment applications (Grady et al. 1999). These biofilms can be modeled in a variety of ways, depending on the manner of growth on the media surface. Using these biofilms in nitrification applications, only the autotrophic growth of ammonia oxidizing bacteria (AOBs) and nitrite oxidizing bacteria (NOBs) are considered.

Nitrification on attached growth processes, such as integrated fixed film activated sludge (IFAS) process is a very different process than with suspended growth. Instead of the biomass being in direct contact with the bulk liquid, it is in contact with a thin film of water which is in 
contact with the bulk liquid. This makes the mechanism behind getting substrate to the biomass a process of diffusion through both the biofilm and the surrounding water film. There is a mass flux through the biofilm that is shown by Figure 2-4. This process makes the nitrification within a biofilm a much more complicated process than the suspended growth application.

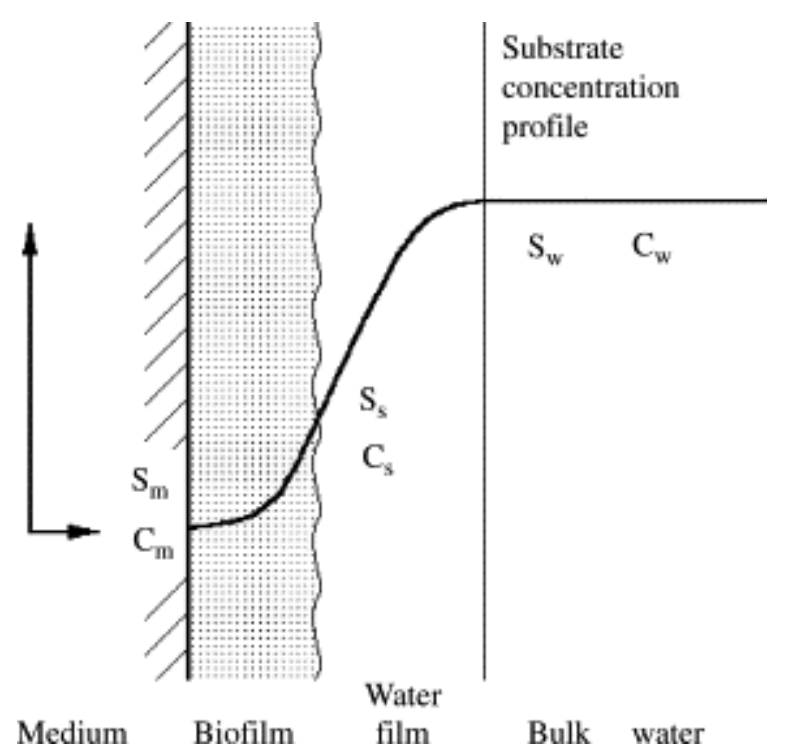

Figure 2-4. Diagram of substrate concentration through water film and biofilm (Chen et al. 2005)

Because the substrate must diffuse into the biofilm in order for it to be consumed, the substrate removal rate is function of the bulk liquid concentration as well as the mass transfer rate of the substrate. As the substrate is able to diffuse through the biofilm and be utilized by the attached biomass the rate of substrate uptake will increase and thus the reaction rates are dictated by the diffusion of substrate into the biofilm. (Chen et al. 2005).

In terms of biofilm modeling, two resistances to substrate transport into the biomass are considered, advection through the water film and diffusion in the biofilm. These methods both allow substrate and oxygen to be transported to the biomass, but the rate of diffusion through a 
biofilm is not constant throughout its depth. Furthermore, biofilms that develop on the surface of biofilm media in wastewater applications do not display homogeneous growth over the surface of the media. The porous and heterogeneous nature of biofilms allows the surrounding water to flow in and out of the biomass. This suggests that advection plays a large roll in allowing the biomass access to substrate. Diffusion is the mechanism in which nutrients, substrate, and oxygen are transferred in the biofilm and the biomass structures within the biofilm. Because advection and diffusion work together in the mass transport through biofilms, both of these parameters should be considered in modeling.

One important concept dealing with biofilms is that substrate not only has to be transferred through the biomass to become bioavailable, but also a surrounding water film. Modeling the general mass transport through a biofilm must take into account transfer through the water film first. This assumes that diffusion is the sole method of transport. In this case $\mathrm{D}_{\mathrm{w}}$ is the diffusion coefficient for the substrate in water and $\mathrm{L}_{\mathrm{w}}$ is the thickness of the surrounding mass transport boundary layer in which diffusion of substrate, oxygen, and nutrients must occur can be written as $\mathrm{L}_{\mathrm{w}}$. Some of the most common factors impacting diffusion through the water film and the thickness of the surrounding mass transport boundary layer are mixing, temperature, and substrate characteristics. Mixing intensity impacts water film thickness. By imparting more mixing energy, the moving biofilms travels at a higher apparent speed compared to the water. This increase in relative velocity between the biofilm and the bulk liquid will cause the surrounding water film to become thinner. Temperature also plays an impact on the water film by changing the absolute viscosity of the bulk liquid and this affects the diffusion coefficient. Substrate also plays a role in biofilm diffusion. Furthermore, the diffusion coefficient for a given substrate in water also affects transport through the mass transfer boundary layer. $\mathrm{S}_{\mathrm{w}}$ and $\mathrm{S}_{\mathrm{s}}$ are 
also important to understand in biofilm modeling applications. $S_{\mathrm{w}}$ and $\mathrm{S}_{\mathrm{s}}$ represent substrate concentrations in the bulk liquid and at the surface of the biofilm, respectively. The difference in these concentrations is related to advection through the water film. Higher substrate concentrations in the bulk liquid ultimately result in faster mass transfer rates to and through the biofilm by increasing the available driving force. Using these parameters, the mass flux through the water film can be written as:

$\mathrm{J}_{\mathrm{s}}=\left(\mathrm{D}_{\mathrm{w}} / \mathrm{Lw}\right)\left(\mathrm{S}_{\mathrm{w}}-\mathrm{S}_{\mathrm{s}}\right)$

As previously discussed, this equation requires a value for the thickness of the water film surrounding the biofilm. (Grady et al. 1999)

Mass transport through the biofilm can be described by slightly modifying Fick's law. Since biofilm diffusion is more complex than free diffusion that Fick's law was designed for, the diffusivity constant is replaced with effective diffusivity. In addition to diffusivity, the driving force behind mass transfer and diffusion into the biofilm is the substrate concentration in the bulk liquid. With higher substrate gradients, more diffusion can occur and essentially, higher substrate oxidation rates. The effective diffusivity is usually smaller than the diffusivity constant due to the presence of extracellular material surrounding the cells in the biofilm, although this varies with the presence of advection through the biofilm. The equation for this mechanism is:

$\mathrm{J}_{\mathrm{s}}=\mathrm{D}_{\mathrm{e}}\left(\mathrm{dS}_{\mathrm{s}} / \mathrm{d}_{\mathrm{x}}\right)$ 
The equation incorporates $D_{e}$, which is the effective diffusion coefficient of the substrate though the biofilm, which is a smaller value than the diffusion coefficient of a given substrate in water because of the less permeable extracellular material incorporated throughout the biofilm. However, the effective diffusivity varies from biofilm to biofilm. It also uses the concentration gradient from the outside of the biofilm to the solid support holding the biofilm. $\mathrm{D}_{\mathrm{e}}$ is dependent on substrate properties including molecular weight.

A fully penetrated biofilm ensures that substrate is bioavailable to the entire biomass in the fixed film. Substrate availability in the biofilm ultimately determines the substrate uptake rate. As substrate begins to become limited, the biofilm ceases to be fully penetrated and kinetics slow down. In this case, performance of biofilm carriers and removal rates is dependent on maintaining higher process DO. This also implies that half saturation constants are going to be naturally higher for biofilm processes, and must be considered to appropriately design and operate a biofilm process. Despite the enhancement of process performance, especially in the case of nitrification, that allow autotrophs to remain present during washout conditions, nitrification performance is impeded as ammonia concentrations drop to low levels.

The final consideration for biofilm modeling is operating the process to allow the biofilm to achieve steady state. In this case, the biofilm is maintained at a thickness that allows for substrate penetration, and also enables an appropriate amount of biomass to exist in the biofilm. By imparting energy to the process biomass will slough at the same rate that new biomass is grown on the fixed film. It is also known that the depth of the biofilm increases when mixing intensity is decreased (Sen et al. 2007). The biofilm thickness is thus partly controlled by sloughing of biomass off of the fixed film that results from mixing energy imparted to the water. Thicker biofilms also decrease the specific surface area available on the media (Sen et al. 2007). 
In addition to this, the added biofilm thickness increases the mixing required to keep the media moving in the bulk liquid, so mixing controls biofilm thickness and mass transport, not only by affecting the mass transport boundary layer thickness, but also biofilm thickness (Sen et al. 2007). Another factor impacting mixing and biomass sloughing is the recycle rate into the IFAS basin. Higher internal mixed liquor recycle increases forward velocity though the tank which increases the mixing requirement to maintain a constant biomass on the biofilm (Sen et al. 2007).

Because diffusion of nutrients, substrate, and oxygen into the biofilm controls the nitrification rate in an attached growth process, it is important to improve the mass transfer capability in the system. Mixing has a direct effect in the water film thickness which, in turn, affects mass transport into the biofilm. Generally, the smaller the water film around the biofilm, the faster substrate and oxygen can pass into the biofilm and become available for the biomass. At this point, very little is understood about how process mechanical configuration (e.g. aeration intensity) affects mass transport boundary layer thickness. It is known at a fundamental level that biofilms are diffusion limited by their nature instead of being kinetically limited, like mixed liquor (Boltz et al. 2009).

\subsection{Reference}

AEsoy, A., Odegaard, H., Haegh, M, Risla, F., Bentzen, G. Upgrading Wastewater Treatment Plants By The Use Of Biofilm Carriers, Oxygen Addition And Pre-treatment In The Sewer Network. Civil and Environmental Engineering. Aaiborg University.

Boltz, J., Daigger, G. 2009. Bulk-Liquid Hydrodynamics Provides Uncertainly In Biofilm Reactor Design.

Chen, S., Ling, J., Blancheton, J. 2006. Nitrification Kinetics Of Biofilm As Affected By Water Quality Factors. Aquacultural Engineering: 34(3): 179-197. 
Choi, N., Phillips, H., Johnson, T.L., Butler, R., Lauro, T. Pilot Testing Of MBBR And IFAS

Treatment Processes For Nitrification And Denitrification At The Mamaroneck WWTP.

Proceedings of the $80^{\text {th }}$ WEFTEC- National Conference of the Water Environment Federation, San Diego, CA. 80: October 13-17, 2007.

Envirosim, 2008. BioWin Version 3.0 Default parameters.

Germain, E., Bancroft, L., Dawson, A., Hinrichs, C., Fricker, L., Pearce, P. Evaluation Of Hybrid Processes For Nitrification By Comparing MBBR/AS And IFAS Configurations. Water Science and Technology: 55(8-9): 43-49.

Grady, C., Daigger, G., Lim, H. 1999. Biological Wastewater Treatment, Theory And Application. New York: Marcel Deker, Inc.

Hubbell, S., Krichten, D. Demonstration And Full Scale Results Of A Plant Upgrade For BNR Using Integrated Fixed-Film Activated Sludge (IFAS) Technology. Proceedings of the $77^{\text {th }}$ WEFTEC- National Conference of the Water Environment Federation. New Orleans, LA, October 2-6, 2004.

Hubbell, S., McDowell, C. Cold Temperature BNR Using Integrated Fixed-Film Activated Sludge (IFAS) Hybrid Technology. Proceedings of the $76^{\text {th }}$ WEFTEC- National Conference of the Water Environment Federation. Los Angeles, CA, October 12-15, 2003.

Jackson, D., Ripley, L., Maurina, T., Hubbell, S. Conversion from Contact Stabilization To Nitrification Using Integrated Fixed Film Activated Sludge (IFAS) In The Colony, Texas. Proceedings of the $80^{\text {th }}$ WEFTEC- National Conference of the Water Environment Federation. San Diego, CA, October 13-17, 2007.

Johnson, T., McQuarrie, J., Shaw, A. Integrated Fixed-Film Activated Sludge (IFAS): The New Choice For Nitrogen Removal Upgrades In The United States. Proceedings of the $77^{\text {th }}$

WEFTEC- National Conference of the Water Environment Federation. New Orleans, LA, October 2-6, 2004.

Johnson, T., Shaw, A. A Pilot-Scale Comparison of IFAS And MBBR To Achieve Very Low Total Nitrogen Concentrations. Proceedings of the $80^{\text {th }}$ WEFTEC- National Conference of the Water Environment Federation. San Diego, CA, October 13-17, 2007.

Jones, R., Sen, D., Lambert, R. Full Scale Evaluation Of Nitrification Performance In An Integrated Fixed Film Activated Sludge Process. Water Science and Technology: 38(1): 71-78.

Kaldate, A., Smedley, S., Turner, T. Evaluation Of IFAS Technology For TN Removal At Chesterfield County BNR Program. Proceedings of the $81^{\text {st }}$ WEFTEC- National Conference of the Water Environment Federation. Chicago, IL, October 18-22, 2008. 
Maas, C., Parker, W., Legge, R. Detachment Of Solids And Nitrifiers In IFAS Systems. Proceedings of the $80^{\text {th }}$ WEFTEC- National Conference of the Water Environment Federation. San Diego, CA, October 13-17, 2007.

Masterson, T., Federico, J., Duerr, S. Upgrading For Total Nitrogen Removal With A Porous Media IFAS System. Proceedings of the $77^{\text {th }}$ WEFTEC- National Conference of the Water Environment Federation. New Orleans, LA, October 2-6, 2004.

Metcalf \& Eddy. 2003. Wastewater Engineering: Treatment and Reuse. Boston: McGraw-Hill, Inc.

McQuarrie, J., Rutt, K., Seda, J., Haegh, M. Observations From The First Year of Full-Scale Operation - The IFAS/BNR Process At The Broomfield Wastewater Reclamation Facility, Broomfield, $C O$. Proceedings of the $77^{\text {th }}$ WEFTEC- National Conference of the Water Environment Federation. New Orleans, LA, October 2-6, 2004.

Motsch, S., Fetherolf, D., Guhse, G., McGettigan, J., Wilson, T. MBBR and IFAS Pilot Program For Denitrification At Fairfax County's Norman Cole Pollution Control Plant. Proceedings of the WEF Nutrient Removal Conference (2007). Baltimore, MD, March 4-7, 2007.

Nelson, D., Renner, T. Improving Performance Of A Conventional Activated Sludge WTF To Provide Nitrification Utilizing Integrated Fixed Film Activated Sludge (IFAS). Proceedings of the $80^{\text {th }}$ WEFTEC- National Conference of the Water Environment Federation. San Diego, CA, October 13-17, 2007.

Odegaard, H., Rusten, B., Siljudalen, J. The Development Of The Moving Bed Biofilm ProcessFrom Idea To Commercial Product.

Onnis-Hayden, A., Dair, D., Johnson, C., Schramm, A., Gu, A. Kinetics And Nitrifying Populations In Nitrogen Removal Processes At A Full-Scale Integrated Fixed-Film Activated Sludge (IFAS) Plant. Proceedings of the $80^{\text {th }}$ WEFTEC- National Conference of the Water Environment Federation. San Diego, CA, October 13-17, 2007.

Park, S., Bae, W., Chung, J., Baek, S. 2007. Empirical Model Of The pH Dependence Of The Maximum Specific Nitrification Rate. Process Biochemistry: 42(12): 1671-1676.

Psaltakis, E., Liubicich, J, Pitt, P., Antonio, P., Posada, S. Demonstration Of Integrated Fixed Film Activated Sludge Process For BNR At The Mamaroneck WWTP. Proceedings of the $76^{\text {th }}$ WEFTEC- National Conference of the Water Environment Federation. Los Angeles, CA, October 12-15, 2003.

Randall, C., Sen, D. Full-Scale Evaluation Of An Integrated Fixed-Film Activated Sludge (IFAS) Process For Enhanced Nitrogen Removal. Water Science and Technology: 33(12): 155-162.

Randall, C., Sen, D. Improving The Aquifas (Unified) Computational Model For Activated Sludge, IFAS and MBBR Systems By Embedding A Multi-Layer Biofilm Diffusion Model Within 
A Multi-Cell Activated Sludge System. Proceedings of the WEF Nutrient Removal Conference (2007). Baltimore, MD, March 4-7, 2007.

Ross, D., Fernandes, W., Briggs, T., Kim, N., Booth, G., Neely, D., Welp, J. Integrated Fixed Film Activated Sludge (IFAS) At The Lakeview WWTP: The Real Implementation Issues.

Proceedings of the $77^{\text {th }}$ WEFTEC- National Conference of the Water Environment Federation. New Orleans, LA, October 2-6, 2004.

Rusten, B., Hem, L., Odegaard, H. 1995. Nitrification Of Municipal Wastewater In Moving Bed Biofilm Reactors. Water Environment Research: 67: 75-86

Sen, D., Murthy, S., Phillips, H., Pattarkine, V., Copithorn, R., Randall, C., Schwinn, D., Banerjee, S. Minimizing Aerobic And Post Anoxic Volume Requirements In Tertiary Integrated Fixed-Film Activated Sludge (IFAS) And Moving Bed Biofilm Reactor (MBBR) Systems Using The Aquifas Model. Proceedings of the $80^{\text {th }}$ WEFTEC- National Conference of the Water Environment Federation. San Diego, CA, October 13-17, 2007.

Sen, D., Randall, C., Brink, W., Farren, G, Pehrson, D., Flournoy, W., Copithorn, R. Understanding The Importance Of Aerobic Mixing, Biofilm Thickness Control And Modeling On The Success Or Failure Of IFAS Systems For Biological Nutrient Removal. Proceedings of the WEF Nutrient Removal Conference (2007). Baltimore, MD, March 4-7, 2007.

Yerrell, K., Gobbie, M., Dold, P., Jones, R., Sickerdick, L. Full-Scale Demonstration Of A FreeMoving Media IFAS Process For Enhancing Nitrification Performance. Proceedings of the $74^{\text {th }}$ WEFTEC- National Conference of the Water Environment Federation. Atlanta, GA, October 1317, 2001. 


\section{METHODOLOGY}

\subsection{Bench Scale Reactor Construction}

The batch reactors were constructed from $9 \mathrm{~L}$, rectangular, clear polycarbonate containers with screw-cap lids with an active reactor volume of $7 \mathrm{~L}$. The mixer paddle extended through the screw-cap opening, and holes were drilled in the top of the container to insert DO and $\mathrm{pH}$ probes. The four reactors were aerated through an air stone and were fed pure oxygen at a low rate, which maintained DO roughly between 3 and $5 \mathrm{mg} / \mathrm{L}$, unless otherwise noted. The reactors were also equipped with a sample port located in the middle of the active volume which allowed for samples to be taken throughout the course of the various experiments performed.

The reactors were placed in a temperature-controlled water bath, and the temperature in each individual reactor in order to maintain a temperature consistent with the temperature of the IFAS tank, which was read and recorded every morning at the time at which the sample is taken. The bath was turned on the day before sample collection to allow time for the bath to adjust to the appropriate temperature.

The $\mathrm{pH}$ in the reactors was controlled to a setpoint between 7.2 and 7.3 for both the ammonia spike and for the nitrite spike experiment. Automatic addition of alkalinity in the form of a concentrated $\mathrm{Na}_{2} \mathrm{CO}_{3}$ solution was provided with Masterflex peristaltic pumps and on/off control to each reactor as needed. If the $\mathrm{pH}$ increased to higher than the controlled values, acid was added manually to return the reactor to the desired experimental $\mathrm{pH}$. $\mathrm{pH}$ was also logged continuously for each experiment using a USB data acquisition system with LABVIEW (National Instruments) running on a laptop computer 
To separate mixing and oxygenation functions, DO was controlled in the bench-scale reactors using pure oxygen. This system included HACH ruggedized LDO probes and solenoid valves connected to a relay controller and USB data acquisition and control system running LABVIEW (National Instruments) on a laptop computer. This system was also used to record temperature and DO every $10 \mathrm{sec}$ for each experiment, from which oxygen uptake rates could be calculated. Rotameters were used in series with the solenoid valves to regulate the oxygen flowrate into the reactors when they were aerating. The DO setpoint for the nitrification kinetics experiments was chosen to match the operational DO setpoints in the IFAS demonstration tank, but these DO setpoints were changed when measuring biofilm kinetics properties to illustrate the effect of DO on the performance of the carriers. Typically, the rate tests maintained a DO between 3 and $5 \mathrm{mg} / \mathrm{L}$ and the more controlled biofilm kinetic properties experiments maintained each reactor at a different and more consistent DO concentration. The diagram shown in Figure 3-1 displays a representation of the reactor construction. 


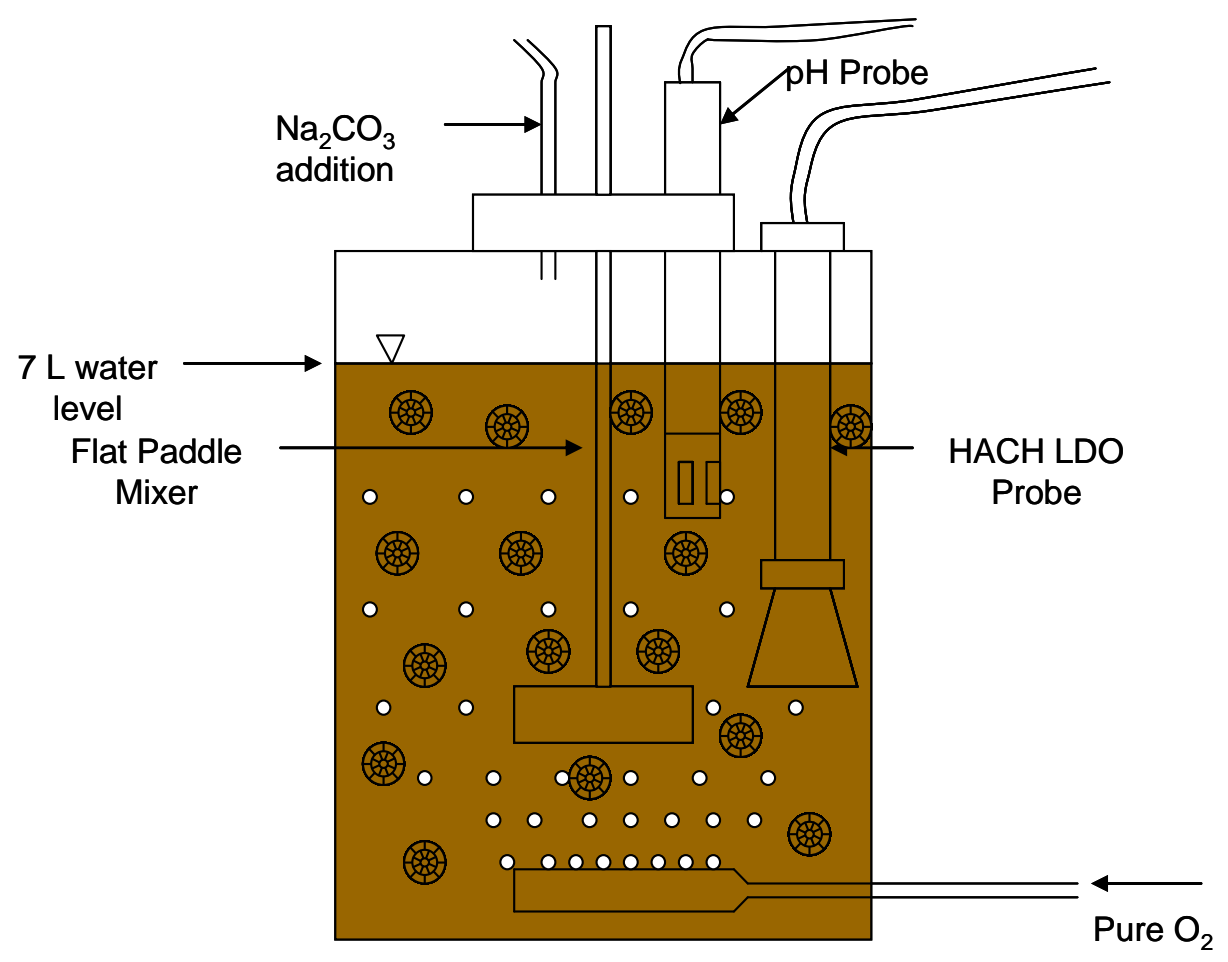

Figure 3-1. Diagram of Reactor Construction

Mixing was provided by flat paddle mixers (dimensions $=3$ in $\mathrm{x} 1$ in) using a Phipps and Bird Jar Tester stirring apparatus to ensure that the same mixing energy was being imparted to all four reactors, simultaneously. Because the reactors were placed in a temperature-controlled bath and the standard Phipps and Bird mixers were unable to reach the bulk liquid in the reactors, each paddle was extended with a 1/4-inch steel rod and couplings. The reactor speed was set at $175 \mathrm{rpm}$ for all of the nitrification experiments and $140 \mathrm{rpm}$ and $100 \mathrm{rpm}$, respectively, for the campaign experiments testing half saturation effects and DO and mixing. These mixing speeds ultimately translated to $\mathrm{G}$ values which varied as described by Table 3-1. 
Table 3-1. G value range for various mixing speeds and temperatures

\begin{tabular}{|c|c|c|c|c|c|}
\hline \multirow{3}{*}{ Constituent } & $\begin{array}{c}\text { Mixing Speed } \\
(\mathrm{RPM})\end{array}$ & $\begin{array}{c}\text { Maximum Temperature } \\
\left({ }^{\circ} \mathrm{C}\right)\end{array}$ & $\begin{array}{c}\text { Minimum Temperature } \\
\left({ }^{\circ} \mathrm{C}\right)\end{array}$ & $\begin{array}{c}\text { Maximum G } \\
\left(\mathrm{s}^{-1}\right)\end{array}$ & $\begin{array}{c}\text { Minimum G } \\
\left(\mathrm{s}^{-1}\right)\end{array}$ \\
\hline \multirow{3}{*}{ Media } & 175 & 27.8 & 14.5 & 259.9 & 234.4 \\
\cline { 2 - 6 } & 140 & 21.2 & 16.9 & 179.6 & 171.5 \\
\cline { 2 - 6 } & 100 & 18.4 & 15.4 & 111.8 & 108.2 \\
\hline \multirow{3}{*}{ Mixed Liquor } & 175 & 27.8 & 14.5 & 168.4 & 150.3 \\
\cline { 2 - 6 } & 140 & 21.2 & 16.9 & 116.5 & 115.6 \\
\cline { 2 - 6 } & 100 & 21.2 & 16.9 & 78.7 & 75.0 \\
\hline
\end{tabular}

G values were calculated based on an experiment performed on the media and mixed liquor with a torque meter attached to the mixing shaft with a coupling. Samples of secondary effluent and media at a 50\% fill and IFAS mixed liquor were collected from the IFAS basin and placed in a reactor and mixed. Torque was measured for a range of mixing speeds from 65 to $200 \mathrm{rpms}$ and $\mathrm{G}$ was calculated from torque. The results of this experiment are presented below in Figures 3-2 and Figures 3-3. It is clear that the presence of media does result in more power transfer to the water and more vigorous mixing.

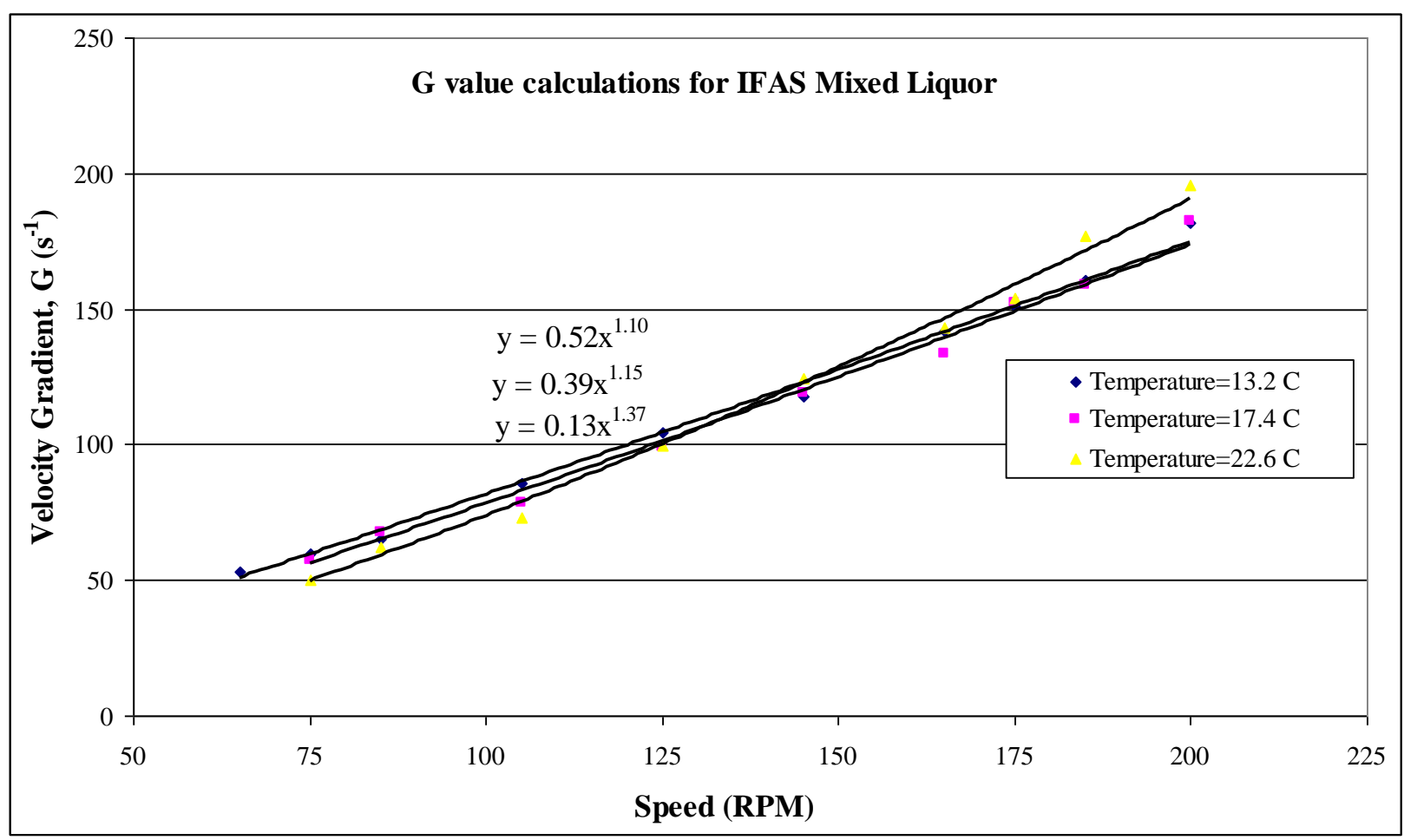

Figure 3-2. G Value Measurements for IFAS Mixed Liquor 


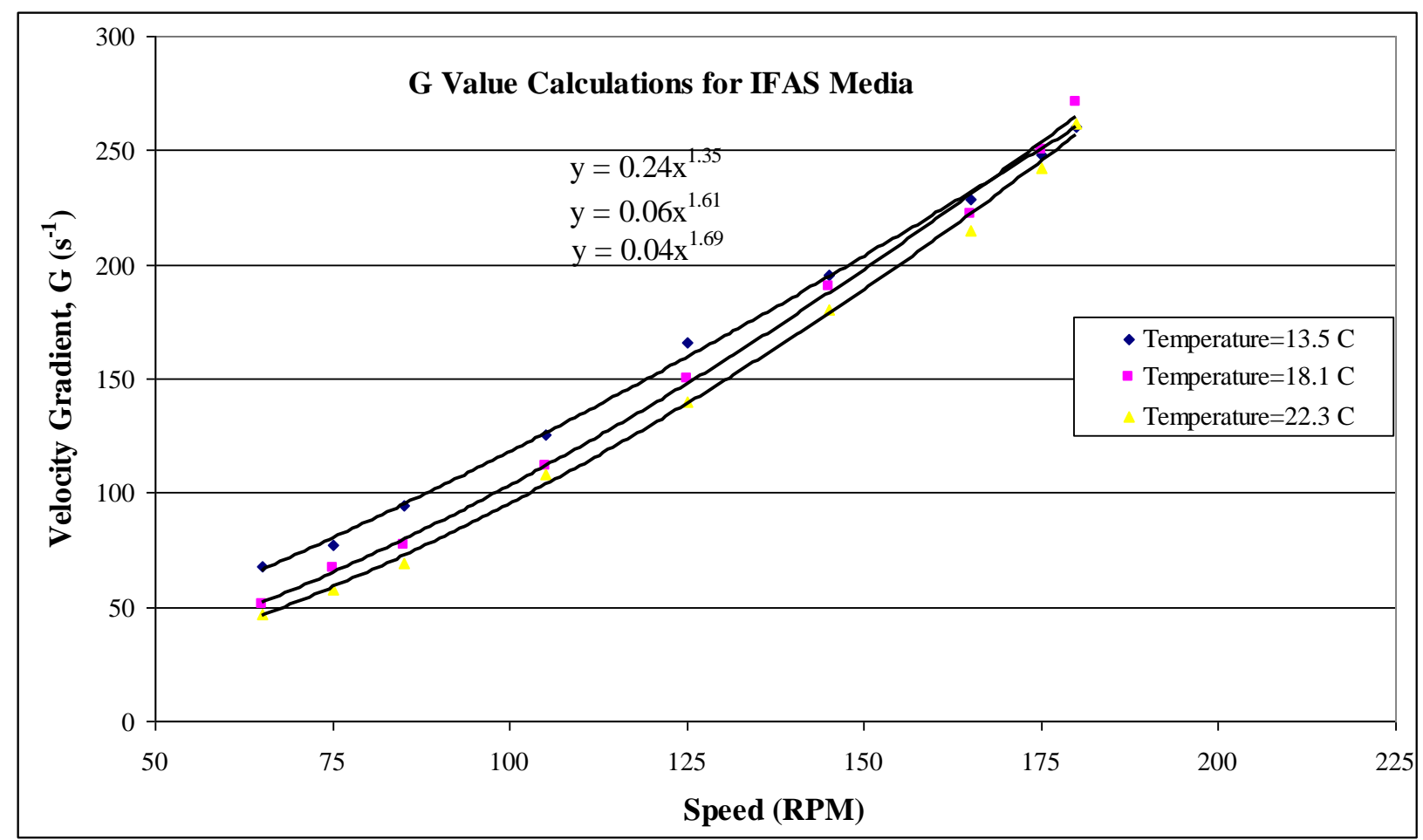

Figure 3-3. G Value Measurements for IFAS Media

\subsection{Reactor Contents}

For IFAS nitrification rate experiments, two of the four reactors were filled with K3 Anox-Kaldnes media, 50\%by volume. In order to achieve this desired media fill, about $5 \mathrm{~L}$ of bulk liquid, one with secondary effluent and the other with IFAS mixed liquor, was first added to the reactors. Then a $2 \mathrm{~L}$ graduated cylinder was used to add $3.5 \mathrm{~L}$ of media to each of the reactors, and the reactors were then filled the rest of the way with bulk liquid to a pre-calibrated line representing $7 \mathrm{~L}$. Mixed liquor from the James River Full scale plant and the IFAS mixed liquor were then poured into their respective reactors to the $7 \mathrm{~L}$ mark.

Figure 3-4 shows all four reactors witting in the temperature-controlled bath. The figure also shows how the reactors were configured for experimentation and how the $\mathrm{pH}$ and DO 
probes were installed. The figure also shows $\mathrm{Na}_{2} \mathrm{CO}_{3}$ addition using the four peristaltic pumps in the background

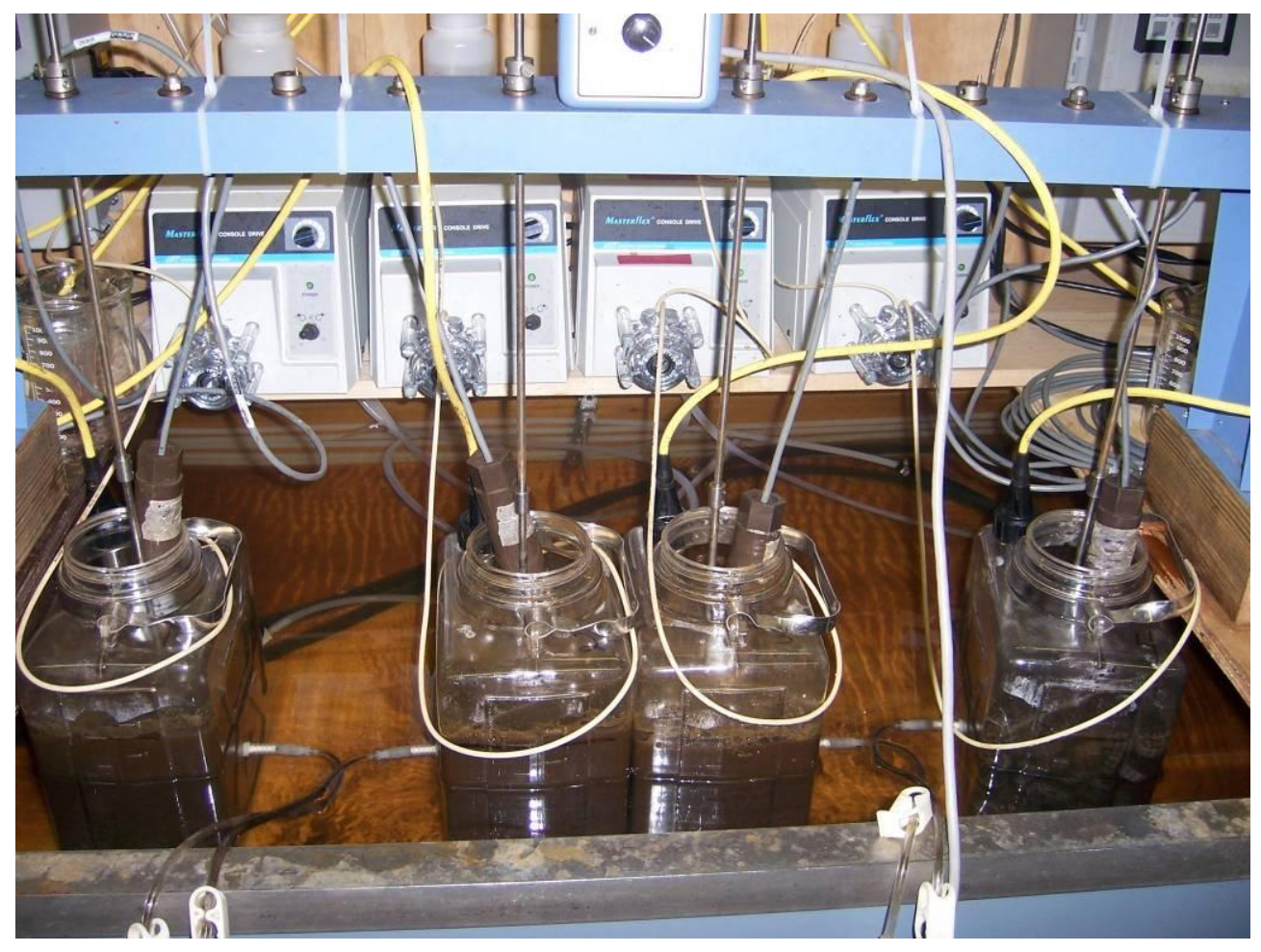

Figure 3-4. Bench-scale testing apparatus.

\subsection{Biomass Sample Collection}

\section{$\underline{\text { 3.3.1 Nitrification Rate Testing }}$}

Various samples for the nitrification rate tests were taken in the morning of every experiment. Samples were taken from the secondary clarifier, the full scale plant, and the IFAS demonstration tank. These samples from the full scale plant were taken and used as the control and the other samples were used to measure the rates in both the IFAS suspended phase and on the carriers individually and then compared to the rates of the suspended phase and carriers combined. 
Samples from the full scale plant aeration basins were collected from the aeration basin with a 5 gallon bucket. The bucket was tied off to the railings with a $25 \mathrm{ft} 1 / 4$ " nylon rope and thrown into the basin. When the bucket had filled, it was pulled out of the reactor and any visible foam was removed from the surface of these samples. One bucket, or approximately five gallons of sample, provided enough biomass for both the AOB and NOB experiments. After collection, the samples were taken back to the laboratory facilities at the plant and aerated with air until the biomass was used for the experiments (within 1 hour for AOB and 3 hours for NOB).

Samples from the IFAS demonstration tank were collected in a similar fashion. Two 5 gallon buckets were used to collect about 10 gallons of sample from the tank. The samples were collected near the middle of the IFAS zone in the demonstration reactor where there the media fill fraction was likely to be about $50 \%$ by volume. After these samples were taken, they were carried back to the lab where the media and bulk liquid were separated and used in the three remaining reactors. This separation was done by pouring the sample into two buckets, one inside of the other. The inside bucket contained numerous $1 / 4$-inch holes drilled into the bottom. The inner bucket was then lifted out of the outer bucket allowing the mixed liquor to gently drain into the bucket without holes. The bucket with holes in the bottom now containing media was gently dipped into a bucket containing secondary effluent to rinse off any remaining biomass not attached to the media.

In addition to the biomass samples collected on the morning for the experiments, 10 gallons of secondary effluent were collected to be used in the last reactor and to rinse the media after the separation step. 
After the samples were collected from the plant, they were divided into four reactors.

The four reactors contained the following biomass:

- Reactor 1- 7 L of mixed liquor from the James River Full Scale Plant

- Reactor 2- 7 L of IFAS mixed liquor

- Reactor 3- 7 L of IFAS mixed liquor with media at $50 \%$ fill

- Reactor 4- 7 L of Secondary Effluent with media at $50 \%$ fill

A $2 \mathrm{~L}$ graduated cylinder was used to measure out $3.5 \mathrm{~L}$ of media, and the media was added to each of these reactors. The two reactors were then filled to a previously calibrated line that represents $7 \mathrm{~L}$. By doing this a $50 \%$ fill by volume is achieved and standardized for every experiment.

The leftover clean secondary effluent, mixed liquor from the full scale plant, and combination of media and suspended growth from the IFAS were saved for the nitrite spike experiment. The samples containing biomass were aerated until the nitrite experiment to ensure that all of the residual ammonia in the samples was oxidized; this eliminated any potential interference with the NOB in the nitrite experiment.

For campaign experiments used to evaluate specific characteristics of the IFAS process, the procedures above were followed; though the contents of the individual reactors differed (i.e. all four reactors filled with media + secondary effluent operated at differing DO setpoint).

\subsubsection{Molecular Sampling}

Molecular sampling was done in conjunction with the nitrification rate testing. At the beginning of each test day, samples for both FISH analysis and QPCR analysis were collected from the suspended growth phase from both the JRWWTP activated sludge and from the IFAS 
suspended growth bacteria. The samples for QPCR were taken by filling four, $2 \mathrm{~mL}$ plastic microcentrifuge tubes with $1.5 \mathrm{~mL}$ samples from the reactor containing mixed liquor from the full scale plant, and four more $2 \mathrm{~mL}$ centrifuge tubes are filled with $2 \mathrm{~mL}$ samples from the reactor containing IFAS mixed liquor. These eight samples were then spun down using a centrifuge at $14000 \mathrm{xg}$ for two minutes. The supernatant was then removed and additional 1.5 $\mathrm{mL}$ samples are added to the centrifuge tubes from their respective reactors. These samples are spun down again at the same speed and duration, and the supernatant is then removed. The samples are then stored in a $-80{ }^{\circ} \mathrm{C}$ freezer until they were ready for analysis. When enough samples had been collected to merit analysis, the molecular samples were shipped on dry ice for QPCR analysis.

Prior to the molecular sampling a solution of $4 \%$ para-formaldehyde was made at the VMI laboratory facilities and then transported to the plant at $4^{\circ} \mathrm{C}$ for use in the preservation of samples collected for FISH analysis. At the same time that samples were taken from Reactors 1 and 2 for QPCR analysis, an additional four $0.5 \mathrm{~mL}$ samples were collected from both Reactors for FISH analysis. After $0.5 \mathrm{mLs}$ of sample had been added to each of the eight centrifuge tubes, $1.5 \mathrm{~mL}$ of the pre-prepared $4 \%$ para-formaldehyde solution is added to each of the tubes. The tubes were shaken well and then stored at $4^{\circ} \mathrm{C}$ until they could be transported back to the VMI laboratories in Lexington and further processed. After the FISH samples were transported back to VMI, they were fixed by centrifuging the biomass down at $5000 \mathrm{xg}$ and decanting the $4 \%$ paraformaldehyde. Then, 2mL of 1X Phosphate Buffered Saline (PBS) was added to each centrifuge tube and the biomass was vortexed to break up the pellet. The $1 \mathrm{X}$ PBS solution was made by addition $8 \mathrm{~g} \mathrm{NaCl}, 0.2 \mathrm{~g} \mathrm{KCl}, 1.44 \mathrm{~g} \mathrm{Na}_{2} \mathrm{HPO}_{4}$, and $0.24 \mathrm{~g} \mathrm{KH}_{2} \mathrm{PO}_{4}$, and then adjusting to a neutral $\mathrm{pH}$. The tubes were centrifuged again at 5000xg and the liquid was discarded and 
replaced with 2 more $\mathrm{mL}$ pf $1 \mathrm{X}$ PBS. This process was repeated once more with the addition of $0.5 \mathrm{~mL}$ of $1 \mathrm{X}$ PBS and $0.5 \mathrm{~mL}$ of $95 \%$ ethanol. The tubes were vortexed and then stored at $4{ }^{\circ} \mathrm{C}$ until ready for analysis. In conjunction with the nitrification rate testing, a QPCR study was performed on the AOB and NOB in both the fixed film and suspended growth phases. By using techniques to preserve samples in the ODU lab facilities, samples were collected and saved for QPCR analysis, which offered insight to the quantity of AOBs and NOBs both in the suspended growth phase as well as the fixed film phase. The biomass on the carriers was also carefully removed from the media to yield a sample large enough to run multiple PCR tests.

\subsubsection{Carrier Biomass Content Measurements}

In addition to the nitrification rate experiments, weekly carrier biomass content samples were taken for the duration of the project as described by Regmi et al. (2008).

\subsection{Experimental Protocol}

\subsubsection{Nitrification Rate Testing}

Immediately after sample addition, the reactors were placed in the temperature-controlled bath and allowed to stabilize in terms of temperature, $\mathrm{pH}$ and $\mathrm{DO}$. The reactors were then spiked with 40-50 mg/ $\mathrm{NH}_{4}{ }^{+}-\mathrm{N}$ and continuously sampled every 25 minutes for approximately two hours. Upon completion of the AOB rate experiment, the contents of the reactors was discarded and replaced with fresh biomass samples. Aerating the new biomass samples for the duration of the first experiment helped to minimize residual ammonia in the NOB experiments. The NOB experiments were conducted identically to the AOB experiment except $40-50 \mathrm{mg} / \mathrm{L}$ of $\mathrm{NO}_{2}{ }^{-} \mathrm{N}$

was added to the reactors instead of $\mathrm{NH}_{4}{ }^{+}-\mathrm{N}$. In addition to spiking each reactor with either 
ammonia or nitrite, all reactors were also spiked with $5 \mathrm{mg} / \mathrm{L}-\mathrm{P}$ to ensure that none of the experiments were nutrient limited by phosphorus.

The samples collected at 25 minute intervals for both the AOB and NOB experiments were then analyzed for $\mathrm{NH}_{4}{ }^{+}-\mathrm{N}, \mathrm{NO}_{2}-\mathrm{N}$, and $\mathrm{NO}_{3}-\mathrm{N}$ concentration over time. At the end of each experiment, samples were also collected for MLSS and MLVSS analysis.

\subsubsection{IFAS Performance Testing - Campaigns}

$\underline{\text { 3.4.2.1 Half-Saturation Coefficient Evaluation (low } \mathrm{NH}_{4}{ }^{+}-\mathbf{N} \text { and } \mathrm{NO}_{2}} \underline{\underline{N}} \underline{\text { ) }}$ : The reactors were controlled to variable DO concentrations of $2,4,6$, and $8 \mathrm{mg} / \mathrm{L}$ and allowed to mix and aerate with pure $\mathrm{O}_{2}$ until each reactor reached the desired DO. The reactors were then spiked with phosphate to ensure that the biomass was not nutrient limited and the reactors are spiked to 25 $\mathrm{mg} / \mathrm{L}$ of either ammonia or nitrite. After the spike the reactors were sampled at appropriate intervals to not only capture the linear rate of nitrification, but also the nitrification rate when substrate concentrations dropped to low levels. The results from these tests were recorded and analyzed to give the half saturation coefficient using four different DO concentrations. This test was conducted three times for AOB and NOB activity on the media at 175 RPM and 100 RPM corresponding to a range of $\mathrm{G}$ values summarized in Table 3.1.1 and as twice for AOB and NOB activity on the media at $100 \mathrm{rpms}$. In addition to testing the IFAS media, the same experiment was conducted one for $\mathrm{AOB}$ and $\mathrm{NOB}$ activity in the mixed liquor at $175 \mathrm{rpms}$.

3.4.2.2 DO and Mixing: The four reactors, containing secondary effluent and a $50 \%$ fill of media by volume were placed into the temperature-controlled bath. The reactors will be set to their respective DO concentrations at 2, 4, 6, and $8 \mathrm{mg} / \mathrm{L}$ and allowed to mix and aerate with 
pure $\mathrm{O}_{2}$ until each reactor has reached the desired DO. Three separate experiments will be conduced in this configuration, each at different mixing velocities of $100 \mathrm{rpm}, 140 \mathrm{rpm}$, and 175 rpm. The reactors will then be spiked with either $25 \mathrm{mg} / \mathrm{L}-\mathrm{N}$ ammonia or nitrite and sampled five times over a two hour period. These samples will be analyzed for ammonia, nitrate, and nitrite. After each two hour experiment, the media and secondary effluent was dumped out of the reactors and replaced with fresh samples. The next experiment then continued at the next mixing velocity. This experiment was conducted twice for AOB and NOB on the IFAS media as well as twice for the AOB and NOB activity in the IFAS mixed liquor.

3.4.2.3 Affect of COD addition on Nitrification Rates: In order to understand how heterotrophic and autotrophic bacteria are distributed in the IFAS tank, and how COD uptake affects nitrification rates on the IFAS media and mixed liquor, an experiment was conducted in which four reactors were run, two containing IFAS mixed liquor and two with IFAS media in secondary effluent at a measured $50 \%$ fill. Of these reactors, one containing mixed liquor, and the other containing media were spiked with $200 \mathrm{mg} / \mathrm{L}$ COD as acetic acid, and then all four reactors were spiked to $25 \mathrm{mg} / \mathrm{L}$ ammonia or nitrite depending on the population of nitrifiers being studied. The reactors were then sampled 5 times over a two hour period and analysis of COD uptake, as well as nitrification kinetics.

\subsection{Sample Preparation for Analysis}

During the rate experiments, the samples collected every 25 minutes were taken from the reactors using a $30 \mathrm{~mL}$ syringe, followed by immediate filtration using a $0.45 \mu \mathrm{m}$ PES membrane filter into a scew-cap vial. After filtration, the samples were analyzed for various 
constituents including $\mathrm{NH}_{4}{ }^{+}-\mathrm{N}, \mathrm{NO}_{2}-\mathrm{N}$, and $\mathrm{NO}_{3}-\mathrm{N}$. Samples were normally analyzed in the field almost immediately after they were collected, and in the case that immediate analysis was not possible for whatever reason the samples were refrigerated to ensure that accurate analysis was conducted for each experiment. In all cases, field analyses were completed within 24 hours. Samples for MLSS and MLVSS analysis were collected in $500 \mathrm{~mL}$ HDPE bottles and stored at $4^{\circ} \mathrm{C}$ until analysis by HRSD Central Environmental Laboratories (CEL). In some cases, filtered samples were preserved for confirmation testing by HRSD CEL for $\mathrm{NH}_{4}{ }^{+}-\mathrm{N}$ and NOx-N. This additional testing provided QA/QC for the analysis performed at the plant.

\subsection{Sample Analysis}

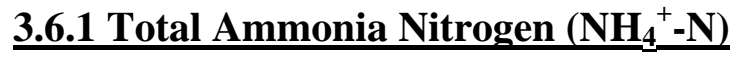

For field analysis, $\mathrm{NH}_{4}{ }^{+}-\mathrm{N}$ was analyzed using $\mathrm{HACH}$ colorimetric method TNT plus 832. Colorimetric methods were performed per $\mathrm{HACH}$ protocols with evaluation of matrix interference and other issues as needed.

\subsubsection{Nitrate $\left(\mathrm{NO}_{3}^{-}-\mathrm{N}\right)$}

For field analysis, $\mathrm{NO}_{3}{ }^{-}-\mathrm{N}$ was analyzed using $\mathrm{HACH}$ colorimetric method TNT plus 836. Colorimetric methods were performed per $\mathrm{HACH}$ protocols with evaluation of matrix interference and other issues as needed.

\section{$\underline{\text { 3.6.3 Nitrite }\left(\mathrm{NO}_{2}-\mathrm{i}\right)}$}

Nitrite analysis was conducted in the field as soon as possible after sample filtration. The standard colorimetric method will be performed using $\mathrm{HACH}$ Nitriver 3 reagent and $10 \mathrm{~mL}$ 
samples. HACH method 8507 is a low range method, so all samples were diluted to concentrations between 0.002 and $0.3 \mathrm{mg} / \mathrm{L} \mathrm{NO}_{2}-\mathrm{N}$ and analyzed per standard protocols.

\subsubsection{MLSS/MLVSS}

Mixed Liquor Suspended Solids and Mixed Liquor Volatile Suspended Solids were performed by both HRSD laboratories and in the VMI laboratories in accordance with Standard Methods (2005). Samples were collected for analysis at the end of every experiment and transported on ice to one of the analysis locations.

\subsection{Reference}

APHA, AWWA, and WEF.

1995. Standard methods for the examination of water and wastewater. Washington, D.C.: APHA.

Regmi, P. 2008. Biological Nutrient Removal Upgrade At The James River Wastewater

Treatment Plant. Civil and Environmental Engineering. Old Dominion University, Norfolk, VA. 


\title{
4 MANUSCRIPT 1: IFAS NITRIFICAITON KINETICS
}

\begin{abstract}
The James River Treatment Plant (JRTP) operated a 2 MGD Integrated Fixed Film Activated Sludge (IFAS) demonstration process from November 2007 to April 2009 to explore IFAS performance and investigate IFAS technology as an option for a full scale plant upgrade in response to stricter nutrient discharge limits in the James River Basin. During the study, nitrification kinetics for both ammonia and nitrite oxidizing bacteria and plastic biofilm carrier biomass content were monitored on a near-weekly basis comparing the IFAS media, the IFAS process mixed liquor, and mixed liquor from the full-scale activated sludge process. Carrier biomass content is variable with respect to temperature and process SRT and relates to the localization of nitrification activity in the IFAS basin. Similar to trends observed for carrier biomass content (Regmi, 2008), ammonia oxidizing bacteria (AOB) and nitrite oxidizing bacteria (NOB) activity also shifted from the fixed film to the suspended phase as water temperatures increased and vice versa as the temperature decreased. The data suggest that $\mathrm{AOB}$ activity occurs on the surface of the biofilm carriers, while NOB activity remains deeper in the biofilm. During the highest temperatures observed in the IFAS tank, AOB activity on the media contributed as little as $30 \%$ of the total nitrification activity in the basin, and after temperatures dropped below $20^{\circ} \mathrm{C}$, AOB activity in the fixed film phase made up $75 \%$ of the total activity in the IFAS basin. During the warmest period of the summer, the media still retained more than $60 \%$ of the total NOB activity, and more than $90 \%$ of the total NOB activity during the period of coldest water temperature. This trend also points out that some AOB and NOB activity remained in the mixed liquor, even during the coldest periods. The retention of nitrification activity in the mixed liquor indicates that the constant sloughing of biomass off of the carriers allowed for
\end{abstract}


autotrophic activity, even during washout conditions. Carrier biomass content and nitrification rates on the IFAS media remained constant along the length of the basin, indicating that the IFAS tank is will mixed with respect to biomass growth, although there was a concentration gradient for soluble species $\left(\mathrm{NH}_{4}-\mathrm{N}, \mathrm{NO}_{2}-\mathrm{N}, \mathrm{NO}_{3}-\mathrm{N}\right)$.

\subsection{INTRODUCTION}

In 2005, new regulations were implemented as part of the Chesapeake Bay 2000 Agreement which require Hampton Roads Sanitation District (HRSD) wastewater treatment plants (WWTPs) discharging to the James River Basin to reduce the aggregate mass discharge of total nitrogen (TN) to 6,000,000 lbs/year (Water Quality Management Planning Regulation ). HRSD staff concluded that biological nutrient removal with IFAS should be employed at the 16.7 MGD James River Treatment Plant (JRTP) as a cost effective strategy to help achieve this aggregate goal, decreasing effluent TN at this facility to approximately $12 \mathrm{mg} / \mathrm{L}$ (annual average). However, IFAS remains a relatively new approach for boosting nitrogen removal performance, and there are still a number of fundamental and applied aspects of this technology that are not clearly understood. Process kinetics are not well defined with respect to variables including dissolved oxygen (DO), mixing intensity/regime, temperature, and localization of AOB and NOB activity. IFAS models that combine an IWA-style activated sludge model with a fundamental non-empirical biofilm model (considering external mass transfer and multicomponent biofilm diffusion) have been developed, but calibrated with limited full-scale experience.

HRSD elected to conduct a demonstration-scale IFAS study at JRTP to evaluate the performance of this process and to develop design criteria before implementation on a wider 
scale. For this demonstration project, a single existing fully-aerobic conventional aeration basin with dedicated secondary clarification, which was previously operated to achieve nitrification during warm weather months only, was converted to a 1.86 MGD (2.22 MGD max month) IFAS train in an MLE configuration with a 50\% fill of AnoxKaldnes plastic biofilm carriers in the aerobic zone only (K3 with a specific surface area of $500 \mathrm{~m}^{2} / \mathrm{m}^{3}$ ). The IFAS process was targeted to achieve complete, year-round nitrification at an operating solids residence time (SRT) well below the washout value for nitrifiers during cold weather periods, suggesting that $\mathrm{AOB}$ and NOB must colonize the IFAS carriers (McQuarrie et al. 2004)

Figure 4-1 represents a process flow diagram (PFD) of the IFAS demonstration tank at the JRTP. The demonstration is set up in the MLE fashion as shown below. The tank has two internal mixed liquor recycle pumps that were operated to not only return mixed liquor to the IFAS tank, but also to manage the distribution of media in the tank. For much of the duration of the demonstration study, the majority of internal mixed liquor recycle was performed by IMLR pump 1 to ensure that media concentrations in the IFAS tank were roughly homogeneous and to prevent media accumulation near the screens. During plant operation, the flows through IMLR pump 1 and IMLR pump 2 varied, but averaged as about 275\% through IMLR pump 1 and 130\% through IMLR pump 2. Operating the two IMLR pumps in this fashion created some concern with substrate short circuiting through IMLR pump 1, but after performing tracer testing, it was determined that an insignificant amount of substrate recycle was occurring and that nitrate recirculation to the anoxic zone was occurring. R1, R2, and R3 are all anoxic zones, and zone $\mathrm{R} 4$ is the tank volume dedicated to IFAS. The smaller R5 zone is also aerobic, but does not contain any IFAS media. For most of the duration of the demonstration the plant performed Garrett wasting except for December 2008, when the plant also wasted some sludge from the 
secondary clarifier. The WAS stream was also used to seed the full scale plant that was not operated for complete nitrification. This seeding allowed nitrifiers to be present in the full scale plant and enabled the full scale plant to achieve nitrification throughout the year.

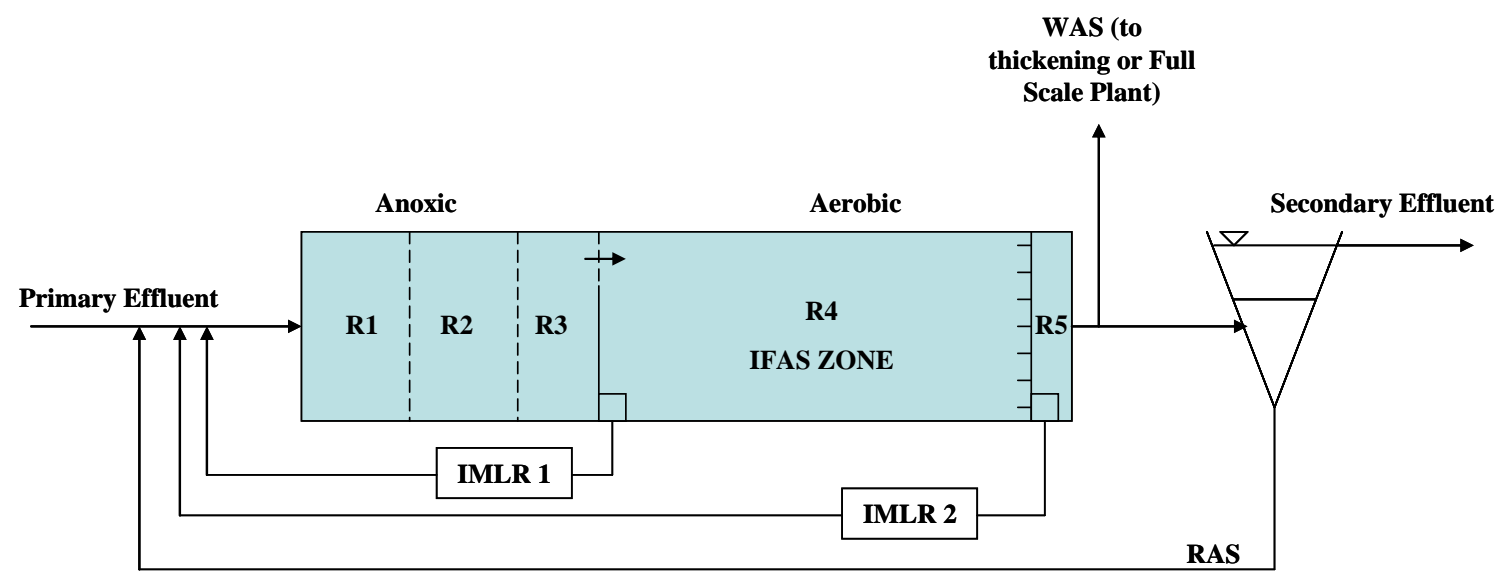

Figure 4-1. Process Flow Diagram of IFAS Demonstration

The IFAS process has been demonstrated to achieve complete nitrification, even at temperatures as low as $8{ }^{\circ} \mathrm{C}$ (Hubbell et al. 2003). Not only does the IFAS process offer the potential for year round nitrification, the technology has demonstrated much higher nitrification kinetics than can be achieved in a conventional activated sludge process (Ross et al. 2004). Furthermore, sloughing of nitrifiers from the IFAS carriers would be expected to "temporarily bioaugment" suspended biomass, providing additional nitrification capacity (Choi et al. 2007). Although nitrification rates have been measured in conjunction with IFAS demonstrations that have been conducted previously, no study has been performed that monitors nitrification rates and localization of $\mathrm{AOB}$ and $\mathrm{NOB}$ activity over the course of a year spanning a range of temperatures (Onnis-Hayden et al. 2007, Yerrell et al. 2001).

At the Broomfield wastewater treatment plant in Broomfield, CO, the IFAS exhibited higher and more consistent removal efficiency than activated sludge (McQuarrie et al. 2004). 
McQuarrie et al. (2004) also reports that effluent ammonia concentrations for the Broomfield WWTP were consistently under $1 \mathrm{mg} / \mathrm{L}-\mathrm{N}$ when the IFAS process had been implemented, where pre-IFAS effluent ammonia ranged much higher, up to $12 \mathrm{mg} / \mathrm{L}-\mathrm{N}$. Hubbell et al. (2004) also reported a significant improvement of ammonia removal capacity of an IFAS upgrade demonstration compared with conventional activated sludge. At the Donner Summit Public Utility District IFAS upgrade, significant ammonia oxidation was reported, even with influent wastewater temperatures as low as $8^{\circ} \mathrm{C}$ (Hubbell et al. 2004). According to the work done by Onnis- Hayden et al. (2007), AOB nitrification rates of $5.04 \mathrm{~g} / \mathrm{m}^{2} /$ day were observed at temperatures of $20^{\circ} \mathrm{C}$ at the Mamaroneck WWTP demonstration. This same study also demonstrated that nitrification rates in the second stage were evenly split between the mixed liquor and the media(Onnis-Hayden et al. 2007).

Another full scale demonstration conducted in the Christies Beach WWTP in South Australia demonstrated that by adding IFAS media to a conventional activated sludge plant essentially doubled the nitrification rates at the wastewater treatment plant, where IFAS nitrate production was measured at $0.19 \mathrm{mg} / \mathrm{L} / \mathrm{min}$ and activated sludge nitrate production rate was $0.088 \mathrm{mg} / \mathrm{L} / \mathrm{min}$ (Yerrell et al. 2001). Pilot testing of the IFAS process was also conducted at the Mamaroneck WWTP, which experienced about $90 \%$ ammonia removal by mass and also experienced about $90 \%$ removal of total nitrogen by mass with a post anoxic zone (Johnson et al. 2007). In addition to the Mamaroneck demonstration, the Norman Cole Demonstration in Fairfax County, VA was able to meet the $2.0 \mathrm{mg} / \mathrm{L}$ effluent NOX-N standard in $18.5-20{ }^{\circ} \mathrm{C}$ wastewater with an average of 0.86 of a short stable period of operation in a last pass IFAS configuration (Motsch et al. 2007). 
The goal of this research was to measure nitrification rates for both ammonia oxidizing bacteria $(\mathrm{AOB})$ and nitrite oxidizing bacteria $(\mathrm{NOB})$ in both suspended growth and fixed film phases from the IFAS demonstration tank at the James River Wastewater Treatment Plant (JRWWTP), in Newport News, Virginia. The specific research goals for this project were:

- Compare nitrification rates measured from January 2008 through January 2009 to find a clear relationship between warm and cold weather conditions on nitrification rates on both the carriers and IFAS mixed liquor and how they compare to mixed liquor from the full scale unmodified aeration basins at the JRTP

- Determine localization of AOB and NOB activity in both phases of the IFAS process

- Achieve a better understanding of IFAS process kinetics

Other experimentation was conducted in conjunction with this testing to achieve a number of goals related to evaluating the IFAS process including:

- Weekly biomass measurements on the IFAS media

- Normal process sampling was performed by HRSD to manage process performance and optimize TN removal in the IFAS basin

\subsection{METHODOLOGY}

Nitrification rates were measured on a near-weekly basis from January 2008 through January 2009. Each day nitrification rates were measured, two experiments were conducted to quantify $\mathrm{AOB}\left(\mathrm{NO}_{\mathrm{X}}\right.$ production basis) and $\mathrm{NOB}\left(\mathrm{NO}_{3}\right.$ production basis) activity. These rates were measured in the full scale plant mixed liquor for a control, as well as the IFAS mixed liquor, the IFAS media, and the IFAS mixed liquor and media combined. These rates were then normalized to mixed liquor concentrations, media surface, and biofilm content depending on the 
contents of each reactor. These measurements were then used to compare performance for each phase of biomass and determine the localization of AOB and NOB populations in the IFAS process.

\subsubsection{Bench Scale Reactor Construction}

The batch reactors were constructed from $9 \mathrm{~L}$, rectangular, clear polycarbonate containers with screw-cap lids with an active reactor volume of $7 \mathrm{~L}$. The mixer paddle extended through the screw-cap opening, and holes were drilled in the top of the container to insert DO and pH probes. The four reactors were aerated through an air stone and were fed pure oxygen at a low rate, which maintained DO roughly between 3 and $5 \mathrm{mg} / \mathrm{L}$, unless otherwise noted. The reactors were also equipped with a sample port located in the middle of the active volume which allowed for samples to be taken throughout the course of the various experiments performed.

The reactors were placed in a temperature-controlled water bath, and the temperature in each individual reactor in order to maintain a temperature consistent with the temperature of the IFAS tank, which was read and recorded every morning at the time at which the sample is taken. The bath was turned on the day before sample collection to allow time for the bath to adjust to the appropriate temperature.

The $\mathrm{pH}$ in the reactors was controlled to a setpoint between 7.2 and 7.3 for both the ammonia spike and for the nitrite spike experiment. Automatic addition of alkalinity in the form of a concentrated $\mathrm{Na}_{2} \mathrm{CO}_{3}$ solution was provided with Masterflex peristaltic pumps and on/off control to each reactor as needed. If the $\mathrm{pH}$ increased to higher than the controlled values, acid was added manually to return the reactor to the desired experimental $\mathrm{pH}$. $\mathrm{pH}$ was also logged 
continuously for each experiment using a USB data acquisition system with LABVIEW (National Instruments) running on a laptop computer

To separate mixing and oxygenation functions, DO was controlled in the bench-scale reactors using pure oxygen. This system included HACH ruggedized LDO probes and solenoid valves connected to a relay controller and USB data acquisition and control system running LABVIEW (National Instruments) on a laptop computer. This system was also used to record temperature and DO every $10 \mathrm{sec}$ for each experiment, from which oxygen uptake rates could be calculated. Rotameters were used in series with the solenoid valves to regulate the oxygen flowrate into the reactors when they were aerating. The DO setpoint for the nitrification kinetics experiments was chosen to match the operational DO setpoints in the IFAS demonstration tank, but these DO setpoints were changed when measuring biofilm kinetics properties to illustrate the effect of DO on the performance of the carriers. Typically, the rate tests maintained a DO between 3 and $5 \mathrm{mg} / \mathrm{L}$ and the more controlled biofilm kinetic properties experiments maintained each reactor at a different and more consistent DO concentration. The diagram shown in Figure 4-2 displays a representation of the reactor construction. 


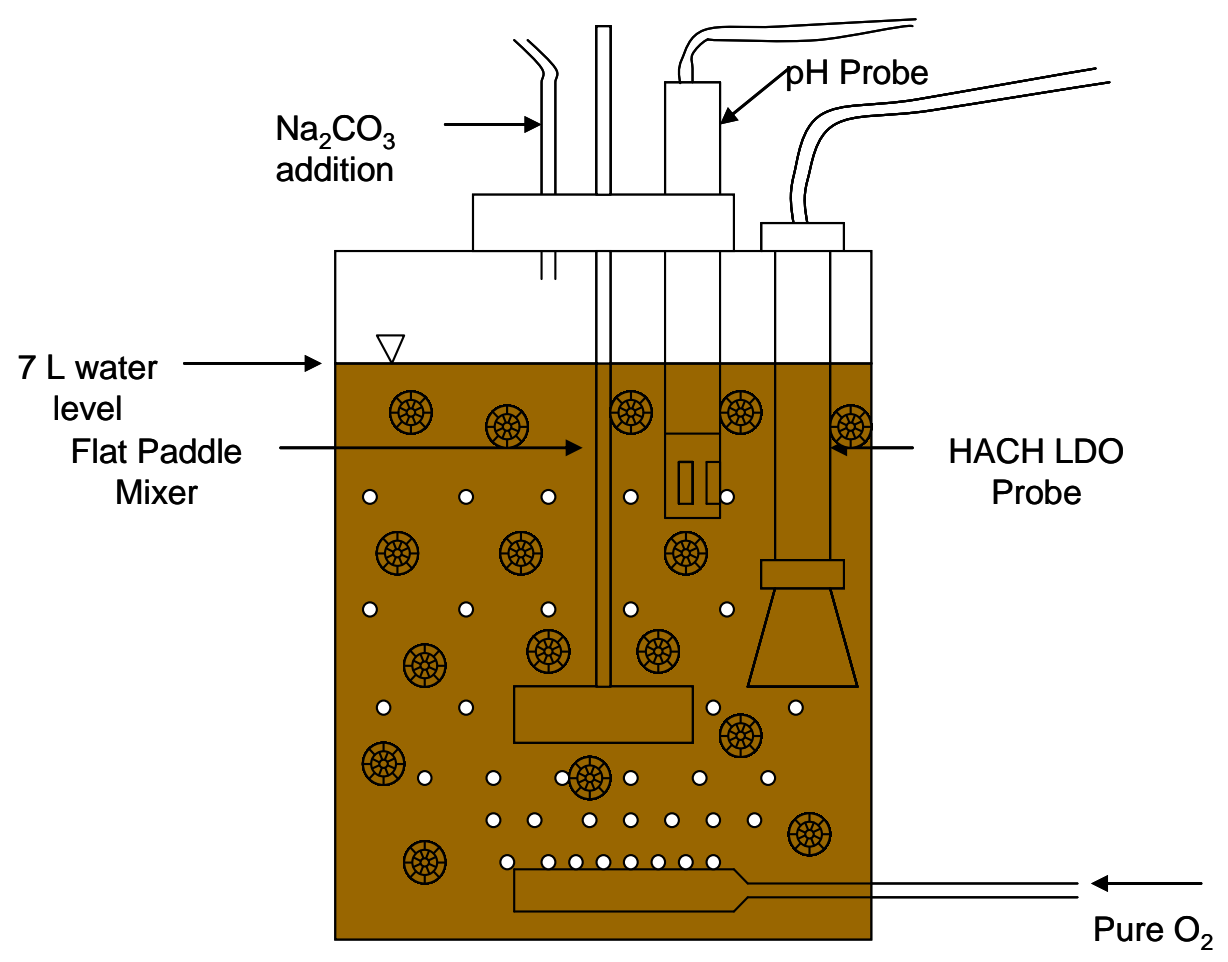

Figure 4-2. Diagram of Reactor Construction

Mixing was provided by flat paddle mixers (dimensions $=3$ in $\mathrm{x} 1$ in) using a Phipps and Bird Jar Tester stirring apparatus to ensure that the same mixing energy was being imparted to all four reactors, simultaneously. Because the reactors were placed in a temperature-controlled bath and the standard Phipps and Bird mixers were unable to reach the bulk liquid in the reactors, each paddle was extended with a 1/4-inch steel rod and couplings. The reactor speed was set at $175 \mathrm{rpm}$ for all of the nitrification experiments and $140 \mathrm{rpm}$ and $100 \mathrm{rpm}$, respectively, for the campaign experiments testing half saturation effects and DO and mixing. These mixing speeds ultimately translated to $\mathrm{G}$ values which varied as described by Table 4-1. 
Table 4-1. G value range for various mixing speeds and temperatures

\begin{tabular}{|c|c|c|c|c|c|}
\hline \multirow{3}{*}{ Constituent } & $\begin{array}{c}\text { Mixing Speed } \\
(\mathrm{RPM})\end{array}$ & $\begin{array}{c}\text { Maximum Temperature } \\
\left({ }^{\circ} \mathrm{C}\right)\end{array}$ & $\begin{array}{c}\text { Minimum Temperature } \\
\left({ }^{\circ} \mathrm{C}\right)\end{array}$ & $\begin{array}{c}\text { Maximum G } \\
\left(\mathrm{s}^{-1}\right)\end{array}$ & $\begin{array}{c}\text { Minimum G } \\
\left(\mathrm{s}^{-1}\right)\end{array}$ \\
\hline \multirow{3}{*}{ Media } & 175 & 27.8 & 14.5 & 259.9 & 234.4 \\
\cline { 2 - 6 } & 140 & 21.2 & 16.9 & 179.6 & 171.5 \\
\cline { 2 - 6 } & 100 & 18.4 & 15.4 & 111.8 & 108.2 \\
\hline \multirow{3}{*}{ Mixed Liquor } & 175 & 27.8 & 14.5 & 168.4 & 150.3 \\
\cline { 2 - 6 } & 140 & 21.2 & 16.9 & 116.5 & 115.6 \\
\cline { 2 - 6 } & 100 & 21.2 & 16.9 & 78.7 & 75.0 \\
\hline
\end{tabular}

G values were calculated based on an experiment performed on the media and mixed liquor with a torque meter attached to the mixing shaft with a coupling. Samples of secondary effluent and media at a 50\% fill and IFAS mixed liquor were collected from the IFAS basin and placed in a reactor and mixed. Torque was measured for a range of mixing speeds from 65 to 200 rpms and $\mathrm{G}$ was calculated from torque. The results of this experiment are presented below in Figures 4-3 and Figures 4-4. It is clear that the presence of media does result in more power transfer to the water and more vigorous mixing.

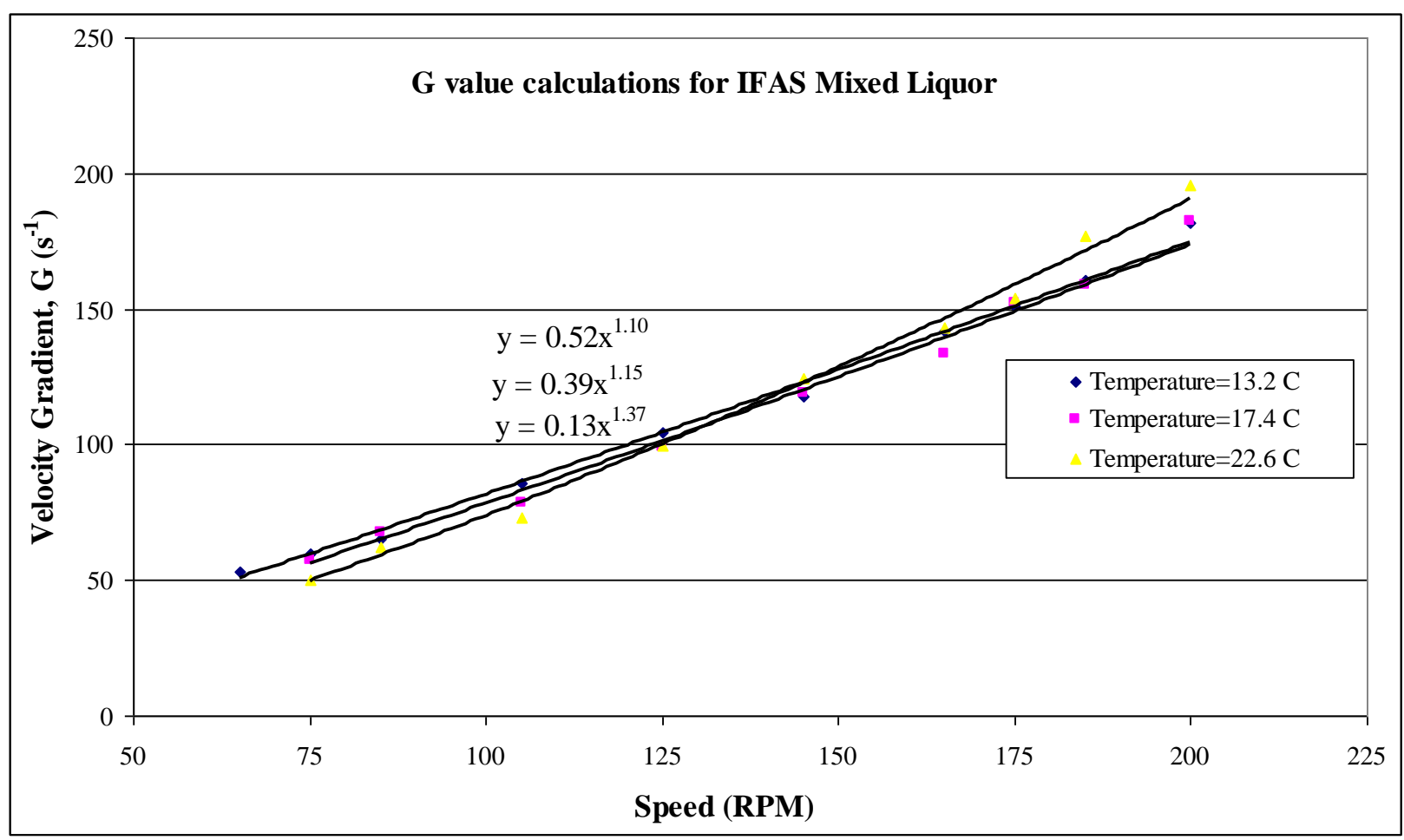

Figure 4-3. G Value Measurements for IFAS Mixed Liquor 


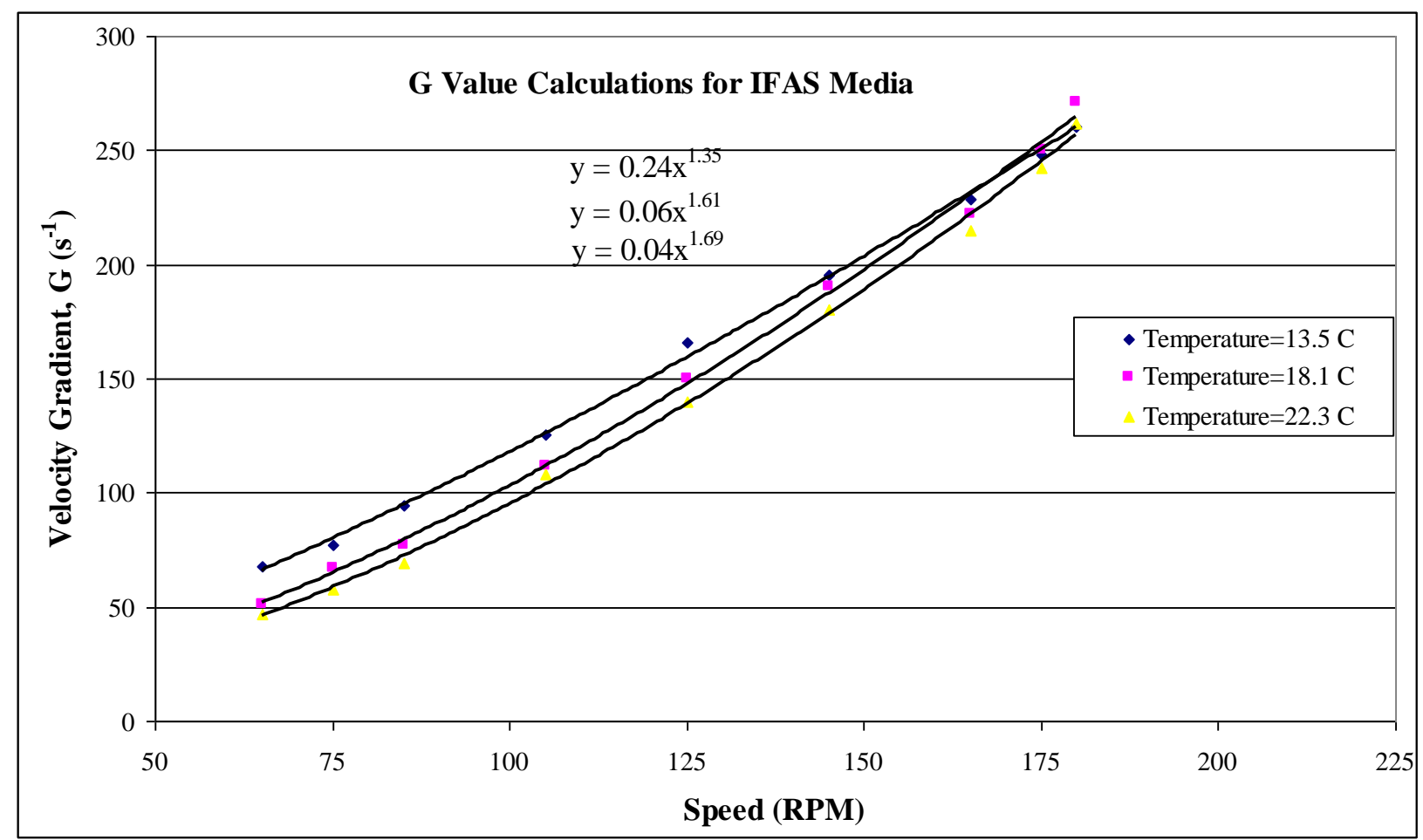

Figure 4-4. G Value Measurements for IFAS Media

\subsubsection{Reactor Contents}

For IFAS nitrification rate experiments, two of the four reactors were filled with $50 \% \mathrm{~K} 3$ Anox-Kaldnes media by volume. In order to achieve this desired media fill, about $5 \mathrm{~L}$ of bulk liquid, one with secondary effluent and the other with IFAS mixed liquor, was first added to the reactors. Then a $2 \mathrm{~L}$ graduated cylinder was used to add $3.5 \mathrm{~L}$ of media to each of the reactors and the reactors were then filled the rest of the way with bulk liquid to a pre-calibrated line representing 7 L. Mixed liquor from the James River Full scale plant and the IFAS mixed liquor were then poured into their respective reactors to the $7 \mathrm{~L}$ mark.

Figure 4-5 shows all four reactors witting in the temperature-controlled bath. The figure also shows how the reactors were configured for experimentation and how the $\mathrm{pH}$ and DO 
probes were installed. The figure also shows $\mathrm{Na}_{2} \mathrm{CO}_{3}$ addition using the four peristaltic pumps in the background

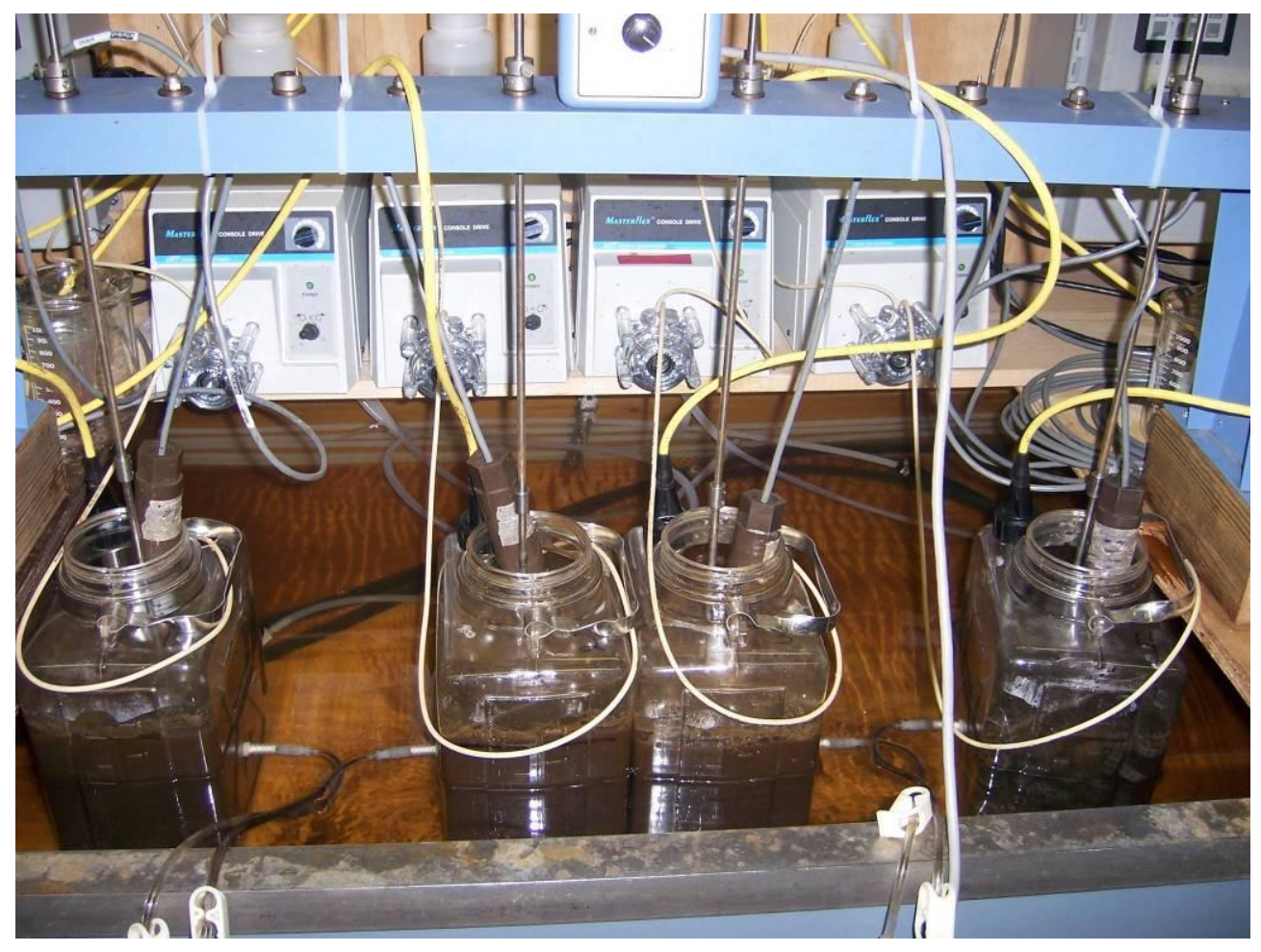

Figure 4-5. Bench-scale testing apparatus.

\subsubsection{Biomass Sample Collection}

\subsubsection{Nitrification Rate Testing}

Various samples for the nitrification rate tests were taken in the morning of every experiment. Samples were taken from the secondary clarifier, the full scale plant, and the IFAS demonstration tank. These samples from the full scale plant were taken and used as the control and the other samples were used to measure the rates in both the IFAS suspended phase and on the carriers individually and then compared to the rates of the suspended phase and carriers combined. 
Samples from the full scale plant aeration basins were collected from the aeration basin with a 5 gallon bucket. The bucket was tied off to the railings with a $25 \mathrm{ft} 1 / 4$ " nylon rope and thrown into the basin. When the bucket had filled, it was pulled out of the reactor and any visible foam was removed from the surface of these samples. One bucket, or approximately five gallons of sample, provided enough biomass for both the AOB and NOB experiments. After collection, the samples were taken back to the laboratory facilities at the plant and aerated with air until the biomass was used for the experiments (within 1 hour for AOB and 3 hours for NOB).

Samples from the IFAS demonstration tank were collected in a similar fashion. Two 5 gallon buckets were used to collect about 10 gallons of sample from the tank. The samples were collected near the middle of the IFAS zone in the demonstration reactor where there the media fill fraction was likely to be about $50 \%$ by volume. After these samples were taken, they were carried back to the lab where the media and bulk liquid were separated and used in the three remaining reactors. This separation was done by pouring the sample into two buckets, one inside of the other. The inside bucket contained numerous $1 / 4$-inch holes drilled into the bottom. The inner bucket was then lifted out of the outer bucket allowing the mixed liquor to gently drain into the bucket without holes. The bucket with holes in the bottom now containing media was gently dipped into a bucket containing secondary effluent to rinse off any remaining biomass not attached to the media.

In addition to the biomass samples collected on the morning for the experiments, 10 gallons of secondary effluent were collected to be used in the last reactor and to rinse the media after the separation step. 
After the samples were collected from the plant, they were divided into four reactors. The four reactors contained the following biomass:

- Reactor 1- 7 L of mixed liquor from the James River Full Scale Plant

- Reactor 2- 7 L of IFAS mixed liquor

- Reactor 3- 7 L of IFAS mixed liquor with media at $50 \%$ fill

- Reactor 4- 7 L of Secondary Effluent with media at $50 \%$ fill

A $2 \mathrm{~L}$ graduated cylinder was used to measure out $3.5 \mathrm{~L}$ of media, and the media was added to each of these reactors. The two reactors were then filled to a previously calibrated line that represents 7 L. By doing this a $50 \%$ fill by volume is achieved and standardized for every experiment.

The leftover clean secondary effluent, mixed liquor from the full scale plant, and combination of media and suspended growth from the IFAS were saved for the nitrite spike experiment. The samples containing biomass were aerated until the nitrite experiment to ensure that all of the residual ammonia in the samples was oxidized; this eliminated any potential interference with the NOB in the nitrite experiment.

\subsubsection{Carrier Biomass Content Measurements}

In addition to the nitrification rate experiments, weekly carrier biomass content samples were taken for the duration of the project as described by Regmi et al (2008). 


\subsubsection{Experimental Protocol}

\subsubsection{Nitrification Rate Testing}

Immediately after sample addition, the reactors were placed in the temperature-controlled bath and allowed to stabilize in terms of temperature, $\mathrm{pH}$ and $\mathrm{DO}$. The reactors were then spiked with $40-50 \mathrm{mg} / \mathrm{L} \mathrm{NH}_{4}{ }^{+}-\mathrm{N}$ and continuously sampled every 25 minutes for approximately two hours. Upon completion of the AOB rate experiment, the contents of the reactors was discarded and replaced with fresh biomass samples. Aerating the new biomass samples for the duration of the first experiment helped to minimize residual ammonia in the NOB experiments. The NOB experiments were conducted identically to the AOB experiment except 40-50 mg/L of $\mathrm{NO}_{2} \neg \mathrm{N}$ was added to the reactors instead of $\mathrm{NH}_{4}{ }^{+} \mathrm{N}$. In addition to spiking each reactor with either ammonia or nitrite, all reactors were also spiked with $5 \mathrm{mg} / \mathrm{L}-\mathrm{P}$ to ensure that none of the experiments were nutrient limited by phosphorus.

The samples collected at 25 minute intervals for both the AOB and NOB experiments were then analyzed for $\mathrm{NH}_{4}{ }^{+}-\mathrm{N}, \mathrm{NO}_{2}-\mathrm{N}$, and $\mathrm{NO}_{3}-\mathrm{N}$ concentration over time. At the end of each experiment, samples were also collected for MLSS and MLVSS analysis.

\subsubsection{Sample Preparation for Analysis}

During the rate experiments, the samples collected every 25 minutes were taken from the reactors using a $30 \mathrm{~mL}$ syringe, followed by immediate filtration using a $0.45 \mu \mathrm{m}$ PES membrane filter into a scew-cap vial. After filtration, the samples were analyzed for various constituents including $\mathrm{NH}_{4}{ }^{+}-\mathrm{N}, \mathrm{NO}_{2}-\mathrm{N}$, and $\mathrm{NO}_{3}-\mathrm{N}$. Samples were normally analyzed in the field almost immediately after they were collected, and in the case that immediate analysis was not possible for whatever reason the samples were refrigerated to ensure that accurate analysis was conducted 
for each experiment. In all cases, field analyses were completed within 24 hours. Samples for MLSS and MLVSS analysis were collected in $500 \mathrm{~mL}$ HDPE bottles and stored at $4^{\circ} \mathrm{C}$ until analysis by HRSD Central Environmental Laboratories (CEL). In some cases, filtered samples were preserved for confirmation testing by HRSD CEL for $\mathrm{NH}_{4}{ }^{+}-\mathrm{N}$ and Nox-N. This additional testing provided QA/QC for the analysis performed at the plant.

\subsubsection{Sample Analysis}

\subsubsection{Total Ammonia Nitrogen $\left(\mathrm{NH}_{4}{ }^{+}-\mathrm{N}\right)$}

For field analysis, $\mathrm{NH}_{4}{ }^{+}-\mathrm{N}$ was analyzed using $\mathrm{HACH}$ colorimetric method TNT plus 832. Colorimetric methods were performed per $\mathrm{HACH}$ protocols with evaluation of matrix interference and other issues as needed.

\subsubsection{Nitrate $\left(\mathrm{NO}_{3}{ }_{3}^{-} \mathrm{N}\right)$}

For field analysis, $\mathrm{NO}_{3}{ }^{-} \mathrm{N}$ was analyzed using $\mathrm{HACH}$ colorimetric method TNT plus 836. Colorimetric methods were performed per $\mathrm{HACH}$ protocols with evaluation of matrix interference and other issues as needed.

\section{$\underline{4.2 .6 .3 ~ N i t r i t e ~}\left(\mathrm{NO}_{2}^{-}-\mathrm{N}\right)$}

Nitrite analysis was conducted in the field as soon as possible after sample filtration. The standard colorimetric method will be performed using $\mathrm{HACH}$ Nitriver 3 reagent and $10 \mathrm{~mL}$ samples. HACH method 8507 is a low range method, so all samples were diluted to concentrations between 0.002 and $0.3 \mathrm{mg} / \mathrm{L} \mathrm{NO}_{2}-\mathrm{N}$ and analyzed per standard protocols. 


\subsubsection{MLSS/MLVSS}

Mixed Liquor Suspended Solids and Mixed Liquor Volatile Suspended Solids were performed by both HRSD laboratories and in the VMI laboratories in accordance with Standard Methods. Samples were collected for analysis at the end of every experiment and transported on ice to one of the analysis locations.

\subsection{RESULTS \& DISCUSSION}

\subsubsection{Plant Operation and Performance Data}

IFAS process temperature, SRT and effluent TN are plotted as a 7-day rolling average in Figures 4-6 and 4-7 below. Because the IFAS process began operation in November 2007, and flow into the IFAS tank was not stabilized until early 2008, a period of acclimation until March 2008 caused unstable performance in the IAS tank. After this acclimation period, the IFAS performance stabilized and nitrification rate tests could begin to offer insight to how and where nitrification activity in the IFAS tank was occurring. Figures 4-6 and 4-7 also highlight periods where external carbon was added, first a sugar-based beverage waste, followed by a crude glycerol product from a biodiesel plant using rendered poultry fat as its feedstock. The sugar waste addition from May 28 through June 30 resulted in a possible yeast overgrowth in the IFAS tank that affected both the IFAS mixed liquor as well as the carriers. In a response to the reported overgrowth of yeast, the process SRT in the IFAS tank was lowered from about 8 days to 4 days, to washout the yeast in the tank allowing the IFAS tank to resume normal performance. This occurred because a period when maximum wasting rates were not able to control mixed liquor concentrations properly in the tank, and high mixed liquor suspended solids were present in the tank. With the exception of this period of upset, plant SRT was maintained 
below 6 days for the entire year, fluctuating periodically. The figures also offer a complete view of temperature in the tank over the course of the 13 months of testing. Effluent TN has been plotted to evaluate the performance of the IFAS tank throughout the year. Although it is clear in Figure 4-6 that the IFAS process achieves complete nitrification and that effluent ammonia concentrations are quite low with the exception of a few upset periods, the effluent TN concentrations remains above that which would be expected for a MLE process, and this was likely due to carbon limitations in the pre-anoxic zone. This trend may also be because the IFAS process must be maintained at a higher DO than a conventional activated sludge process, and the internal mixed liquor recycle pumps continuously returned mixed liquor with high DO to the anoxic zone. As seen in Figure 4-7, the IFAS process was consistently able to achieve very low NH4-N concentrations for the entire duration of the demonstration, with the exception of the startup and acclimation period at the beginning of the nitrification rate testing, the upset period in June caused by the addition of sugar waste, and the period in December 2008 when the plant did not Garrett waste sludge. 


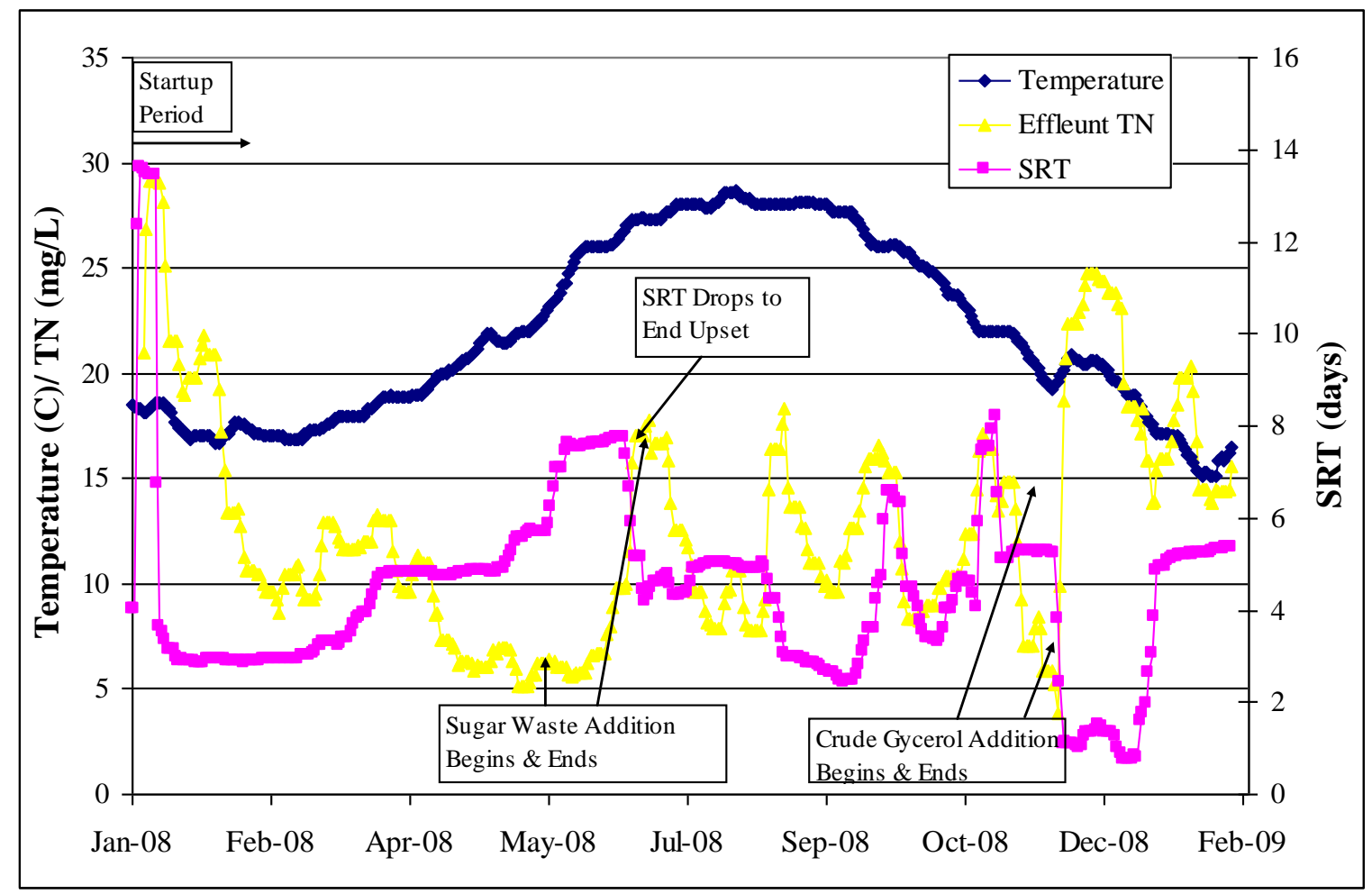

Figure 4-6. IFAS Operating Data Based on a 7 Day Rolling Average

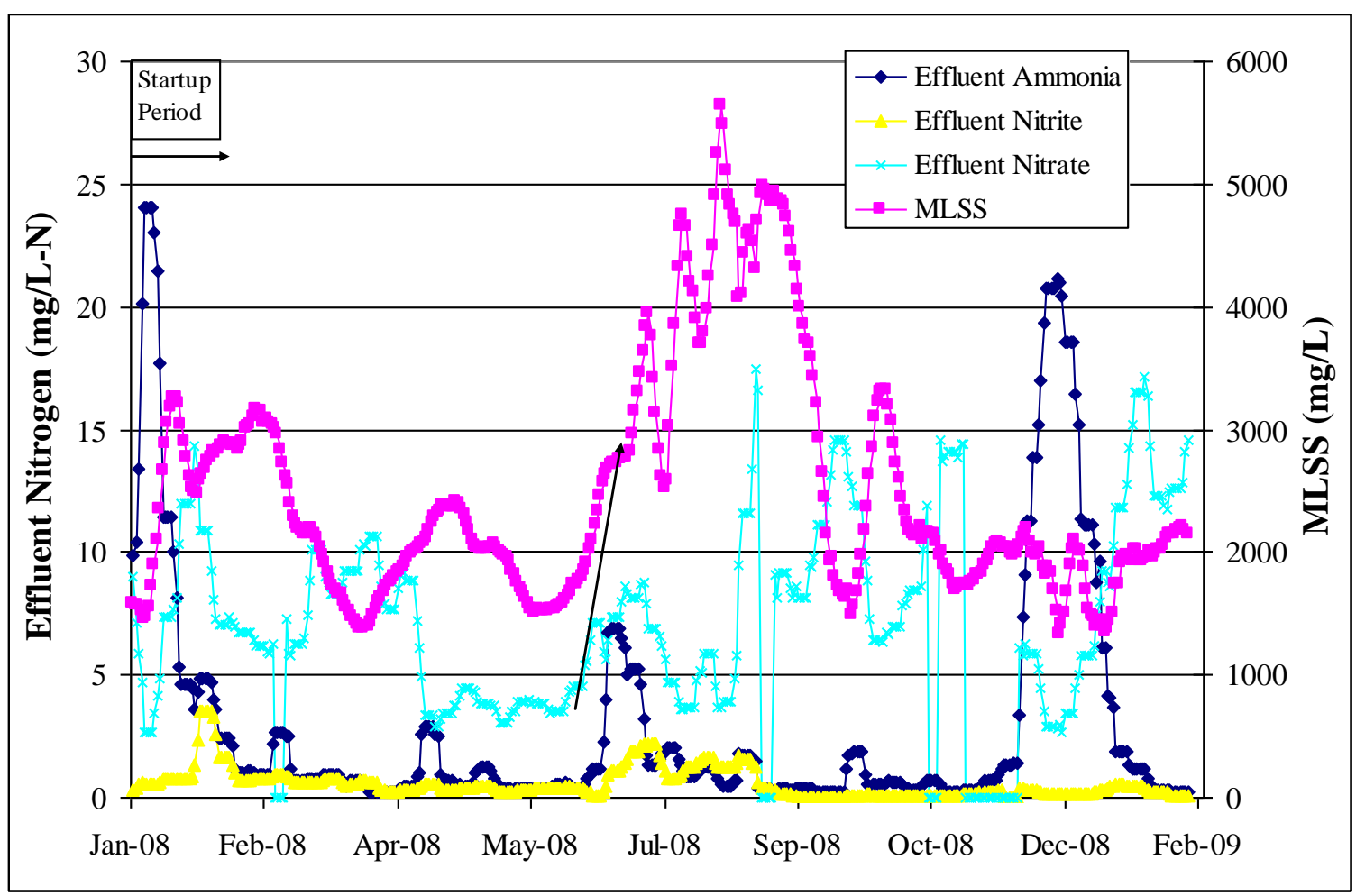

Figure 4-7. IFAS Operating Data Based on a 7 Day Rolling Average 


\subsubsection{Temperature and Biomass Measurements}

One important parameter monitored weekly in conjunction to the nitrification rate testing was the temperature in the IFAS demonstration tank. Figure 4-8 below displays the temperature in the IFAS basin, recorded at the time of sample collection, and the temperatures recorded in the reactors for both $\mathrm{AOB}$ and $\mathrm{NOB}$ experiments. Although there were some limitations associated with batch reactor temperature control, a clear relationship can be made between the actual IFAS temperature and the temperatures in the bench scale reactors.

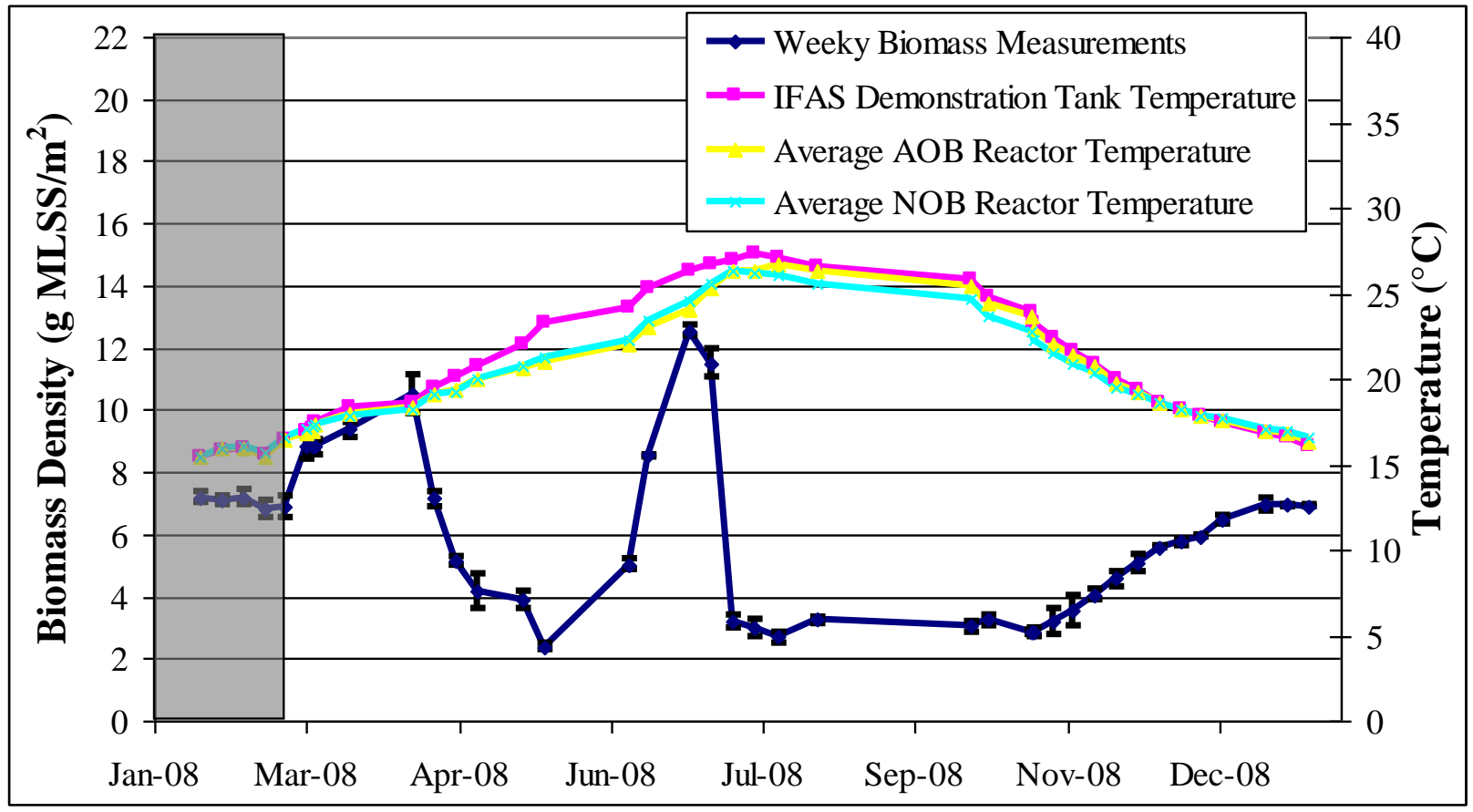

Figure 4-8. Recorded Temperatures for All Four Bench Scale Reactors (5-point rolling average) and Biomass Measurements on the Carriers at Three Different Locations. (Acclimation period shaded)

Carrier biomass content measurements are shown in Figure 4-8 over the course of the nitrification rate testing. Error bars represent the standard deviation of three independent media samples collected along the length of the tank (Regmi et al. 2008). These error bars depict and 
important observation made for the duration of the nitrification rate testing, that biomass measurements did not change along the length of the IFAS tank. This observation implies that biofilm on the media reached a steady state, where the rate of sloughing equaled the rate of biomass growth on the biofilm, and biomass concentrations on the media were maintained by mixing in the tank. The increase of biomass until late March was likely due to continued acclimation of the IFAS tank and a time where the biofilm had not yet reached steady state conditions. The trend presented in Figure 4-8 shows that temperature plays a key role in determining the biomass content in the biofilm. Colder temperatures that normally result in washout conditions promote autotrophic growth on the media, where nitrifiers can experience an extended SRT. Furthermore, temperature impacts the mixing energy imparted to the process, which in turn controls sloughing. Since DO demand can be met with less aeration in colder temperatures, and mixing energy in the tank is controlled through aeration, the increase in biomass in colder temperatures could also result from reduced mixing viscosity or lower $\mathrm{G}$ values. Biomass content on the carriers also shows a clear reduction in warmer conditions. During this time, process SRT was increasing, and with longer SRT and warmer temperatures, autotrophic growth is promoted in the mixed liquor.

During these times, Figure 4-8 clearly shows a migration of biomass off of the carriers and into the suspended fraction. For the duration of June, an upset period associated with the addition of sugar waste resulting in possible yeast proliferation can be found on the figure. During this upset, process SRT increased, process DO decreased, and some heterotrophic growth was likely transferred out of the pre-anoxic to the IFAS zone due to carbon addition, all of which lead to a significant increase in carrier biomass. In order to end the upset and resume normal operation, carbon addition was terminated and process DO and wasting were increased, resulting 
in a lower SRT, which is associated with the loss of carrier biomass. As IFAS temperatures cooled into the winter of 2008/2009, carrier biomass increased as expected. At this time, process SRT ranged from 2 to 5 days resulting in a migration of autotrophic growth onto the media where nitrifiers could be exposed to longer SRTs.

Figure 4-9 below demonstrates the clear relationship between temperature and carrier biomass content between $17^{\circ} \mathrm{C}$ and $23^{\circ} \mathrm{C}$ where the densities fluctuate linearly from $3 \mathrm{~g}$ MLSS $/ \mathrm{m}^{2}$ and $7 \mathrm{~g} \mathrm{MLSS} / \mathrm{m}^{2}$. The plot also illustrates the minimum and maximum biomass concentrations on the carriers. At temperatures above $23^{\circ} \mathrm{C}$, the biomass no longer increases on the carriers, and the same is true for the biomass on the carriers at temperatures below $17^{\circ} \mathrm{C}$. Figure 4.5 also includes biomass concentrations taken during times of upset for the IFAS tank. The most notable upset period was the yeast overgrowth in the tank in the early summer as a result of adding sugar waste as an external carbon source to the anoxic zone before the IFAS process. The unstable operating period associated with the start up of the demonstration tank is also responsible for some of the outliers at lower temperatures. 


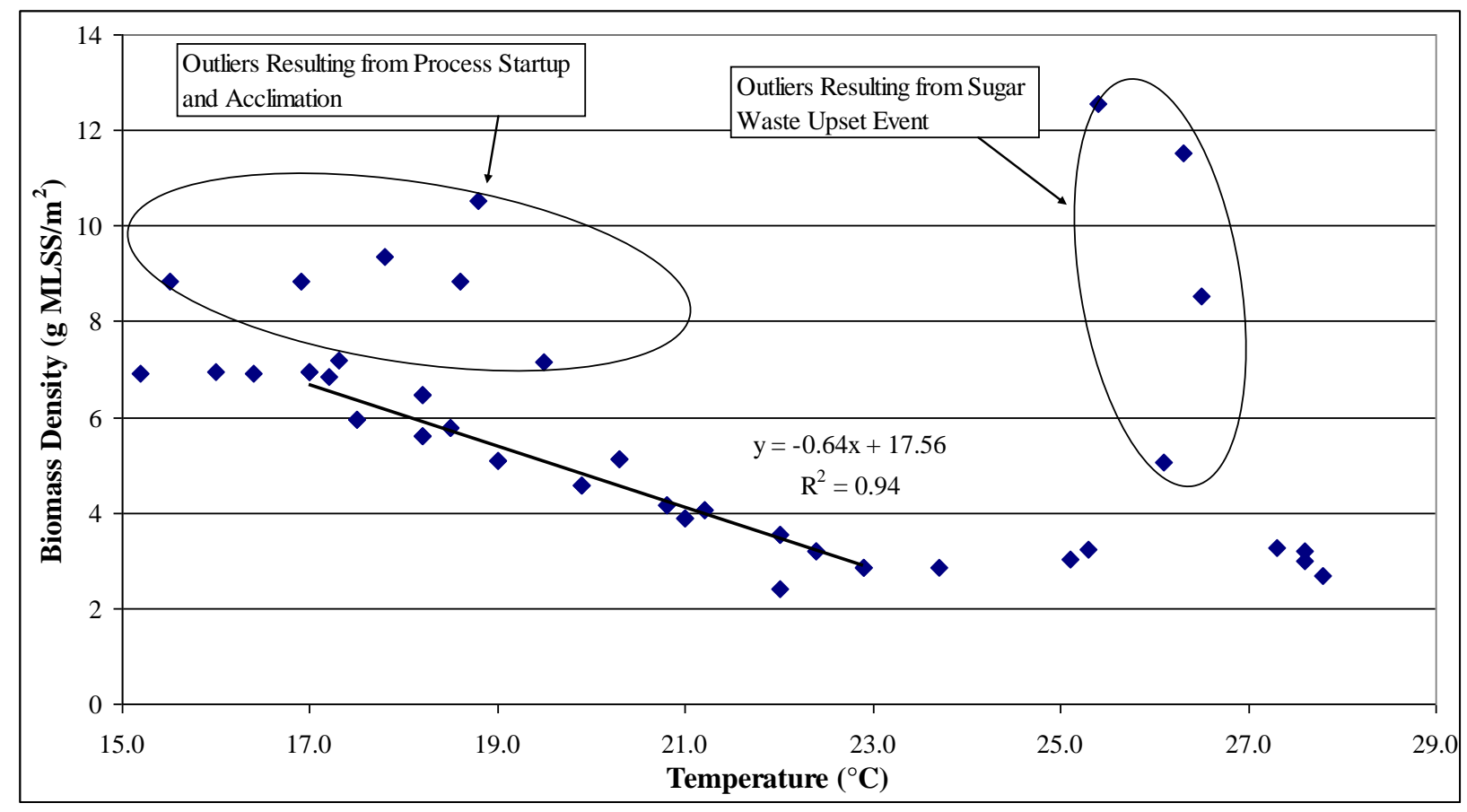

Figure 4-9. Biomass Measurements on the Carriers vs. Temperature

\subsubsection{Typical Nitrification Rate Test Results}

Mixing intensity in the IFAS basin can be calculated using air flow into the coarse bubble aerators. Figure 4-10 below plots the velocity gradient in the basin for the course of the nitrification rate testing. The plot indicates that $\mathrm{G}$ in the IFAS tank remains relatively constant over the course of the year at about $250 \mathrm{~s}^{-1}$. This shows that as temperatures cool and the aeration requirements decrease to maintain DO in the tank. Because of this drop in aeration, mixing decreases slightly, however, as the water becomes more viscous during cooling, the $\mathrm{G}$ value for the same air flow increases. It is this phenomenon that allows the velocity gradient to remain relatively constant year round. 


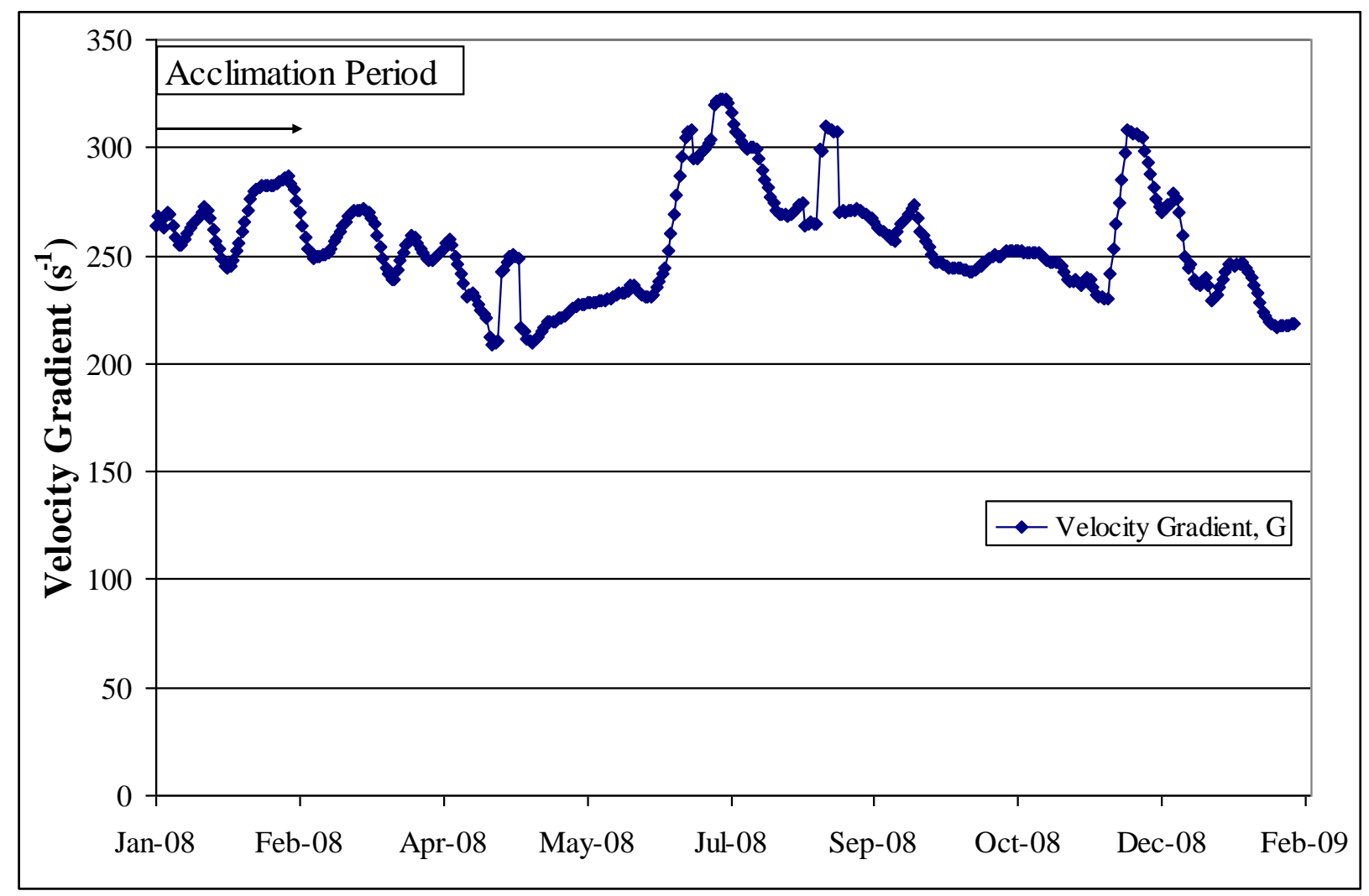

Figure 4-10. Velocity Gradient in the IFAS tank

Figure 4-9 and Table 4-2 represent typical results from a routine set of AOB and NOB rate measurements using samples collected under cold weather conditions from January 12, 2009. For normal weekly experiments, AOB activity was determined by adding $\mathrm{NH}_{4}-\mathrm{N}$ and monitoring $\mathrm{NO}_{3}-\mathrm{N}, \mathrm{NO}_{2}-\mathrm{N}, \mathrm{NH}_{4}-\mathrm{N}$ over time. For $\mathrm{NOB}$ activity, samples were allowed to aerate to ensure that $\mathrm{NH}_{4}-\mathrm{N}$ was low, and then $\mathrm{NO}_{2}-\mathrm{N}$ was added and $\mathrm{NO}_{3}-\mathrm{N}$ and $\mathrm{NO}_{2}-\mathrm{N}$ were monitored over time. To measure $\mathrm{AOB}$ activity slope the $\mathrm{NO}_{\mathrm{X}}$ slope over time was used and for NOB activity, the slope of $\mathrm{NO}_{3}$ production was used. Under routine conditions, the ammonia concentration was below detection for all of the NOB experiments. However, there were a number of cases where the AOB activity was so low in the full-scale plant mixed liquor (due to partial or negligible nitrification activity in the full-scale plant activated sludge process) that it 
was not possible to wait for complete ammonia depletion before spiking with nitrite and beginning the NOB rate measurement. In order to calculate NOB rates for the full scale plant in the presence of ammonia, it was first determined whether the AOB rates for the full scale plant were higher than the NOB rates. This analysis was performed by checking for nitrite accumulation in the AOB rate tests. An accumulation of nitrite during the AOB tests indicated that while ammonia was being slowly oxidized, the NOB rate was even slower. If nitrite accumulation was measured during the AOB rate test, then a regression analysis was performed for the nitrite production rate during the AOB activity measurement. The NOB activity was assumed to be the nitrate production rate in these AOB tests if the regression for nitrate production was statistically significant. Nitrification rates on January 12, 2009 show that most of the AOB and NOB activity in the IFAS process was occurring on the media and not the mixed liquor as described by Figure 4-11 and Table 4-2. 

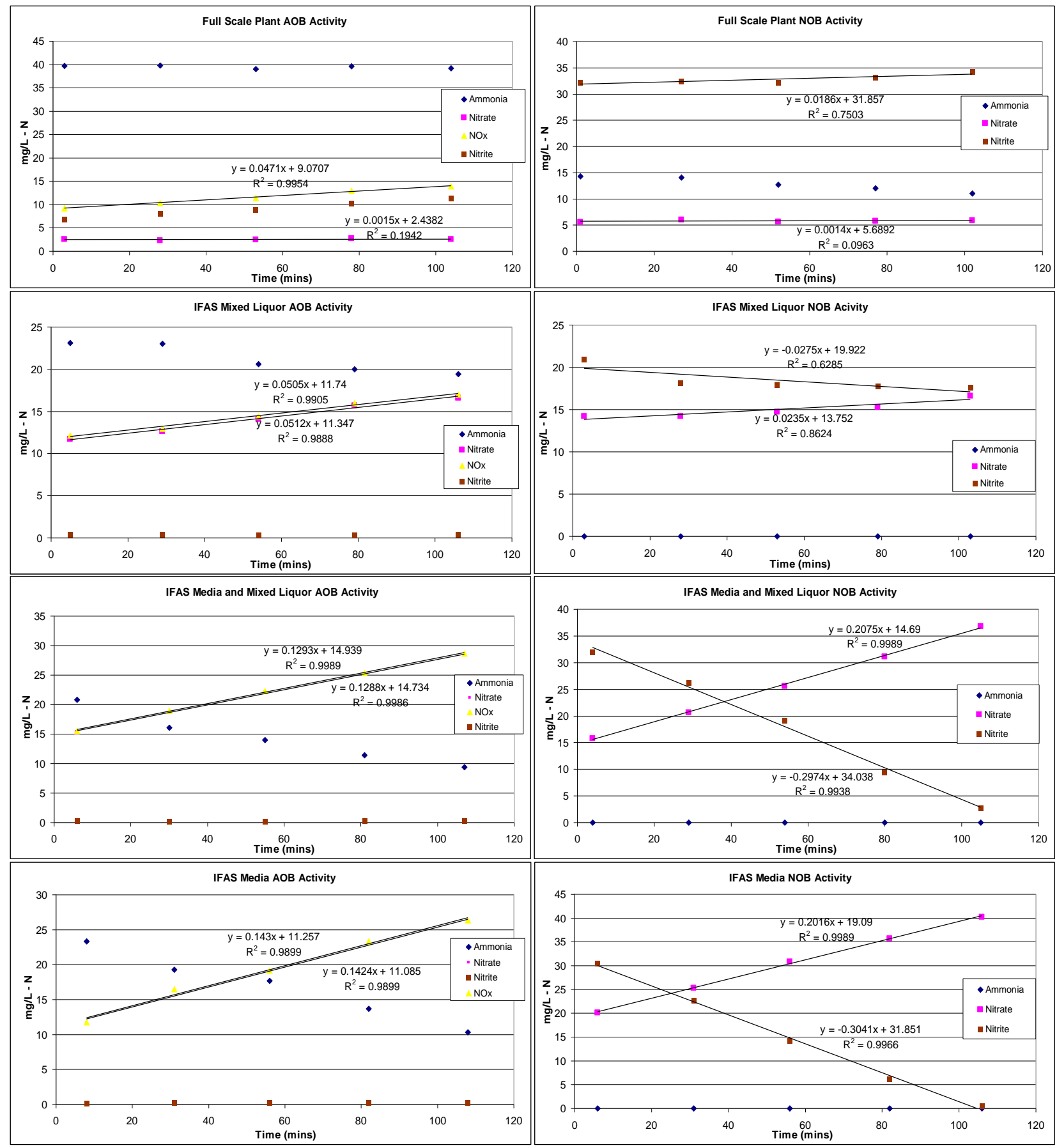

Figure 4-11 AOB and NOB nitrification rate test results for January 12, 2009

The regression analysis performed on the AOB nitrate slope for the full scale plant mixed liquor was statistically significant with a $95 \%$ confidence interval on the slope that did not 
include negative values, so the NOB activity can be quantified as $0.092 \mathrm{mg} / \mathrm{L} / \mathrm{hr}$, or $0.0405 \mathrm{mg} / \mathrm{g}$ MLSS/hr. As shown in Table 4-2, the AOB activity for the IFAS mixed liquor and the full scale plant were similar; however, unlike the full scale plant, some NOB activity was present in the IFAS mixed liquor. These results are representative of typical cold weather conditions. NOB activity in the IFAS mixed liquor at such cold temperatures indicates that suspended phased nitrifiers are active despite the basin being operated at washout conditions. One possible explanation for the presence of NOB activity in the IFAS mixed liquor is the continual bioaugmentation as a result of sloughing of biomass from the carriers. Furthermore, the data below indicate that a majority of nitrification activity, both $\mathrm{AOB}$ and $\mathrm{NOB}$ occurred on the media and not the suspended phase of the IFAS process. The percent nitrification activity for both AOB and NOB populations in the mixed liquor can be calculated by dividing the measured nitrification rate by the sum of the nitrification activity occurring in both the suspended phase and attached phase nitrifiers. On January 12,2009 , about $74 \%$ of the AOB activity was occurring on the media, with $26 \%$ occurring in the mixed liquor and about $90 \%$ of the NOB activity was occurring on the IFAS media with the remaining $10 \%$ occurring in the mixed liquor. An interesting phenomenon that was consistently observed was that the sum of the nitrification rates measured for the IFAS mixed liquor and media separately was higher than the total nitrification rate measured when the media and mixed liquor were combined. One possible explanation for this difference is that more sloughing occurred in the reactor containing media only making substrate more accessible to the biofilm in the experiments. Also, the presence of mixed liquor changes the density and viscosity of the bulk liquid slightly and may have had an effect on substrate advection through the mass transport boundary layer, though it seems unlikely that this could account for the differences observed. 
Table 4-2. AOB and NOB nitrification rate test results for January 12, 2009

\begin{tabular}{|c|c|c|c|c|c|c|c|c|}
\hline Summary & Experiment & $\begin{array}{c}\mathrm{NO}_{\mathrm{X}} \text { Slope } \\
\mathrm{mg} / \mathrm{L} / \mathrm{hr}\end{array}$ & $\begin{array}{c}\mathrm{NO}_{3} \text { Slope } \\
\mathrm{mg} / \mathrm{L} / \mathrm{hr}\end{array}$ & $\begin{array}{c}\text { Nit Rate } \mathrm{NO}_{\mathrm{X}} \mathrm{mg} / \mathrm{g} \\
\mathrm{MLSS} / \mathrm{hr}\end{array}$ & $\begin{array}{c}\text { Nit Rate } \mathrm{NO}_{3} \mathrm{mg} / \mathrm{g} \\
\mathrm{MLSS} / \mathrm{hr}\end{array}$ & $\begin{array}{c}\text { Nit Rate } \mathrm{NO}_{\mathrm{X}} \\
\mathrm{g} / \mathrm{m}^{2} / \text { day }\end{array}$ & $\begin{array}{c}\text { Nit Rate } \mathrm{NO}_{3} \\
\mathrm{~g} / \mathrm{m}^{2} / \text { day }\end{array}$ & $\begin{array}{c}\% \text { Calculated } \\
\text { Activity }\end{array}$ \\
\hline \multirow{2}{*}{ Full Scale Plant } & $\mathrm{AOB}$ & 2.826 & 0.0923 & 1.239 & 0.0405 & -------- & -------- & \\
\hline & NOB & ------- & 0.0000 & ------- & 0.000 & ------- & -------- & \\
\hline \multirow{2}{*}{ IFAS Mixed Liquor } & $\mathrm{AOB}$ & 3.033 & ------- & 1.417 & ------- & ------- & -------- & $26 \%$ \\
\hline & NOB & ------- & 1.4074 & ------- & 0.664 & ------- & -------- & $10 \%$ \\
\hline \multirow{2}{*}{$\begin{array}{l}\text { IFAS Mixed Liquor } \\
\text { with Media }\end{array}$} & $\mathrm{AOB}$ & 7.756 & ------- & 3.591 & ------- & 0.745 & & \\
\hline & NOB & ------ & 12.452 & ------ & 5.188 & ------ & 1.195 & \\
\hline \multirow{2}{*}{ IFAS Media Only } & $\mathrm{AOB}$ & 8.580 & 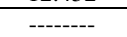 & ------- & ------- & 0.824 & ------- & $74 \%$ \\
\hline & NOB & ------- & 12.096 & -------- & -------- & ------- & 1.161 & $90 \%$ \\
\hline
\end{tabular}

\subsubsection{Effect of Sampling Location}

Although carrier biomass content was found to be consistent along the length of the IFAS zone, nitrification rate testing was performed at different locations along the IFAS tank to determine if the rates in the IFAS zone were related to the available substrate concentrations. The IFAS zone represents a relatively plug flow regime with a L:W ratio of approximately 4 , and tank profiling measurements (Regmi et al. 2008; data not shown) suggested clear ammonia, nitrate and nitrite concentrations gradients over the length of the tank. As a result, it was of interest to determine whether the IFAS carriers exhibited changing nitrification activity over the length of the IFAS zone. Figure 4-12 displays a plot of AOB and NOB activity for IFAS media alone at four different sampling locations along the IFAS tank. The figure provides a further indication that sampling location had a negligible effect on the nitrification potential of the carriers in a plug flow process. The effect of slightly higher DO concentrations in the benchscale test reactors at the $20 \mathrm{ft}$ and $27 \mathrm{ft}$ sampling locations is sufficient to explain the somewhat higher nitrification rates at these locations.

These results suggest that even though there is a gradient of soluble species (ammonia, nitrate, and nitrite), suggesting plug flow conditions; the media is well mixed over the length of 
the IFAS zone. This presents problems for modeling the tank whereby there is a need to model the IFAS zone as CSTRs in series for the soluble species, but as a completely mixed zone for carrier nitrification activity. Conventional modeling techniques would assume the nitrifier activity is proportional to the ammonia or nitrite concentration to which carriers are exposed, whereas the data suggest that over the timescale of biomass growth (effective SRT), the media is being mixed throughout the tank. Visual observations of the robust mixing in the tank seem to confirm these results. The gradient for soluble species exists even when IMLR pump \#1 was being operated, suggesting that the pump does help both return nitrate to the anoxic zone and reduce the media accumulation at the effluent end of the IFAS zone.

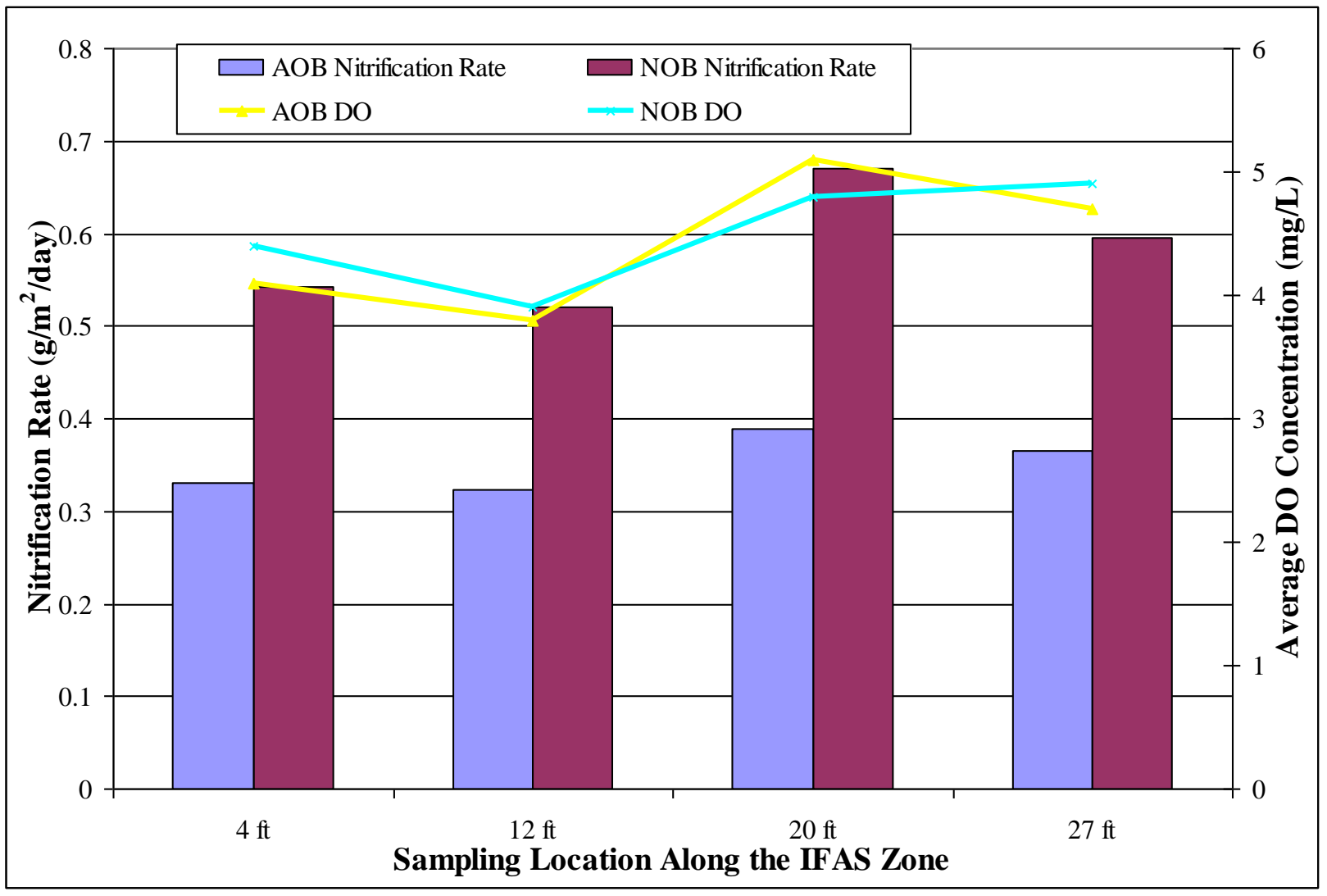

Figure 4-12. Nitrification Rates vs. Sampling Location 


\subsubsection{Nitrification Kinetics}

Figures 4-13 shows the AOB and NOB nitrification activity in the IFAS mixed liquor, the IFAS media, the media and mixed liquor combined, and the full-scale plant mixed liquor over the course of the testing period. Figure 4-13A suggests that AOB populations in the IFAS suspended growth phase are less prone to complete washout, even at colder temperatures, and it demonstrates the shift in AOB activity to the carriers in colder temperatures. The balance point suggested by these data, where the IFAS mixed liquor and media have similar nitrification capacity, is approximately $23^{\circ} \mathrm{C}$, the same temperature that indicated a minimum carrier biomass content (see Figure 4-9). Also, unlike the mixed liquor, which experienced a dramatic increase in $\mathrm{AOB}$ activity during the warm weather conditions, the IFAS media demonstrated more gradual changes in nitrification capacity as seasonal water temperature fluctuations occurred. The observation that the sum of the nitrification rates in the individual phases of the IFAS process were more than measured nitrification rates when the two phases were combined is also apparent here.

Figure 4-13A also shows that there is a year round presence of AOB populations in the mixed liquor of the full scale plant and the IFAS tank, despite being operated in washout conditions. AOB activity in the IFAS mixed liquor can be explained by continual sloughing of biomass off of the carriers which seeded the IFAS tank in cold temperatures. Also, until August, Garrett wasting from the IFAS basin was used to seed the full scale plant, thus AOB activity in the IFAS mixed liquor was transferred to the full scale plant mixed liquor.

Figure 4-13B compares the measured nitrification rates for each of the NOB experiments conducted over the course of the year. This plot shows that unlike the AOB populations in the IFAS tank, most of the NOB activity remained on the media, even in warmer summertime 
conditions. The NOB activity was also much lower in the full scale plant than the AOB activity. The NOB activity in the full scale plant did increase when the water temperature was warmer, but experienced a washout condition as the James River Plant operators reduced the plant SRT in response to the yeast overgrowth attributed to the addition of sugar waste as an external carbon source, but NOB activity in the full scale plant resumed in late August and early September.

Figures 4-12C and 4-13D below show the percent total calculated AOB and NOB activity in both the IFAS suspended phase and on the carriers. The percent total activity was calculated by dividing the activity in the individual phases by the sum of the rates in the two phases, which shows the percent total activity of the mixed liquor and media normalized to $100 \%$.

The brief increase of percent AOB activity on the carriers and decrease in the mixed liquor in June and July corresponds to the upset period caused by the addition of sugar waste to the anoxic zone of the IFAS basin. Figure 4-13C shows that after October the nitrification on the media quickly increased to about $75 \%$ of the total AOB activity and then leveled off. This indicates that even in cold weather conditions that would normally result in complete washout of AOB populations in the mixed liquor, about $25 \%$ of the AOB activity remains in the suspended phase. NOB activity on the carriers accounted for at least $60 \%$ of the total NOB activity in the IFAS tank, and as the temperature in the IFAS basin approaches $20^{\circ} \mathrm{C}$, the NOB activity on the carriers becomes as high as $80 \%$ of the total NOB activity.

As AOB populations, likely inhabiting the surface of the biofilm, oxidize ammonia to nitrite, the nitrite becomes immediately available to NOB in the biofilm, having already diffused in the form of ammonia. Because NOB populations seemed to inhabit the deeper parts of the biofilm, this may have been the cause of less detachment of NOB and more accumulation on the carriers, and therefore less bio-augmentation of NOB populations occurred in the IFAS mixed 
liquor. This helps to explain why the IFAS basin tends to retain $25 \%$ of the AOB activity in the mixed liquor in cold weather conditions and closer to $10 \%$ of the NOB activity.
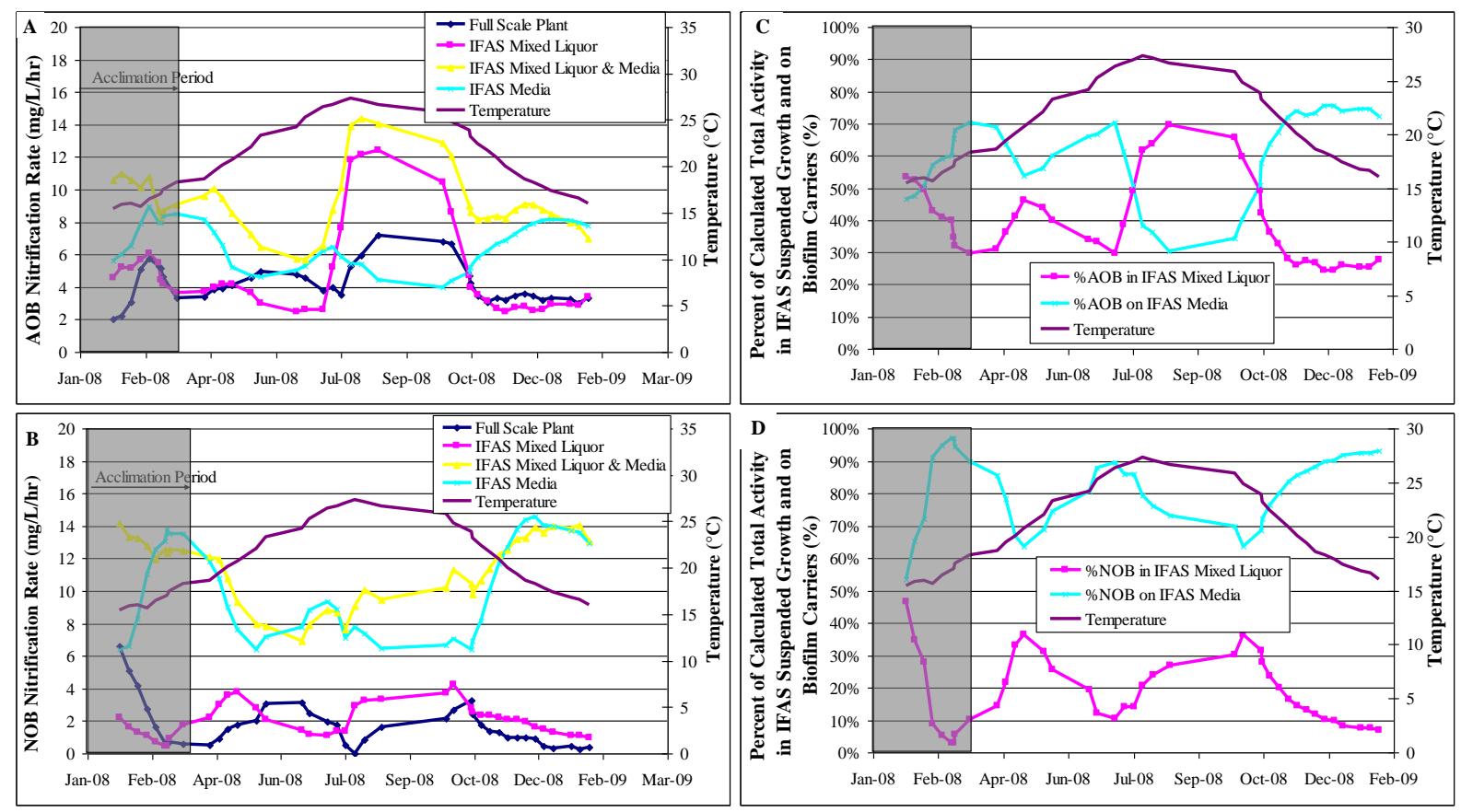

Figure 4-13. A=Nitrification Rates for AOB Experiments (5-point Rolling Average); $\mathrm{B}=$ Nitrification Rates for NOB Experiments (5-point Rolling Average); $\mathrm{C}=\mathrm{Percent}$ of Calculated AOB Activity on IFAS Mixed Liquor \& Media (5-point Rolling Average); D=Percent of Calculated NOB Activity on IFAS Mixed Liquor \& Media (5-point Rolling Average). (Acclimation period shaded)

Figure 4-14A offers a visual comparison of the AOB activity in mixed liquor of both processes normalized to the mixed liquor concentrations in their respective basins. The plot shows that $\mathrm{AOB}$ activity in both processes follow the same general trend. It is clear that the AOB activity increased during warm periods and declined during winter months. Again, it is apparent that at no point in the year was AOB activity in either basin completely lost, though for the full-scale process this was likely due to Garrett wasting from the IFAS tank to the full-scale plant aeration basins, and the associated AOB seeding. Despite temperatures reaching as low as 
$14.5^{\circ} \mathrm{C}$, which requires a minimum SRT of about 3.5 days to achieve nitrification and effluent ammonia concentrations of $0.5 \mathrm{mg} / \mathrm{L}-\mathrm{N}$ (process SRT at this time was 2.9 days), both basins retained AOB populations year round. The IFAS mixed liquor was also constantly receiving biomass that sloughed off of the media. This constant bio-augmentation of nitrifiers to the mixed liquor helps to explain how the basins are able to maintain $\mathrm{AOB}$ activity, even under conditions that would typically washout all autotrophic growth.
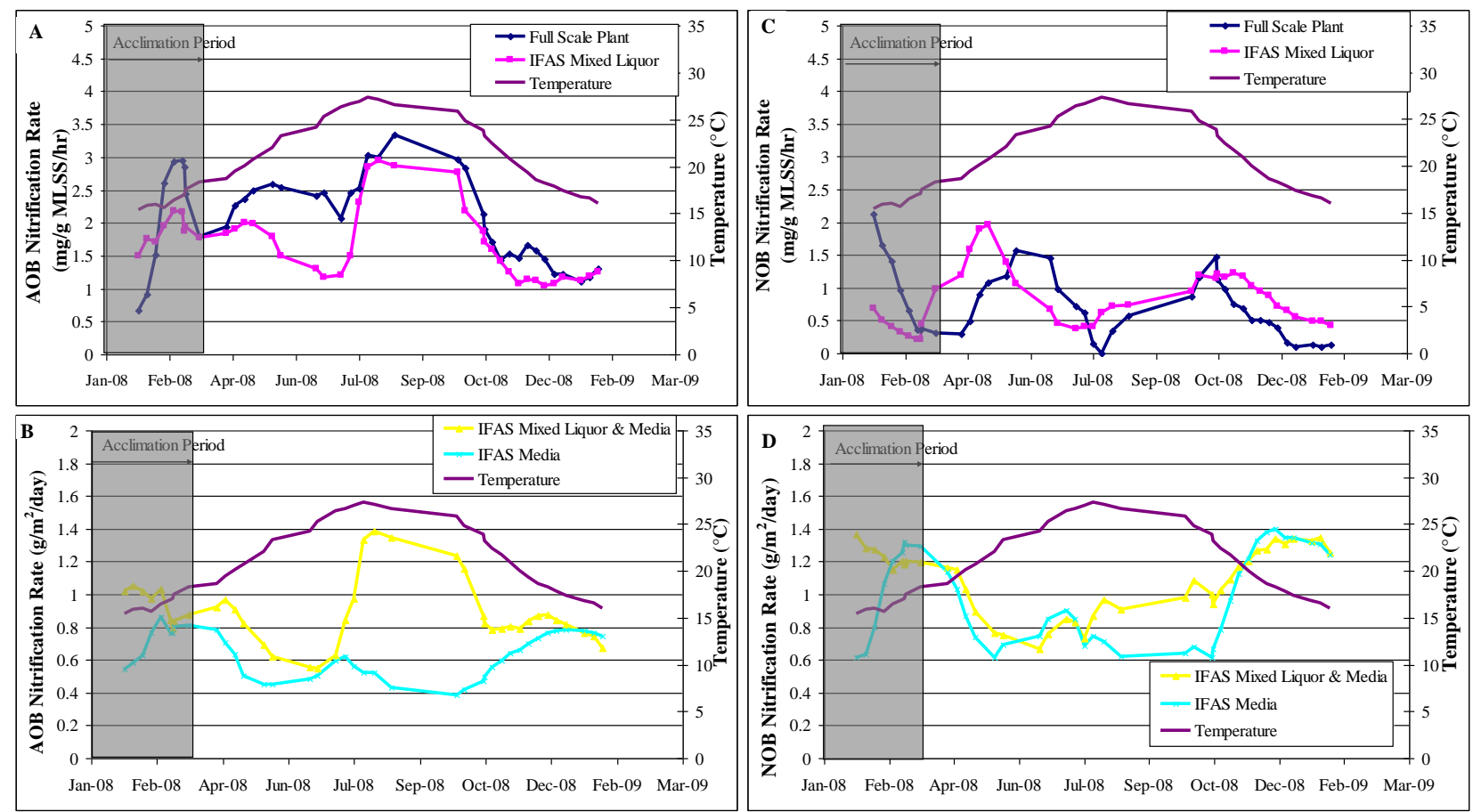

Figure 4-14. Nitrification Rates: A=Mixed Liquor AOB (5-point Rolling Average); B=Mixed Liquor NOB (5-point Rolling Average); $\mathrm{C}=$ Carrier AOB (5-point Rolling Average); $\mathrm{D}=\mathrm{Carrier}$ NOB (5-point Rolling Average). (Acclimation period shaded) 

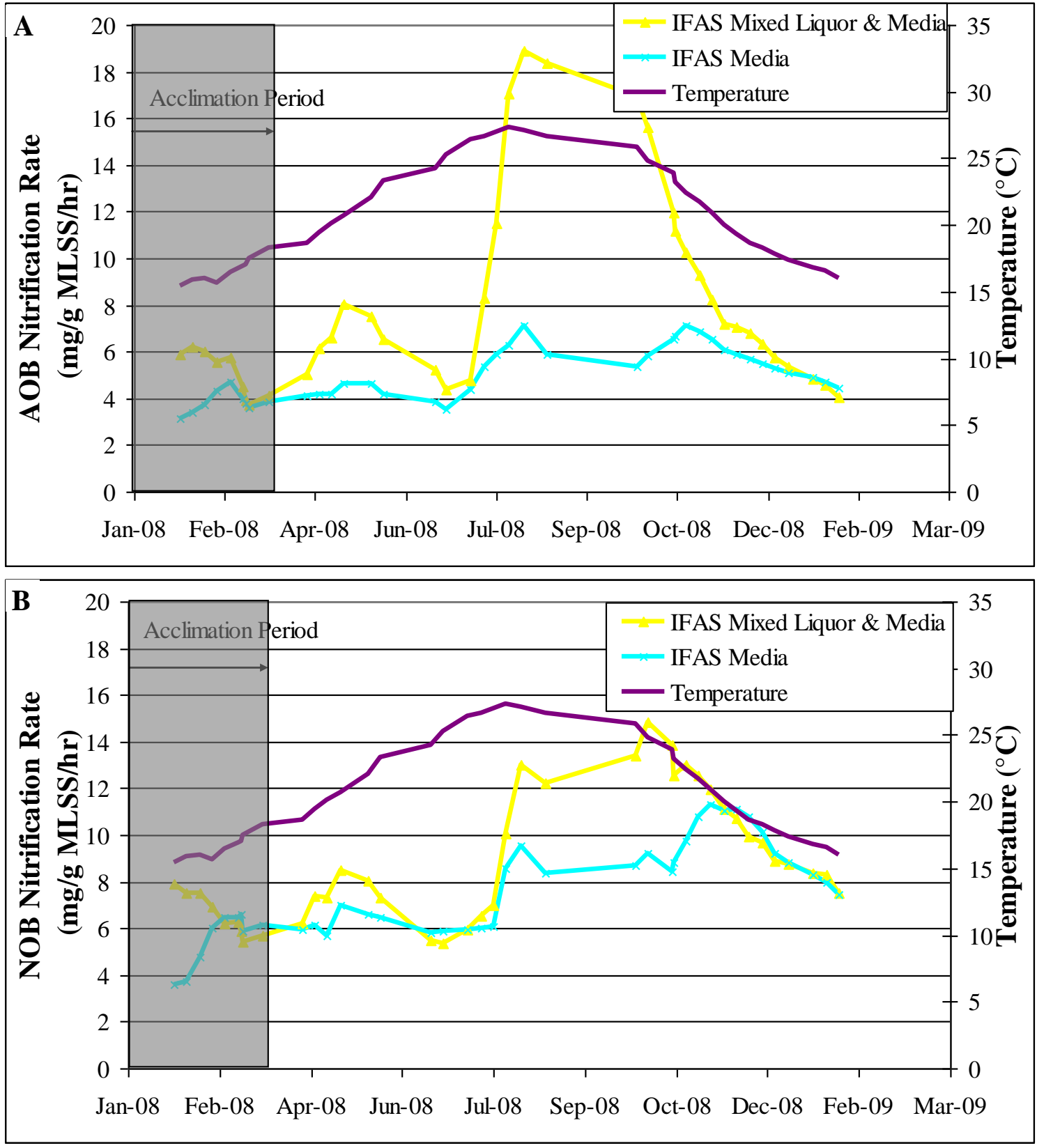

Figure 4-15. Carrier Nitrification rates Normalized to biomass content: $A=A O B ; B=N O B$. (Acclimation period shaded)

\subsubsection{Oxygen Uptake}

Oxygen uptake rates (OURs) were also monitored in the batch experiments to be compared with theoretical rates based on the extent of nitrification occurring. Figure 4-16 below compares predicted OUR to measured OUR in the reactors. The predicted OUR was calculated 
based on the stoichiometric oxygen requirement for ammonia and nitrite oxidation. It is clear that all of the measured OURs for AOB experiments containing mixed liquor are positively correlated with and slightly less than theoretical OURs. The difference in the plots can be attributed to endogenous decay occurring simultaneously with the AOB rate tests. The measured OUR for all of the NOB experiments containing mixed liquor do not demonstrate a clear relationship for either the full-scale plant samples or the sample with IFAS mixed liquor with media. It is unclear why this might be the case. It is clear, however, that for both AOB and NOB OUR on the media only (Figure 4-16 D and H), the measured rate was very similar to the theoretical rate suggesting that there was a distinct lack of heterotrophic decay associated with the biofilm on the IFAS carries. 

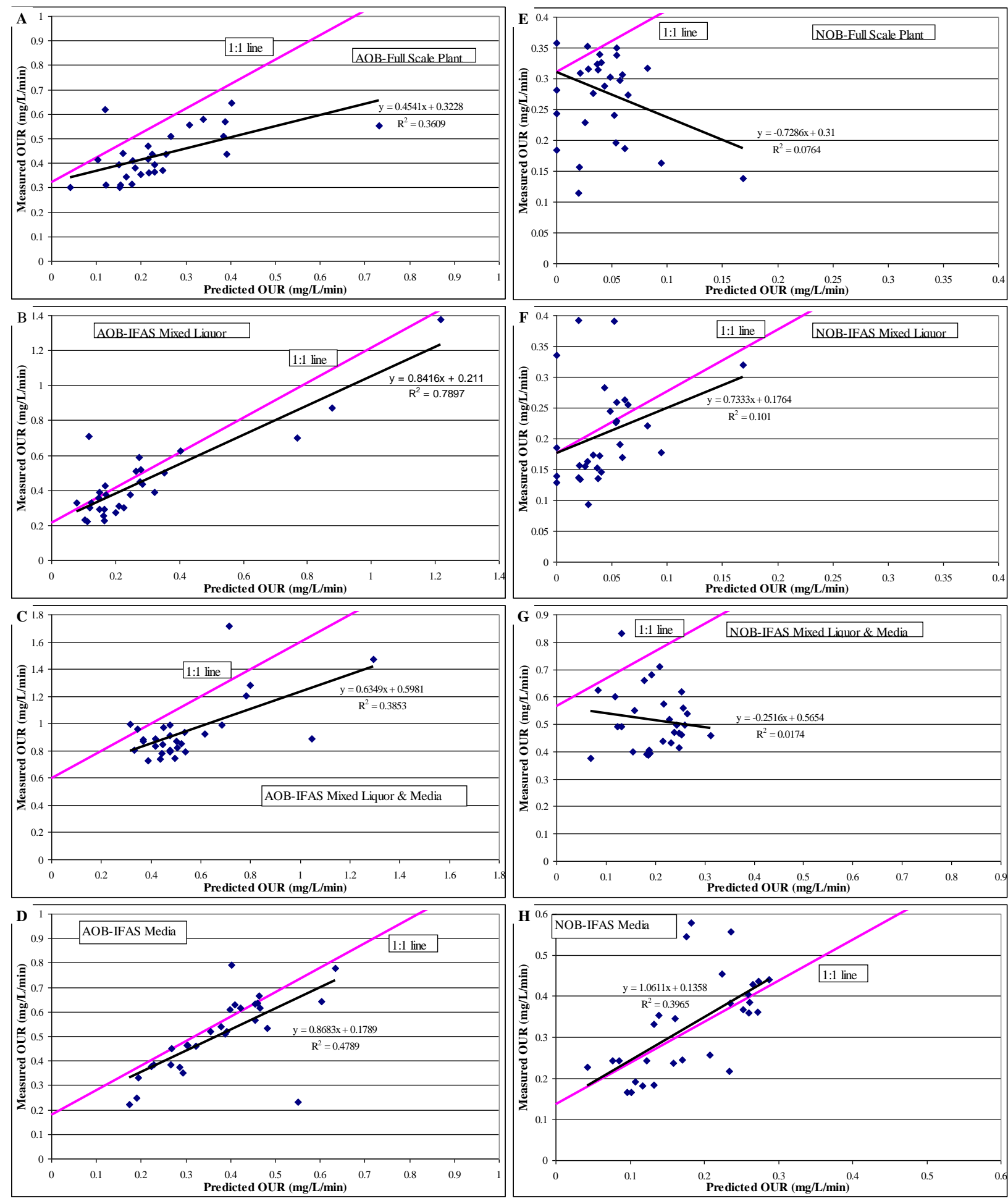

Figure 4-16. Measured OUR vs. Predicted OUR A. Full Scale Plant AOB; B. IFAS Mixed Liquor AOB; C. IFAS Mixed Liquor and Media AOB; D. IFAS Media AOB; E. Full Scale Plant NOB; F. IFAS Mixed Liquor NOB; G. IFAS Mixed Liquor and Media NOB; H. IFAS Media NOB 


\subsection{CONCLUSION}

Nitrification rate testing has offered a great deal of insight into the performance of the IFAS process for a number of operating conditions and temperatures. Biofilm carrier content serves as a tool when assessing process health and changes according to temperature and process operation. Biofilm content measurements were homogeneous throughout the length of the IFAS zone which indicates that the IFAS zone is well mixed, despite being a plug flow reactor by nature. This trend is also consistent with nitrification activity. Nitrification rates, both $\mathrm{AOB}$ and NOB, were constant on carriers throughout the length of the IFAS zone despite the decline substrate concentration, also suggesting that IFAS zone is well mixed with respect to biomass growth. As temperature changed seasonally, biomass moved on and off the carriers for a number of reasons. As water temperature increased higher than $23{ }^{\circ} \mathrm{C}$, carrier biomass content began to decline significantly, corresponding with a significant shift of AOB activity from the fixed film phase to the mixed liquor. This sloughing of biomass and shift of nitrification activity to the mixed liquor occurred when operating conditions, like process SRT, supported autotrophic growth in the suspended phase of the IFAS tank. Then, as temperature cooled in the basin in the late autumn and early winter, biomass content on the carriers steadily increased from about $3 \mathrm{~g} \mathrm{MLSS} / \mathrm{m}^{2}$ to about $7 \mathrm{~g}$ MLSS $/ \mathrm{m}^{2}$. This shift on the carriers occurred for two reasons. One reason is that the IFAS basin began to approach washout conditions for nitrifiers. As a result, autotrophs moved to the fixed film phase where they could be exposed to a higher effective SRT. The second reason for the shift of biomass onto the carriers is probably a result of a reduction in mixing input to the tank. At low temperatures, less aeration is required to maintain DO in the tank, so the decreased aeration intensity likely also resulted in decreased agitation of the media and thus less sloughing of biomass. 
AOB and NOB activity localization is dependent on temperature and process SRT. AOB activity appears to inhabit the surface of the biofilm and smoothly transition between the biofilm and suspended fraction as temperature and operating conditions, such as SRT, change. AOB activity in the mixed liquor represents half of the total AOB activity in the IFAS zone when temperatures reach and exceed $23{ }^{\circ} \mathrm{C}$. When temperature dropped to below $20^{\circ} \mathrm{C}, \mathrm{AOB}$ activity on the media made up a maximum $75 \%$ of the total AOB activity in the IFAS tank. When temperature in the basin peaked, $\mathrm{AOB}$ activity in the basin was at its lowest, making up only $30 \%$ of the total AOB activity in the IFAS basin. The majority of NOB activity remains on the carriers year round and makes much less of a transition from the biofilm to the mixed liquor as temperatures and SRT increase and conditions that support autotrophic growth improve. NOB on the carriers never decreased to less than $60 \%$ of the total NOB activity in the tank, and NOB activity increased to over $90 \%$ of the total NOB activity in the tank during the colder wintertime temperatures. This phenomenon indicates that NOB activity also has a much higher affinity for the carriers and that NOB activity occurs deeper in the biofilm. This probably makes sense given the immediate availability of nitrite produced in the biofilm as a result of local AOB activity. However, AOB and NOB activity remains in the IFAS mixed liquor, even during washout conditions, due to "bio-augmentation" caused by sloughing of biomass off of the carriers.

The data suggest two possible biofilm configurations as shown in Figure 4-17 below. The most likely scenario (Figure 4-17A) would appear to involve AOB at the surface of the biofilm and NOB located further within. This hypothesis is supported by effective Ks data and the observation of more significant $\mathrm{AOB}$ activity in the mixed liquor during colder periods (suggesting better bioaugmentation). However, it is also well accepted that suspended growth 
NOB are more susceptible than AOB to low DO concentrations (Ko for NOB is higher than AOB). This combined with the effective Ko data reported elsewhere (Thomas et al, 2009) suggests that NOB could be located at the surface of the biofilm (Figure 4-17B). Based on fullscale tank TN removal under DO-limited conditions, there did appear to be some degree of simultaneous nitrification-denitrification activity occurring, and this suggests a deep heterotrophic biofilm was also likely present.

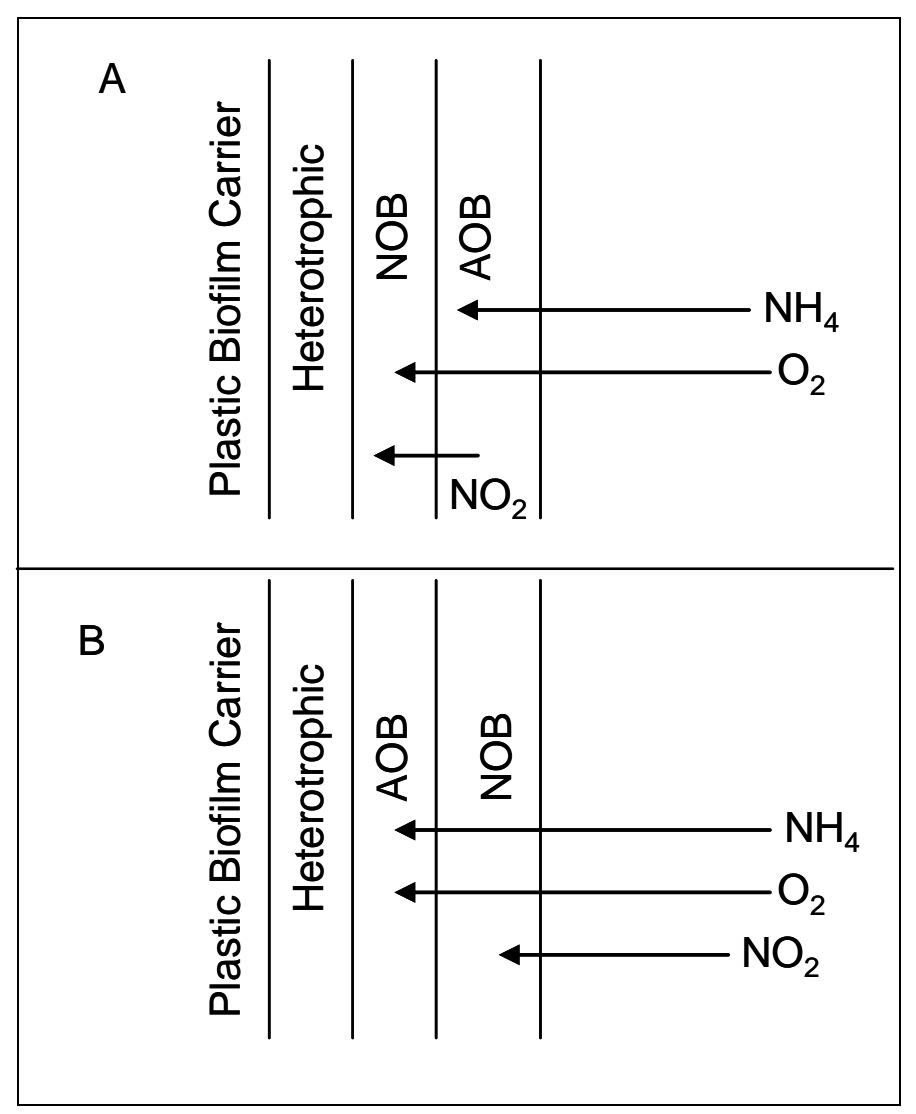

Figure 4-17. Possible Biofilm Configurations

\subsection{References}

APHA, AWWA, WEF 1995. Standard methods for the examination of water and wastewater. Washington, D.C.: APHA. 
Choi, N., Phillips, H., Johnson, T.L., Butler, R., Lauro, T. Pilot Testing Of MBBR And IFAS Treatment Processes For Nitrification And Denitrification At The Mamaroneck WWTP. Proceedings of the $80^{\text {th }}$ WEFTEC- National Conference of the Water Environment Federation, San Diego, CA. 80: October 13-17, 2007.

Hubbell, S., McDowell, C. Cold Temperature BNR Using Integrated Fixed-Film Activated Sludge (IFAS) Hybrid Technology. Proceedings of the $76^{\text {th }}$ WEFTEC- National Conference of the Water Environment Federation. Los Angeles, CA, October 12-15, 2003.

McQuarrie, J., Rutt, K., Seda, J., Haegh, M. Observations From The First Year of Full-Scale Operation - The IFAS/BNR Process At The Broomfield Wastewater Reclamation Facility, Broomfield, $C O$. Proceedings of the $77^{\text {th }}$ WEFTEC- National Conference of the Water Environment Federation. New Orleans, LA, October 2-6, 2004.

Onnis-Hayden, A., Dair, D., Johnson, C., Schramm, A., Gu, A. Kinetics And Nitrifying Populations In Nitrogen Removal Processes At A Full-Scale Integrated Fixed-Film Activated Sludge (IFAS) Plant. Proceedings of the $80^{\text {th }}$ WEFTEC- National Conference of the Water Environment Federation. San Diego, CA, October 13-17, 2007.

Regmi, P. 2008. Biological Nutrient Removal Upgrade At The James River Wastewater Treatment Plant. Civil and Environmental Engineering. Old Dominion University, Norfolk, VA.

Ross, D., Fernandes, W., Briggs, T., Kim, N., Booth, G., Neely, D., Welp, J. Integrated Fixed Film Activated Sludge (IFAS) At The Lakeview WWTP: The Real Implementation Issues. Proceedings of the $77^{\text {th }}$ WEFTEC- National Conference of the Water Environment Federation. New Orleans, LA, October 2-6, 2004.

Water Quality Management Planning Regulation. Chapter 720. 9 VAC 25-820-70.

Yerrell, K., Gobbie, M., Dold, P., Jones, R., Sickerdick, L. Full-Scale Demonstration Of A FreeMoving Media IFAS Process For Enhancing Nitrification Performance. Proceedings of the $74^{\text {th }}$ WEFTEC- National Conference of the Water Environment Federation. Atlanta, GA, October 13$17,2001$. 


\title{
5 MANUSCRIPT 2: TESTING OF PARAMETERS IMPACTING IFAS NITRIFICATION PERFORMANCE
}

\author{
Abstract \\ The James River Treatment Plant (JRTP) has operated a 2 MGD Integrated Fixed Film \\ Activated Sludge (IFAS) demonstration study beginning in late 2007 to explore IFAS \\ performance and investigate the IFAS technology as an option for a full scale plant upgrade in \\ response to stricter nutrient discharge limits in the James River Basin. In addition to the weekly \\ nitrification rate measurements, experiments were also conducted to determine how operational \\ inputs such as dissolved oxygen (DO) and mixing affect the nitrification rates. Mixing intensity \\ had a clear impact on nitrification rates by increasing the velocity gradient in the bulk liquid and \\ decreasing the mass transfer boundary layer mass transfer resistance. At higher mixing \\ intensities, advection through the mass transfer boundary layer increased making substrate more \\ available to the biofilm. The affect of mixing was much more profound at low DO, whereas \\ increased mixing had less effect on nitrification rates at higher bulk liquid DO. DO also affected \\ nitrification rates, such that as DO increased it penetrated deeper into the biofilm increasing the \\ nitrification rate in a linear fashion until the biofilm became saturated. Another aspect of the \\ research was modeling effective half saturation effects for AOB and NOB activity in the fixed \\ film phase. The modeling work demonstrated that $\mathrm{K}_{\mathrm{S}}$ for $\mathrm{AOB}$ activity on the media was similar \\ to accepted suspended growth $\mathrm{K}_{\mathrm{S}}$ values, while $\mathrm{K}_{\mathrm{S}}$ for NOB activity on the media was \\ considerably higher than suspended growth $\mathrm{K}_{\mathrm{S}}$. This trend indicates that nitrite was not as \\ bioavailable in the biofilm and resists diffusion into the deeper part of the biofilm where NOB \\ activity takes place. $\mathrm{K}_{\mathrm{O}}$ for both $\mathrm{AOB}$ and $\mathrm{NOB}$ activity in the biofilm was higher than typical \\ suspended growth values because of boundary layer and biofilm diffusion resistances. In
}


addition, the presence of readily degradable organics did not significantly affect nitrification rates on the media, but did reduce nitrification rates in the mixed liquor. That, combined with low chemical oxygen demand (COD) uptake rates indicates that little heterotrophic activity is occurring on the media.

\subsection{INTRODUCTION}

As nutrient discharge limits continue to become more stringent, a number of approaches have been taken to develop new techniques to meet these limits. The IFAS process is a relatively new technology focused at retrofitting existing wastewater treatment plants that have limited space for plant expansion. IFAS technology gives plants an ability to upgrade their conventional activated sludge processes to a process that achieves year round nitrification without expanding or increasing the plant's footprint. Although this technology has been tested and proven to work, especially in cold environments for plants operating below washout conditions, process kinetics are still undefined. Many variables, such as bulk liquid DO and mixing intensity have a known effect on biofilm kinetics, but IFAS kinetics have yet to be studied in depth in the context of these parameters. In addition to analyzing performance based on DO and mixing regimes, half saturation effects of the biofilm have not been identified for design and modeling purposes. IFAS models that combine an IWA-style activated sludge model with a fundamental nonempirical biofilm model (considering external mass transfer and multi-component biofilm diffusion) have been developed, but calibrated with limited full-scale experience.

In 2005, new regulations were implemented as part of the Chesapeake Bay 2000 Agreement which require Hampton Roads Sanitation District (HRSD) wastewater treatment plants (WWTPs) discharging to the James River Basin to reduce the aggregate mass discharge of 
total nitrogen (TN) to 6,000,000 lbs/year (Water Quality Management Planning Regulation ). HRSD staff concluded that biological nutrient removal with IFAS should be employed at the 16.7 MGD James River Treatment Plant (JRTP) as a cost effective strategy to help achieve this aggregate goal, decreasing effluent TN at this facility to approximately $12 \mathrm{mg} / \mathrm{L}$ (annual average). HRSD elected to conduct a demonstration-scale IFAS study at JRTP to evaluate the performance of this process and to develop design criteria before implementation on a wider scale. For this demonstration project, a single existing fully-aerobic conventional aeration basin with dedicated secondary clarification, which was previously operated to achieve nitrification during warm weather months only, was converted to a 1.86 MGD (2.22 MGD max month) IFAS train in an MLE configuration with a 50\% fill of AnoxKaldnes plastic biofilm carriers in the aerobic zone only (K3 with a specific surface area of $500 \mathrm{~m}^{2} / \mathrm{m}^{3}$ ). The IFAS process was targeted to achieve complete, year-round nitrification at an operating solids residence time (SRT) well below the washout value for nitrifiers during cold weather periods, suggesting that $\mathrm{AOB}$ and NOB must colonize the IFAS carriers (McQuarrie et al. 2004). In addition, the IFAS process has been demonstrated to achieve complete nitrification, even at temperatures as low as $8{ }^{\circ} \mathrm{C}$ (Hubbell et al. 2003). Not only does the IFAS process offer the potential for year round nitrification, the technology has demonstrated much higher nitrification kinetics than can be achieved in a conventional activated sludge process (Ross et al. 2004). In addition, some work has been done to measure $\mathrm{K}_{\mathrm{O}}$ values for the IFAS process, but $\mathrm{K}_{\mathrm{S}}$ values have not been calculated for the IFAS process (Yerrell et al. 2001).

Because diffusion of nutrients, substrate, and oxygen into the biofilm controls the nitrification rate in an attached growth process it is important to improve the mass transfer capability in the system. Mixing has a direct effect in the water film thickness which in turn 
affects mass transport into the biofilm. Generally, the smaller the mass transfer boundary layer around the biofilm, the faster substrate and oxygen can pass into the biofilm and become available for the biomass. At this point very little is understood about how process mechanical configuration (e.g. aeration intensity) affects mass transport boundary layer thickness. It is known at a fundamental level that biofilms are diffusion limited by their nature instead of being kinetically limited like mixed liquor (Boltz et al. 2009).

The goal of this research was to measure nitrification rates for both ammonia oxidizing bacteria $(\mathrm{AOB})$ and nitrite oxidizing bacteria $(\mathrm{NOB})$ in both suspended growth and fixed film phases from the IFAS demonstration tank at the James River Wastewater Treatment Plant (JRWWTP), in Newport News, Virginia to achieve a number of observations. The specific research goals for this project were to:

- Achieve a better understanding of IFAS process kinetics

- Quantify the effect of mixing and DO on mass transport boundary layer (i.e. mixing intensity)

- Measure half saturation effects on the media to better understand mass transport issues for ammonia, nitrite, and oxygen and calibrate existing models to optimize modeling of the IFAS process and other biofilm processes

- Measure the effect of COD addition on nitrification rates in the mixed liquor and on the carriers

\subsection{METHODOLOGY}

These additional experimental campaigns were conducted in conjunction with the nitrification rate testing from January 2008 through January 2009. These experiments target external influences, such as mixing, DO, and presence of COD on maximum nitrification rates, 
and also measure effective half saturation effects. These parameters identify operational set points and influence design criteria for the IFAS process. These experiments target kinetics on the IFAS media only, although some experiments on the IFAS mixed liquor were conducted for comparative purposes. In this case, experiments were run at different DO setpoints and the reactors

\subsubsection{Bench Scale Reactor Construction}

The batch reactors were constructed from $9 \mathrm{~L}$ rectangular clear polycarbonate containers with screw-cap lids with an active reactor volume of $7 \mathrm{~L}$. The mixer paddle extended through the screw-cap opening, and holes were drilled in the top of the container to insert DO and $\mathrm{pH}$ probes. The four reactors were aerated through an air stone and were fed pure oxygen at a low rate, which maintained DO at varying DO depending on the goals of the campaign experiment. The reactors were also equipped with a sample port located in the middle of the active volume which allowed for samples to be taken throughout the course of the various experiments performed.

The reactors were placed in a temperature-controlled water bath, and the temperature in each individual reactor in order to maintain a temperature consistent with the temperature of the IFAS tank, which was read and recorded every morning at the time at which the sample is taken. The bath was turned on the day before sample collection to allow time for the bath to adjust to the appropriate temperature.

The $\mathrm{pH}$ in the reactors was controlled to a setpoint between 7.2 and 7.3 for both the ammonia spike and for the nitrite spike experiment. Automatic addition of alkalinity in the form of a concentrated $\mathrm{Na}_{2} \mathrm{CO}_{3}$ solution was provided with Masterflex peristaltic pumps and 
on/off control to each reactor as needed. If the $\mathrm{pH}$ increased to higher than the controlled values, acid was added manually to return the reactor to the desired experimental $\mathrm{pH}$. $\mathrm{pH}$ was also logged continuously for each experiment with LABVIEW (National Instruments) and recorded with the results from each test.

To separate mixing and oxygenation function, DO was controlled in the bench-scale reactors using pure oxygen. This system included HACH ruggedized LDO probes and solenoid valves connected to a relay controller and USB data acquisition and control system running LABVIEW (National Instruments) on a laptop computer. This system was also used to record temperature and DO every $10 \mathrm{sec}$ for each experiment, from which oxygen uptake rates could be calculated. Rotameters were used in series with the solenoid valves to regulate the oxygen flowrate into the reactors when they were aerating. The DO setpoint varied for the campaign experiments to illustrate the effect of DO on the performance of the carriers. The diagram shown in Figure 5-1 displays a representation of the reactor construction. 


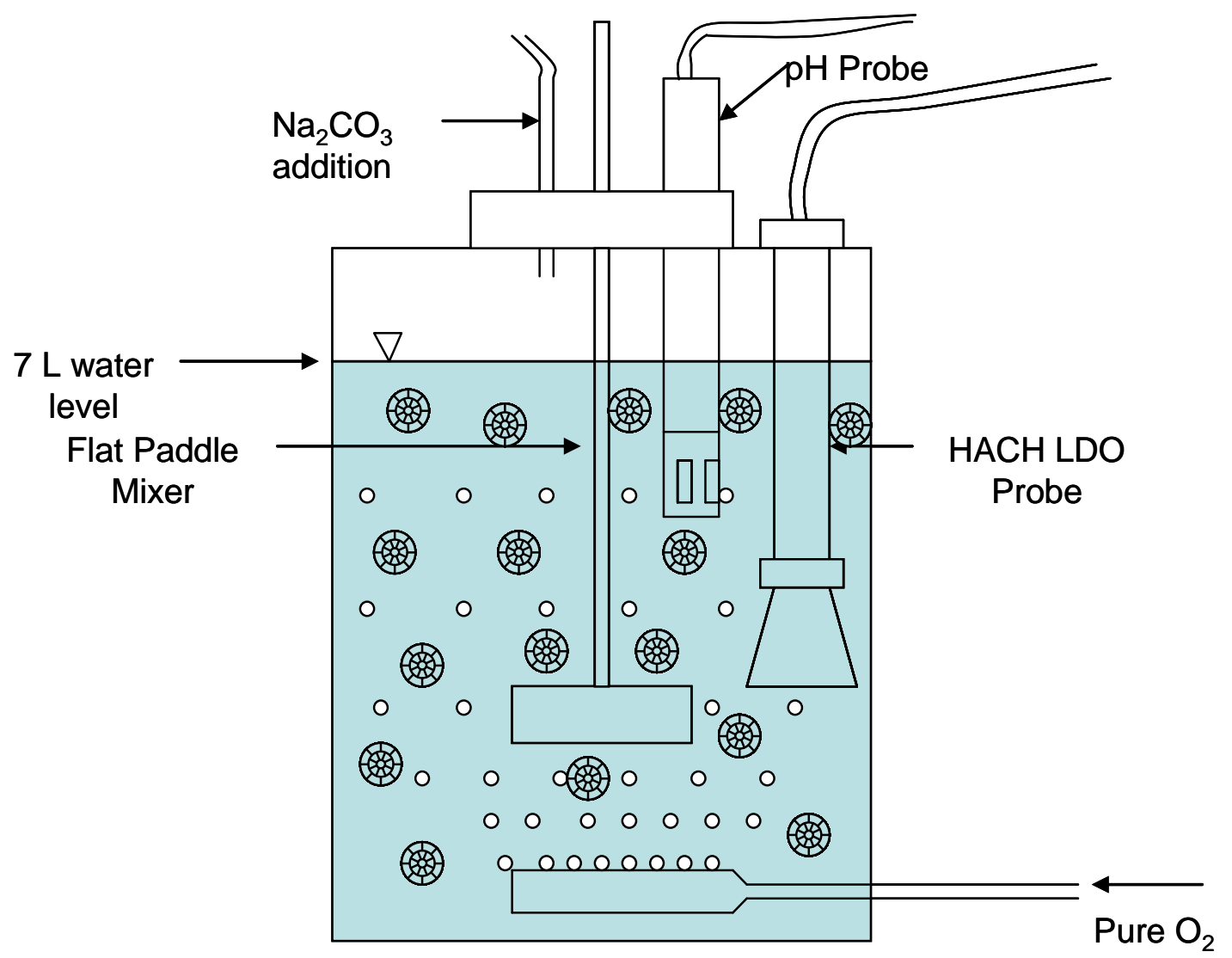

Figure 5-1. Diagram of Reactor Construction

Mixing was provided by flat paddle mixers (dimensions $=3$ in $\mathrm{x} 1$ in) using a Phipps and Bird Jar Tester stirring apparatus to ensure that the same mixing energy was being imparted to all four reactors simultaneously. Because the reactors were placed in a temperature-controlled bath and the standard Phipps and Bird mixers were unable to reach the bulk liquid in the reacto4rs, each paddle was extended with a 1/4" steel rod with a coupling. The reactor speed was set at 175 rpms, $140 \mathrm{rpms}$ and $100 \mathrm{rpms}$ for the campaign experiments testing half saturation effects and DO and mixing. These mixing speeds ultimately translated to $\mathrm{G}$ which were calculated based on an experiment performed on the media and mixed liquor with a torque meter attached to the mixing shaft with a coupling as described by Thomas et al. (2009). 


\subsubsection{Reactor Contents}

For many of the campaign experiments, all four of the reactors were filled with $50 \% \mathrm{~K} 3$ Anox-Kaldnes media by volume. In order to achieve this desired media fill, about $5 \mathrm{~L}$ of secondary effluent was first added to the reactors. Then a $2 \mathrm{~L}$ graduated cylinder was used to add 3.5 $\mathrm{L}$ of media to each of the reactors and the reactors were then filled the rest of the way with secondary effluent to a pre-calibrated line representing $7 \mathrm{~L}$. Mixed liquor from the IFAS tank were used in a number of campaign experiments and was poured into the reactors to the $7 \mathrm{~L}$ mark.

\subsubsection{Biomass Sample Collection}

\subsubsection{Nitrification Rate Testing}

Samples for the campaign experiments were taken from the secondary clarifier and the IFAS demonstration tank. Samples from the IFAS demonstration tank were collected with 5 gallon buckets near the middle of the IFAS zone in the demonstration reactor where there the media fill fraction was likely to be about $50 \%$ by volume. After these samples were taken, they were carried back to the lab where the media and bulk liquid were separated. For campaigns only requiring IFAS media, the mixed liquor was discarded after separation, and for experiments on the IFAS mixed liquor were separated, and the media was transported back to the IFAS tank. This separation was done by pouring the sample into two buckets, one inside of the other. The inside bucket contained numerous $1 / 4$-inch holes drilled into the bottom. The inner bucket was then lifted out of the outer bucket allowing the mixed liquor to gently drain into the bucket without holes. The bucket with holes in the bottom now containing media was gently dipped 
into a bucket containing secondary effluent to rinse off any remaining biomass not attached to the media.

In addition to the biomass samples collected on the morning for the experiments, enough secondary effluent to fill the reactors and rinse the media was collected. After the samples were collected from the plant, they were divided into four reactors. These four reactors contained secondary effluent and media with a $50 \%$ fill by volume for campaign experiments focused on the carriers, and IFAS mixed liquor for campaign experiments focused on the IFAS mixed liquor alone.

\subsubsection{Experimental Protocol}

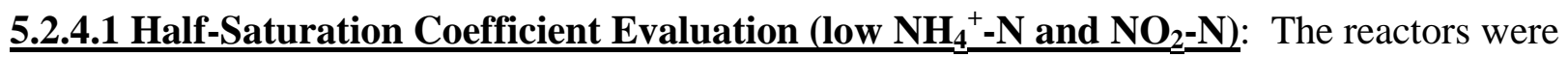
controlled to variable DO concentrations of $2,4,6$, and $8 \mathrm{mg} / \mathrm{L}$ and allowed to mix and aerate with pure $\mathrm{O}_{2}$ until each reactor reached the desired DO. The reactors were then spiked with phosphate to ensure that the biomass was not nutrient limited and the reactors are spiked to 25 $\mathrm{mg} / \mathrm{L}$ of either ammonia or nitrite. After the spike the reactors were sampled at appropriate intervals to not only capture the linear rate of nitrification, but also the nitrification rate when substrate concentrations dropped to low levels. The results from these tests were recorded and analyzed to give the half saturation coefficient using four different DO concentrations. This test was conducted three times for AOB and NOB activity on the media at 175 RPM and 100 RPMS corresponding to a range of $\mathrm{G}$ values summarized in Table 3.1.1 and as twice for AOB and NOB activity on the media at $100 \mathrm{rpms}$. In addition to testing the IFAS media, the same experiment was conducted one for $\mathrm{AOB}$ and $\mathrm{NOB}$ activity in the mixed liquor at $175 \mathrm{rpms}$. 
5.2.4.2 DO and Mixing: The four reactors, containing secondary effluent and a 50\% fill of media by volume were placed into the temperature-controlled bath. The reactors will be set to their respective DO concentrations at 2, 4, 6, and $8 \mathrm{mg} / \mathrm{L}$ and allowed to mix and aerate with pure $\mathrm{O}_{2}$ until each reactor has reached the desired DO. Three separate experiments will be conduced in this configuration, each at different mixing velocities of $100 \mathrm{rpm}, 140 \mathrm{rpm}$, and 175 rpm. The reactors will then be spiked with either $25 \mathrm{mg} / \mathrm{L}-\mathrm{N}$ ammonia or nitrite and sampled five times over a two hour period. These samples will be analyzed for ammonia, nitrate, and nitrite. After each two hour experiment, the media and secondary effluent will be dumped out of the reactors and replaced with fresh samples. The next experiment will then continue at the next mixing velocity. This experiment was conducted twice for AOB and NOB on the IFAS media as well as twice for the AOB and NOB activity in the IFAS mixed liquor.

5.2.4.3 Affect of COD addition on Nitrification Rates: In order to understand how heterotrophic and autotrophic bacteria are distributed in the IFAS tank, and how COD uptake affects nitrification rates on the IFAS media and mixed liquor, an experiment was conducted in which four reactors were run, two containing IFAS mixed liquor and two with IFAS media in secondary effluent at a measured 50\% fill. Of these reactors, one containing mixed liquor, and the other containing media were spiked with $200 \mathrm{mg} / \mathrm{L} \mathrm{COD}$ as acetic acid, and then all four reactors were spiked to $25 \mathrm{mg} / \mathrm{L}$ ammonia or nitrite depending on the population of nitrifiers being studied. The reactors were then sampled 5 times over a two hour period and analysis of COD uptake as well as nitrification kinetics. 


\subsubsection{Sample Preparation for Analysis}

During the rate experiments, the samples collected every 25 minutes were taken from the reactors using a $30 \mathrm{~mL}$ syringe, followed by immediate filtration using a $0.45 \mu \mathrm{m}$ PES membrane filter into a scew-cap vial. After filtration, the samples were analyzed for various constituents including $\mathrm{NH}_{4}{ }^{+}-\mathrm{N}, \mathrm{NO}_{2}-\mathrm{N}$, and $\mathrm{NO}_{3}-\mathrm{N}$. Samples were normally analyzed in the field almost immediately after they were collected, and in the case that immediate analysis was not possible for whatever reason the samples were refrigerated to ensure that accurate analysis was conducted for each experiment. In all cases, field analyses were completed within 24 hours. Samples for MLSS and MLVSS analysis were collected in $500 \mathrm{~mL}$ HDPE bottles and stored at $4^{\circ} \mathrm{C}$ until analysis by HRSD Central Environmental Laboratories (CEL). In some cases, filtered samples were preserved for confirmation testing by HRSD CEL for $\mathrm{NH}_{4}{ }^{+} \mathrm{N}$ and NOx-N. This additional testing provided $\mathrm{QA} / \mathrm{QC}$ for the analysis performed at the plant.

\subsubsection{Sample Analysis}

\section{$\underline{\text { 5.2.6.1 Total Ammonia Nitrogen }\left(\mathrm{NH}_{4}{ }^{+}-\mathrm{N}\right)}$}

For field analysis, $\mathrm{NH}_{4}{ }^{+}-\mathrm{N}$ was analyzed using $\mathrm{HACH}$ colorimetric method TNT plus 832. Colorimetric methods were performed per $\mathrm{HACH}$ protocols with evaluation of matrix interference and other issues as needed.

\subsubsection{Nitrate $\left(\mathrm{NO}_{3}{ }^{-}-\mathrm{N}\right)$}

For field analysis, $\mathrm{NO}_{3}^{-}-\mathrm{N}$ was analyzed using $\mathrm{HACH}$ colorimetric method TNT plus 836. Colorimetric methods were performed per $\mathrm{HACH}$ protocols with evaluation of matrix interference and other issues as needed. 


\subsubsection{Nitrite $\left(\mathrm{NO}_{2}^{-}-\mathrm{N}\right)$}

Nitrite analysis was conducted in the field as soon as possible after sample filtration. The standard colorimetric method will be performed using $\mathrm{HACH}$ Nitriver 3 reagent and $10 \mathrm{~mL}$ samples. HACH method 8507 is a low range method, so all samples were diluted to concentrations between 0.002 and $0.3 \mathrm{mg} / \mathrm{L} \mathrm{NO}_{2}-\mathrm{N}$ and analyzed per standard protocols.

\subsubsection{MLSS/MLVSS}

Mixed Liquor Suspended Solids and Mixed Liquor Volatile Suspended Solids were performed by both HRSD laboratories and in the VMI laboratories in accordance with Standard Methods. Samples were collected for analysis at the end of every experiment and transported on ice to one of the analysis locations.

\subsection{RESULTS \& DISCUSSION}

\subsubsection{DO and Mixing}

Mixing intensity in the IFAS basin can be calculated using air flow into the coarse bubble aerators. Figure 5-2 below plots the velocity gradient in the basin for the course of the nitrification rate testing. The plot indicates that $\mathrm{G}$ in the IFAS tank remains relatively constant over the course of the year at about $250 \mathrm{~s}^{-1}$. This shows that as temperatures cool and the aeration requirements decrease to maintain DO in the tank. Because of this drop in aeration, mixing decreases slightly, however, as the water becomes more viscous during cooling, the $G$ value for the same air flow increases. It is this phenomenon that allows the velocity gradient to remain relatively constant year round. 


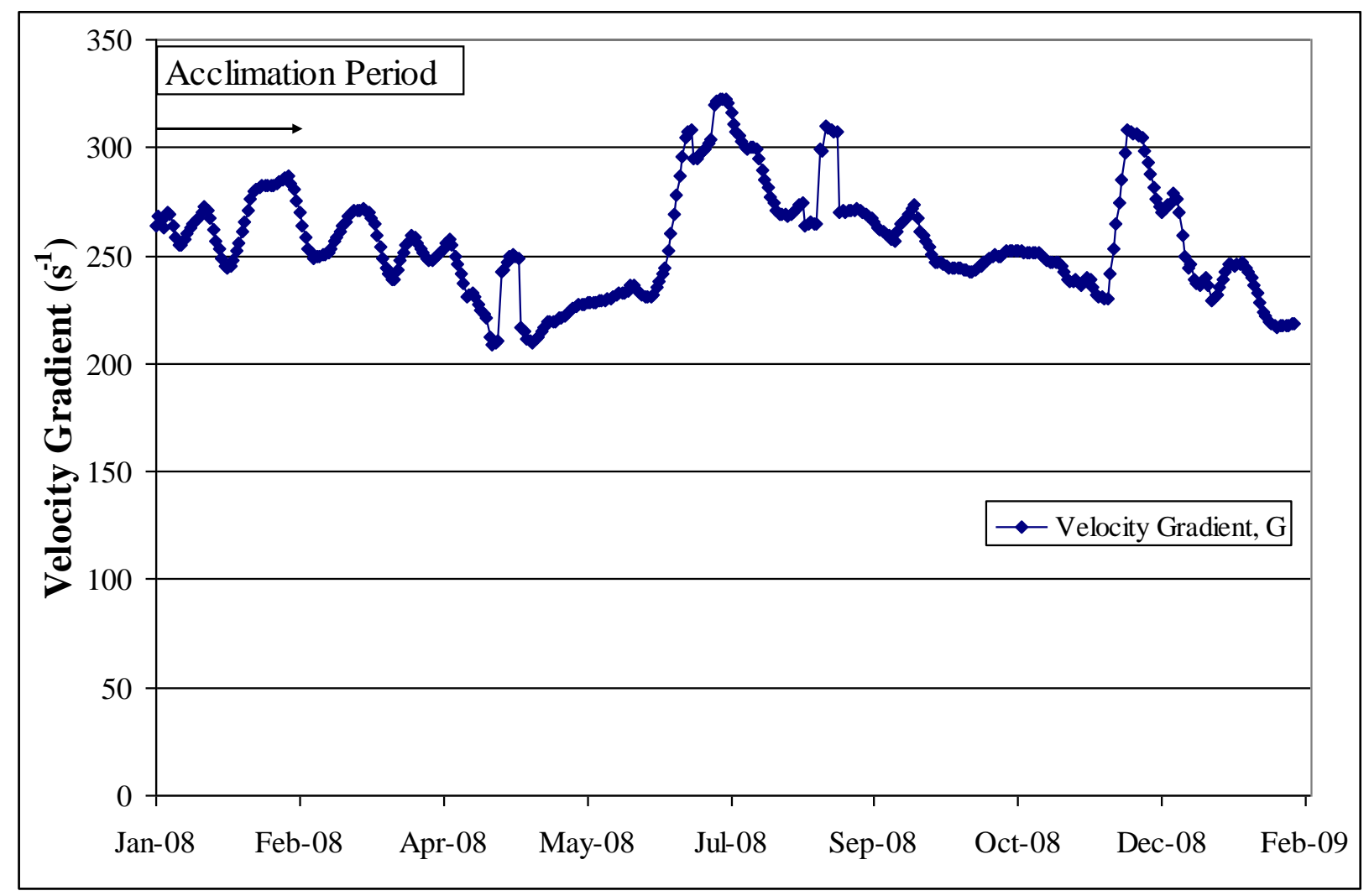

Figure 5-2. Velocity Gradient in the IFAS tank

DO concentrations in the bulk liquid as well as mixing energy imparted to the water both play a role in the mass transport of substrate to and within the biofilm. Figures 5-3A, 5-3B, 53C, and 5-3D below outline the effects of both mixing energy and DO on AOB and NOB activity on the carriers. Figures 5-3A and 5-3B summarize the mixing and DO effects on AOB activity on the carriers for two different experiments conducted on November 18, 2008 and January 13, 2009. These dates correspond to dates when nitrification activity on the IFAS media was recorded to be in excess of at least $60 \%$ of the AOB activity occurring in the IFAS basin (Thomas et al, 2009). The figures demonstrate that with all experiments conducted nitrification rates on the media increased steadily as DO concentrations were increased from $2 \mathrm{mg} / \mathrm{L}$ to 8 $\mathrm{mg} / \mathrm{L}$. The plots also indicate that AOB rates continue to increase in a linear fashion as DO concentrations in the bulk liquor reach $8 \mathrm{mg} / \mathrm{L}$. This indicates that the biofilm has not reached 
saturation for $\mathrm{AOB}$ activity, even at $\mathrm{DO}$ of $8 \mathrm{mg} / \mathrm{L}$ and that biofilm saturation occurs at a higher DO. These plots help to visualize the dependence on substrate availability on biofilm kinetics and that higher concentration of substrate in the bulk liquid allows the substrate to diffuse further into the biofilm and become more available to nitrifying populations located on the carriers.

Similarly, NOB activity on the carriers was also tested by varying DO concentrations in the bulk liquid and mixing intensity. Figures 5-3C and 5-3D below outline the results from NOB experiments conducted on November 19, 2008 and January 14, 2009. As previously discussed, these dates correspond with times in which more than $80 \%$ of the total NOB activity was occurring on the media. Like the AOB experiments, it is clear from the figures that DO concentrations in the bulk liquor impacts the nitrification rates on the IFAS carriers. However, unlike the AOB experiments, NOB activity ceases to increase linearly as DO concentrations exceed $6 \mathrm{mg} / \mathrm{L}$ in the bulk liquid. This observation indicates that the NOB populations are saturated at lower DO concentrations than AOB populations.

Because the NOB activity does not increase with DO concentrations higher than $6 \mathrm{mg} / \mathrm{L}$, a clearer picture of mixing intensity effects can be observed in Figures 5-32C and 5-3D. Like the AOB activity, mixing intensity imparted to the water does not affect nitrification kinetics as much as DO; but, mixing energy still helps to increase substrate availability in the biofilm. In Figure 5-3D, it seems that the saturating DO concentration is dictated in part by mixing. At lower mixing speeds, the DO concentrations have a much higher effect on nitrification kinetics, and by increasing the mixing energy in the water, the mass transport of substrate into the biofilm, in this case DO, is much easier.

The plots also helps to show that mixing energy makes substrate more available to the biofilm by making the water film surrounding the biofilm thinner, making mass transport 
through the water film much easier. The mixing, however, does little to affect mass transport through the biofilms, though it may have made them thinner by inducing higher detachment rate in the bench-scale test reactors, unlike bulk DO concentrations which affect mass transport through both the water film and the biofilm.

In addition, temperature makes some significant impacts on nitrification rates measured for these experiments. As temperature decreases, microbial activity and metabolism slows down, resulting in slower nitrification rates at colder temperatures. In addition, it has been shown that carrier biofilm content increase with temperature as environmental conditions in the IFAS tank approach washout conditions. The added biomass on the carriers creates more resistance to diffusion into the biofilm, making substrate more difficult to access and slowing the nitrification rates (Thomas et al. 2009). In addition to affecting biofilm diffusion, the diffusion coefficient decreases as a result of an increase in water viscosity which creates more resistance in the mass transfer boundary layer. Temperatures affects on water density also have an effect on the velocity gradient in the water, G, which, in some ways, off-sets the effect on the diffusion coefficient. As temperature decreases, the velocity gradient increases adding mixing energy to the system. 

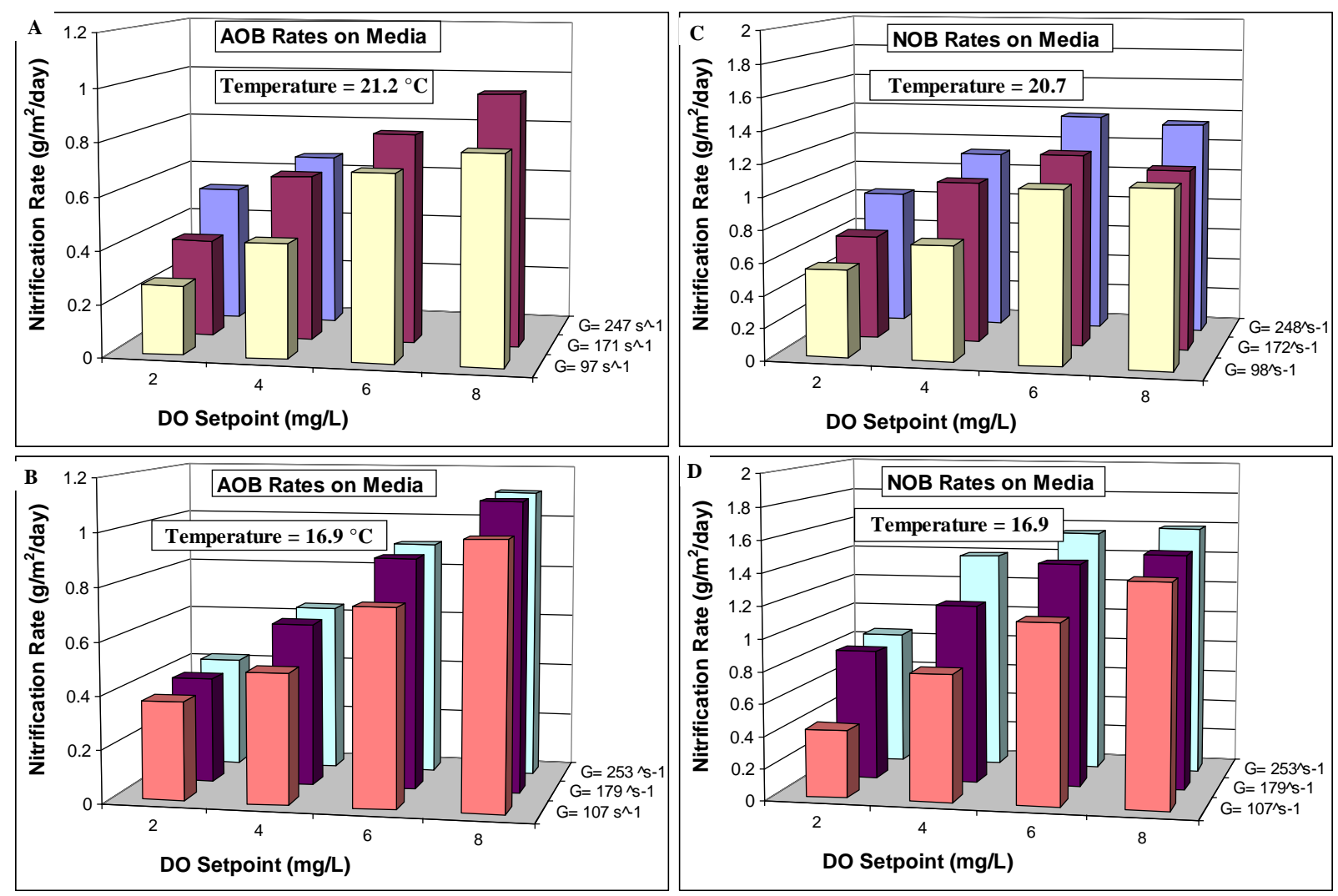

Figure 5-3 A=DO and Mixing Effects IFAS Media Nitrification Rates: A=AOB November 18, 2008; B=AOB January 13, 2009; C=NOB November 19, 2008; D=NOB January 14, 2009.

Mixing and DO effects were also tested for the IFAS mixed liquor. Figures 5-4A, 5-4B, 5-4C, and 5-4D outline the results from two AOB activity and two NOB activity experiments conducted by varying the bulk liquid DO and mixing energy imparted to the water. The experiments conducted on the IFAS mixed liquor enable a comparison be made in regards to mass transport in the water film and biofilm of the IFAS media, and the activated sludge flocs in the mixed liquor. It is clear from the data that neither DO concentrations nor mixing intensity impact the measured nitrification rates in the mixed liquor, which have been normalized to mixed liquor concentrations. This is because activated sludge flocs allow substrate to diffuse into the floc from all directions, whereas the biofilms on the media can only access substrate in one direction. The data suggest that nitrification rates are unaffected by DO concentration above 
$2 \mathrm{mg} / \mathrm{L}$, regardless of the applied mixing intensity. As presented in Table 5-1, this is as expected based on the expected Ko values for nitrifiers growing in normal activated sludge.

Table 5-1. $K_{O}, K_{S}$, and $\mu_{\max }$ Data for Mixed Liquor

\begin{tabular}{|c|c|c|c|c|}
\hline \multirow{4}{*}{ AOB } & $\begin{array}{c}\mathrm{K}_{\mathrm{O}} \\
\mathrm{mg} / \mathrm{L}-\mathrm{O}_{2}\end{array}$ & $\begin{array}{c}\mathrm{K}_{\mathrm{S}} \\
\mathrm{mg} / \mathrm{L}-\mathrm{N}\end{array}$ & $\begin{array}{c}\mu_{\max } \\
\mathrm{d}^{-1}\end{array}$ & Source \\
\hline \multirow{3}{*}{ NOB } & 0.25 & 0.7 & 0.9 & Envirosim 2008 \\
\cline { 2 - 5 } & $0.2-0.4$ & ----------- & ---------- & Peng et al. 2006 \\
\cline { 2 - 6 } & 0.5 & 1 & 0.77 & Grady et al. 1999 \\
\cline { 2 - 6 } & 0.5 & 0.05 & 0.7 & Envirosim 2008 \\
\cline { 2 - 6 } & $1.2-1.5$ & ---------- & ---------- & Peng et al. 2006 \\
\hline & 0.68 & 1.3 & 0.82 & Grady et al. 1999 \\
\hline
\end{tabular}
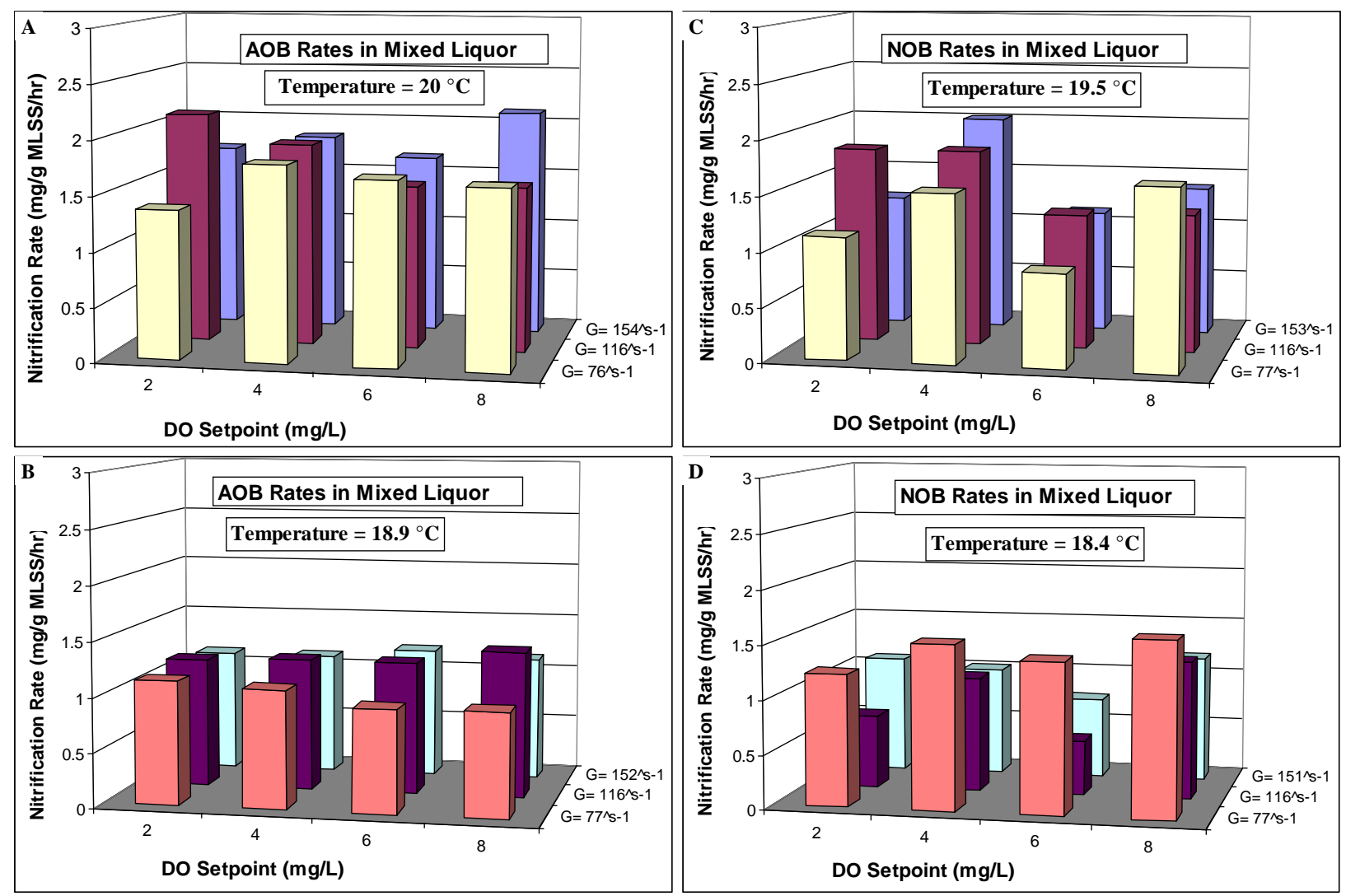

Figure 5-4. DO and Mixing Effects on IFAS Mixed Liquor: A=AOB November 25, 2008; $\mathrm{B}=\mathrm{AOB}$ December 16, 2008; C=NOB November 26, 2008; D=NOB December 17, 2008 


\subsubsection{Effective Half-Saturation Values for IFAS Activity}

Figure 5-5 shows a representative example of how effective half saturation effects were calculated. The term "effective" is used here to describe the combined impact of biomass substrate affinity and IFAS carrier mass transport limitations. Although these data could be used to conduct detailed biofilm/IFAS process modeling, this approach allows a relatively simple comparison of AOB and NOB kinetic limitations posed by the IFAS process. For comparison, typical suspended growth Ks and Ko values for AOB and NOB are reported in Table 5-1 above.

Since $K_{O}$ effects had to be accounted for when calculating $K_{S}$, the results from all of the DO setpoints were used to determine a single $\mathrm{K}_{\mathrm{S}}$ value for each experiment. The $\mathrm{K}_{\mathrm{S}}, \mathrm{K}_{\mathrm{O}}$, and maximum nitrification rate were calculated by simultaneously fitting the four sets (for each DO setpoint) of data to the integrated Monod equation below using either ammonia versus time (AOB) or nitrite versus time (NOB) data:

$$
\frac{d N}{d t}=\left(\frac{q^{*} N}{K s+N}\right)\left(\frac{O}{K o+O}\right)
$$

Integrating

$$
\frac{K s}{q} \ln \left(\frac{N}{N o}\right)+\frac{1}{q} N-N o=\left(\frac{O}{K o+O}\right) * t
$$

Rearranging

$$
t=\frac{\left(\frac{K s}{q} * \ln \frac{N}{N o}+\frac{1}{q} *(N-N o)\right)}{\frac{O}{K o+O}}
$$

where:

$\mathrm{K}_{\mathrm{S}}=$ effective substrate half saturation coefficient $(\mathrm{mg} / \mathrm{L})$

$\mathrm{K}_{\mathrm{O}}=$ effective oxygen half saturation effects $(\mathrm{mg} / \mathrm{L})$

$\mathrm{r}=\operatorname{rate}(\mathrm{mg} / \mathrm{L} / \mathrm{min})$ 
$\mathrm{q}=$ maximum rate $(\mathrm{mg} / \mathrm{L} / \mathrm{min})$

$\mathrm{N}=$ substrate concentration $(\mathrm{mg} / \mathrm{L}-\mathrm{N})$

$\mathrm{N}_{0}=$ initial substrate concentration $(\mathrm{mg} / \mathrm{L}-\mathrm{N})$

$\mathrm{O}=\mathrm{DO}$ concentration $(\mathrm{mg} / \mathrm{L})$

$\mathrm{t}=$ time (minutes)
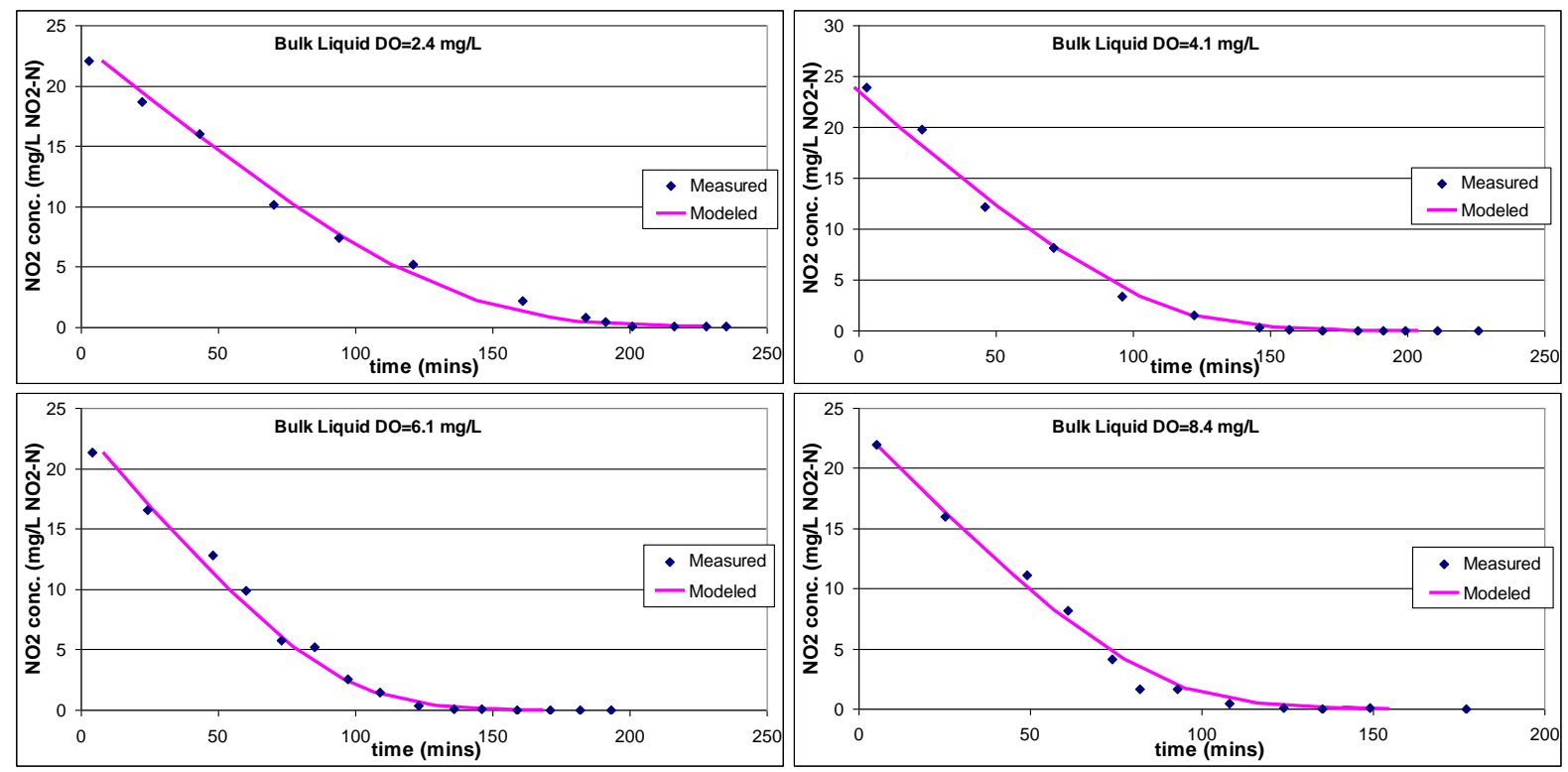

Figure 5-5. Representative Model Fitting for Ks and Ko effects- June 24, 2008

Table 5-2. Diffusion coefficients for Nitrite, Ammonium, and Oxygen at $25{ }^{\circ} \mathrm{C}$

\begin{tabular}{|c|c|c|}
\hline & $\begin{array}{c}\mathrm{D}_{\mathrm{W}} \\
\mathrm{cm}^{2} / \mathrm{s}\end{array}$ & Source \\
\hline Ammonium & $1.95 \mathrm{E}-05$ & Lyde et al. 1996 \\
\hline Nitrite & $1.91 \mathrm{E}-05$ & Lyde et al. 1996 \\
\hline \multirow{2}{*}{ Oxygen } & $2.10 \mathrm{E}-05$ & Lyde et al. 1996 \\
\cline { 2 - 3 } & $2.60 \mathrm{E}-05$ & Nazaroff et al. 2001 \\
\hline
\end{tabular}

Table 5-2 above summarizes diffusion coefficients for ammonia, nitrite, and oxygen.

This table shows that there are insignificant differences in the ability for each of these substrates to diffuse into the biofilm. 
Results are summarized in Table 5-3 below. First, $\mathrm{K}_{\mathrm{O}}$ for both AOB and NOB populations on the carriers are higher than typically considered for suspended growth nitrifiers( $\mathrm{AOB}$ is $244 \%$ higher and $\mathrm{NOB}$ is $54 \%$ higher), indicating that there is a mass transport limitation for oxygen in the biofilm. Oxygen is much denser than ammonia by mass, so when considering these two substrates on a mass basis, it makes sense that the $\mathrm{K}_{\mathrm{O}}$ for $\mathrm{AOB}$ activity in the biofilm is higher than mixed liquor. Higher $\mathrm{K}_{\mathrm{O}}$ values for $\mathrm{AOB}$ activity might also indicate that $\mathrm{AOB}$ populations exist deeper in the biofilm, contrary to what is indicated by the nitrification kinetics testing on the IFAS carriers (Thomas et al. 2009). The $\mathrm{K}_{\mathrm{O}}$ for NOB activity in the biofilm is only slightly higher than typical $\mathrm{K}_{\mathrm{O}}$ values for mixed liquor which may only be a result of general mass transport issues associated with biofilm activity. This increase may also confirm that NOB populations exist deeper in the biofilm than AOB populations. In addition, $\mathrm{K}_{\mathrm{O}}$ values for $\mathrm{NOB}$ are only slightly higher than for mixed liquor confirming the higher affinity of oxygen to NOB activity.

Measured $\mathrm{K}_{\mathrm{S}}$ values for $\mathrm{AOB}$ activity on the carriers are only $33 \%$ higher than $\mathrm{K}_{\mathrm{S}}$ values associated with AOB activity in mixed liquor. This indicates that ammonia is available to AOB populations in the biofilm and that $\mathrm{AOB}$ populations have the same affinity for ammonia. This may indicate that AOB populations inhabit the surface of the biofilm, where diffusion of ammonia into the mass transport boundary layer and the biofilm do not affect the availability of the substrate to the biomass. Unlike $\mathrm{K}_{\mathrm{S}}$ for $\mathrm{AOB}$ activity measured in these experiments, $\mathrm{K}_{\mathrm{S}}$ values measured for NOB are much higher $(2168 \%)$ than $\mathrm{K}_{\mathrm{S}}$ values associated with NOB activity in mixed liquor. The much higher $\mathrm{K}_{\mathrm{S}}$ values indicate that mass transport of nitrite is much slower in the biofilm than in the suspended growth application. This slow diffusion of nitrite, which is molecularly denser than oxygen, into the biofilm may also explain why the $\mathrm{K}_{\mathrm{O}}$ 
for NOB activity is not much higher than typical $\mathrm{K}_{\mathrm{O}}$ values for NOB activity in mixed. The higher $\mathrm{K}_{\mathrm{S}}$ and diffusion limitations also indicate that NOB populations are present deeper in the biofilm. One important consideration to keep in mind is that the $\mathrm{K}_{\mathrm{S}}$ and $\mathrm{K}_{\mathrm{O}}$ data collected for the carriers may not represent nitrite oxidation in the full scale application of free moving biofilm technologies. In these experiments, the bulk liquid is spiked with nitrite and nitrite has to diffuse through the mass transport boundary layer and the entire biofilm before it is bioavailable to NOB populations, whereas in full scale application of these carriers, nitrite is available to the biomass when AOB activity converts ammonia to nitrite. Essentially, in the full scale application of these carriers, nitrite does not have to diffuse through the mass transport boundary layer and the biofilm to be bioavailable, instead AOB activity on the surface of the biofilm makes nitrite immediately available to the NOB populations in the biofilm without having to account for diffusion.

Table 5-3. Summary of all $\mathrm{K}_{\mathrm{S}}$ experiments

\begin{tabular}{|c|c|c|c|c|c|c|c|}
\hline Date & Experiment & $\begin{array}{c}\text { Temperature } \\
{ }^{\circ} \mathrm{C}\end{array}$ & $\begin{array}{c}\mathrm{G} \\
\mathrm{s}^{-1}\end{array}$ & $\begin{array}{c}\text { Max Rate } \\
\mathrm{g} / \mathrm{m}^{2} / \mathrm{day}\end{array}$ & $\begin{array}{c}\text { Max Rate } \\
\mathrm{mg} / \mathrm{g} \text { MLSS/hr }\end{array}$ & $\begin{array}{c}\mathrm{K}_{\mathrm{S}} \\
\mathrm{mg} / \mathrm{L}-\mathrm{N}\end{array}$ & $\begin{array}{c}\mathrm{K}_{\mathrm{O}} \\
\mathrm{mg} / \mathrm{L}-\mathrm{O}\end{array}$ \\
\hline 4-Jun-08 & AOB- Carriers & 24.0 & 241.9 & 1.87 & --------- & 0.93 & 0.90 \\
\hline 22-Jul-08 & AOB- Carriers & 27.3 & 235.4 & 1.02 & --------- & 0.87 & 0.76 \\
\hline 10-Dec-08 & AOB- Carriers & 19.0 & 93.5 & 0.81 & --------- & 0.91 & 0.88 \\
\hline 30-Dec-08 & AOB- Carriers & 18.1 & 103.1 & 0.80 & -------- & 1.0 & 0.90 \\
\hline 12-Nov-08 & AOB- Mixed Liquor & 21.7 & 157 & -------- & 2.25 & 0.43 & $0.25^{*}$ \\
\hline 2-Jun-08 & NOB- Carriers & 23.5 & 242.8 & 1.47 & --------- & 1.1 & 0.76 \\
\hline 24-Jun-08 & NOB- Carriers & 26.6 & 236.8 & 1.44 & --------- & 1.1 & 0.88 \\
\hline 4-Nov-08 & NOB- Carriers & 22.7 & 244.4 & 1.79 & -------- & 1.1 & 0.67 \\
\hline 9-Dec-08 & NOB- Carriers & 18.4 & 102.6 & 1.79 & -------- & 1.2 & 0.79 \\
\hline 27-Jan-09 & NOB- Carriers & 15.4 & 111.8 & 1.74 & --------- & 1.2 & 0.74 \\
\hline 11-Nov-08 & NOB- Mixed Liquor & 21.7 & 157 & --------- & 2.28 & 0.55 & 0.50 \\
\hline
\end{tabular}

Note: * Accepted values of $\mathrm{K}_{\mathrm{O}}$ for Mixed Liquor used

Evaluation of $\mathrm{K}_{\mathrm{O}}$ and $\mathrm{K}_{\mathrm{S}}$ effects on the IFAS carriers provides insight to how substrates at low concentrations are transported to and consumed in the biofilm. At low bulk liquid substrate concentration, half saturation effects include both the intrinsic biomass substrate 
affinity as well as the mass transfer of the substrate to and within the biofilm. Because of the mass transport issues related to biofilms, half saturation effects on both DO and reduced nitrogen species create multiple limiting substrates that impact growth and nitrification rates on the IFAS media.

Figures 5-6A, 5-6B, 5-6C, and 5-6D below show $\mathrm{K}_{\mathrm{O}}$ data for three AOB and NOB experiments at high mixing speeds and two AOB and NOB experiments at low mixing speeds. These values plot maximum nitrification rates against DO in the bulk liquid, but it is important to note that the maximum rates shown in these plots is not the same maximum rate calculated with the model. The data portrayed in the figures are consistent with the results from the experiments comparing the effect of DO concentrations in the bulk liquid and mixing speeds. It is clear that as DO increases, both $\mathrm{AOB}$ and NOB activity increases on the IFAS media, although, as discussed previously, the effect is much more profound on the AOB activity. The effect of DO on NOB activity is more clearly defined at lower mixing speeds, when the water film surrounding the biofilm is thicker and mass transport into the biofilm is more difficult. In fact, the only plot with available $\mathrm{KO}$ data is figure $5-5 \mathrm{D}$, which displays a profound relationship between DO and nitrification rate. 

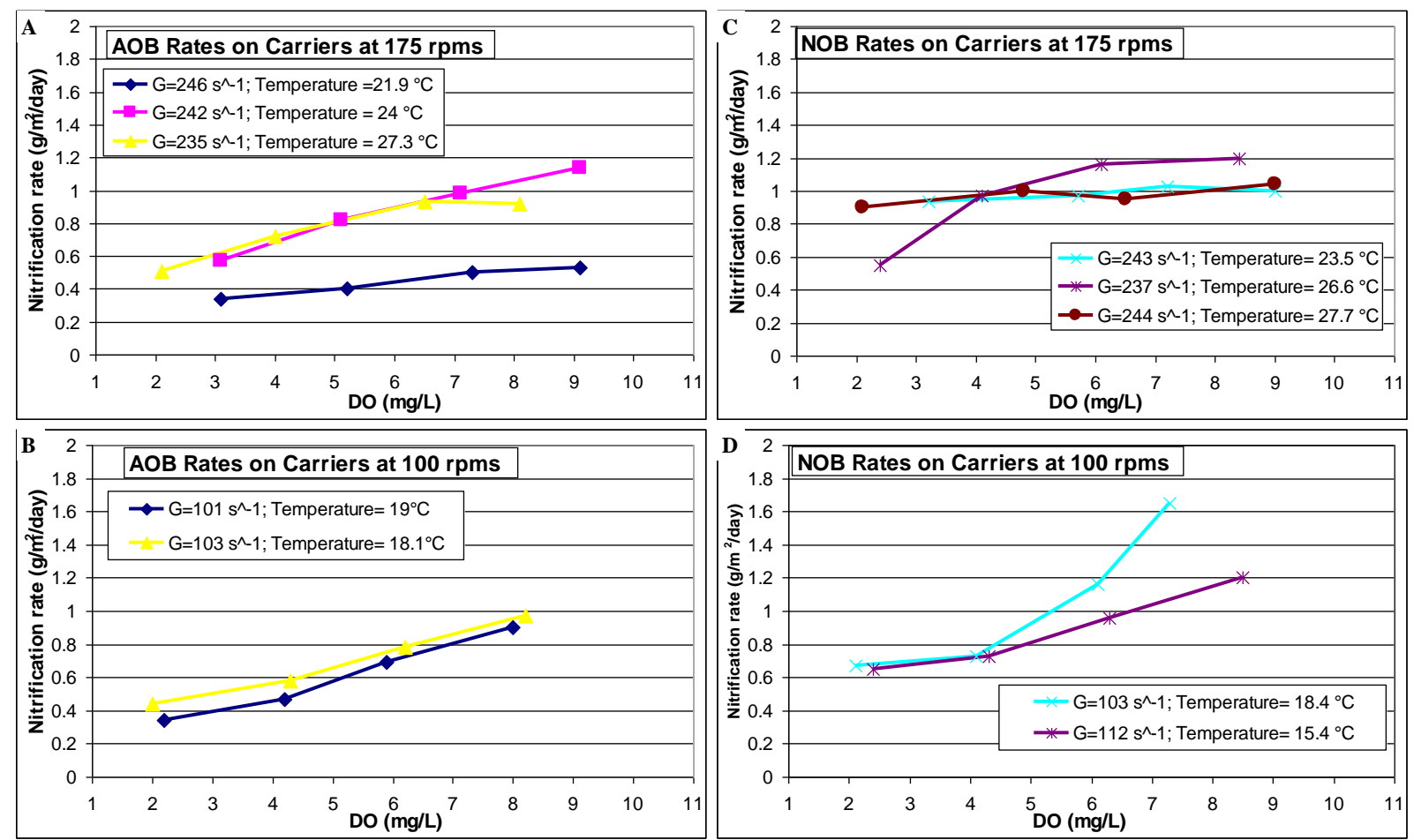

Figure 5-6. Nitrification Rates vs. DO on the IFAS Media: A=AOB @ 175 RPMS; B=AOB @ 100 RPMS; C=NOB @175 RPMS; D=NOB @100 RPMS

It is important to compare the half saturation effects of the IFAS media to the IFAS mixed liquor. Figure 5-7 summarizes the results of two half saturation effect experiments, one AOB and the other NOB. The plot enforces the results for the DO and mixing experiments conducted for the IFAS mixed liquor, and because the previously discussed experiments determined that DO and mixing have no effect of nitrification rates in the mixed liquor, it was unnecessary to conduct more experiments. Figure 5-7 confirms that DO does not affect nitrification rates for the IFAS mixed liquor for DO concentrations ranging from $2 \mathrm{mg} / \mathrm{L}$ to $8 \mathrm{mg} / \mathrm{L}$, and only affects the activated sludge flocs at very low DO concentrations. 


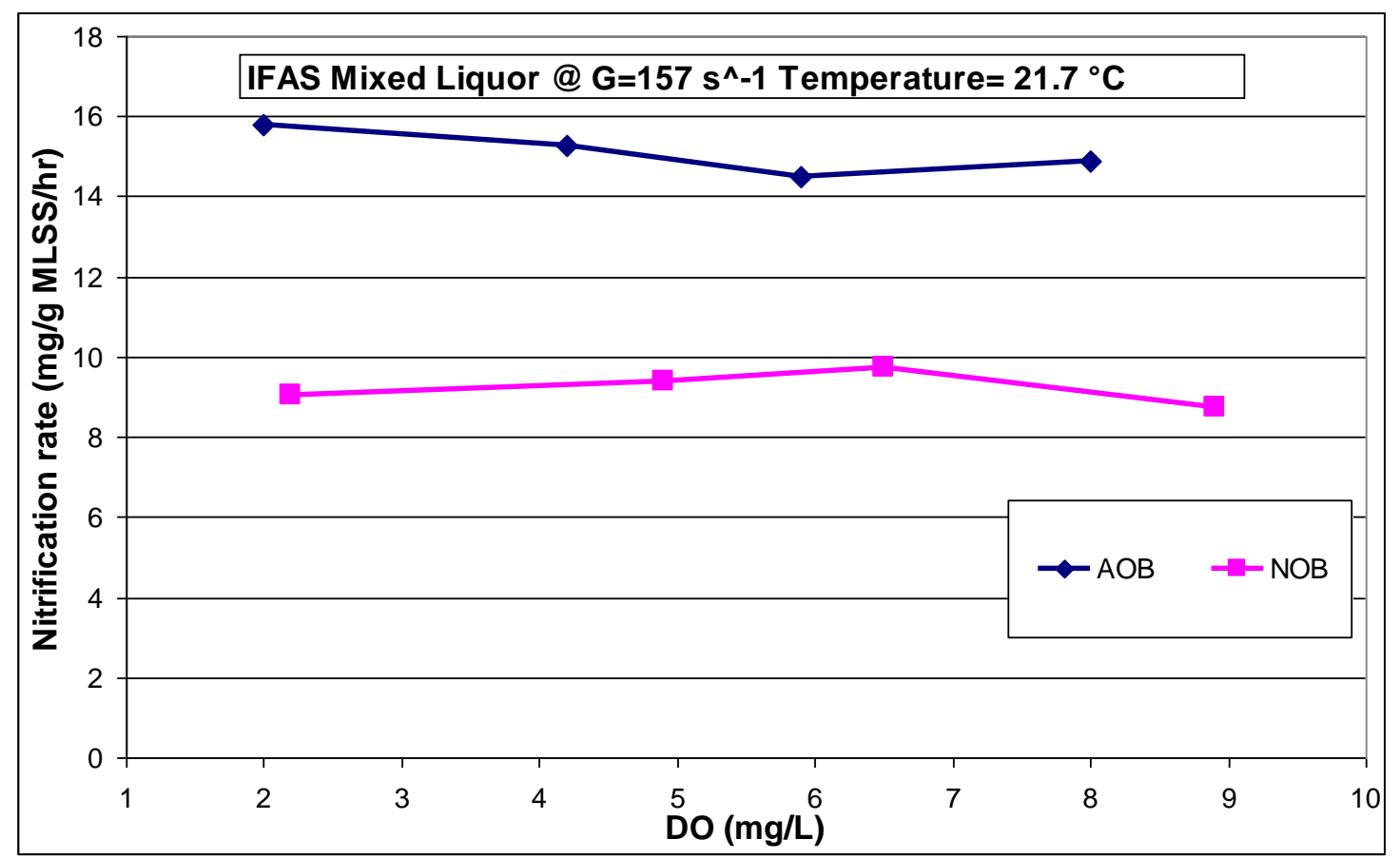

Figure 5-7. AOB and NOB Nitrification Rates on the IFAS Mixed Liquor versus DO

\subsubsection{Effect of COD addition on Nitrification Rates}

The IFAS mixed liquor and media were impacted by COD addition in different ways.

Figure 5-9 shows the results from two different experiments conducted comparing the how COD addition affects both $\mathrm{AOB}$ and NOB nitrification rates on the IFAS media. From Figure 5-8, it is clear that COD addition does not have an impact on nitrification kinetics for $\mathrm{AOB}$ or NOB populations on the IFAS carriers. In addition to having no significant impact on nitrification rates, Figure 5-8 demonstrates that the media demonstrated very low COD uptake rates, indicating that very little to no heterotrophic growth has occurred on the media, and that most of the biomass on the media appears to be autotrophic. As water temperature in the basin decreased, the biomass concentration increased on the carriers. On December $2^{\text {nd }}$, the water temperature was $18.8{ }^{\circ} \mathrm{C}$ corresponding to a biomass content measurement of $5.09 \mathrm{~g} \mathrm{MLSS} / \mathrm{m}^{2}$, and on January $28^{\text {th }}$, the water temperature was $15.3^{\circ} \mathrm{C}$ resulting in a increase of biomass content 
to $6.92 \mathrm{~g} \mathrm{MLSS} / \mathrm{m}^{2}$. It is clear that the additional biomass on the IFAS media did not substantially increase the COD removal potential of the carriers.

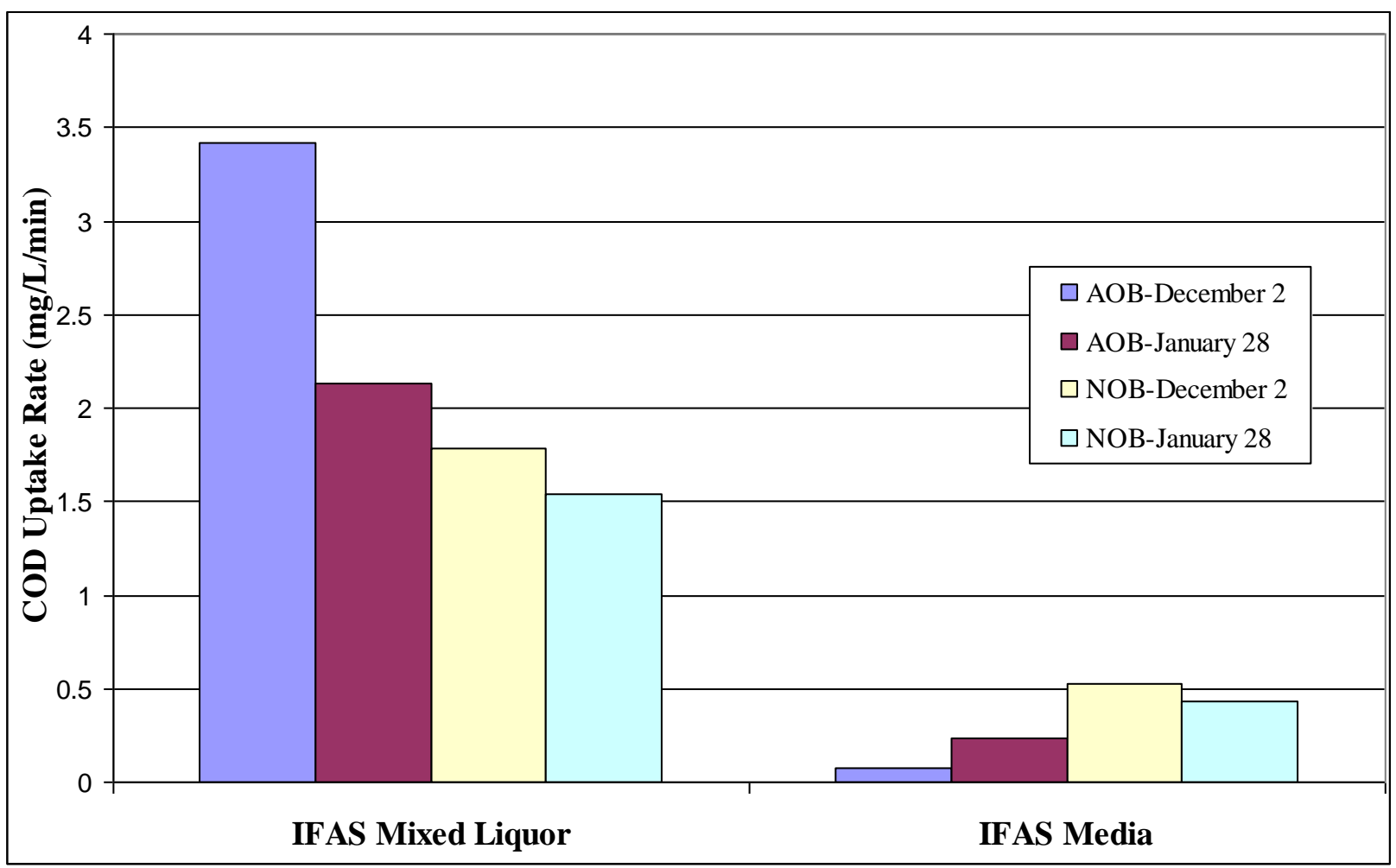

Figure 5-8. COD Uptake Rates for IFAS Mixed Liquor and Media 

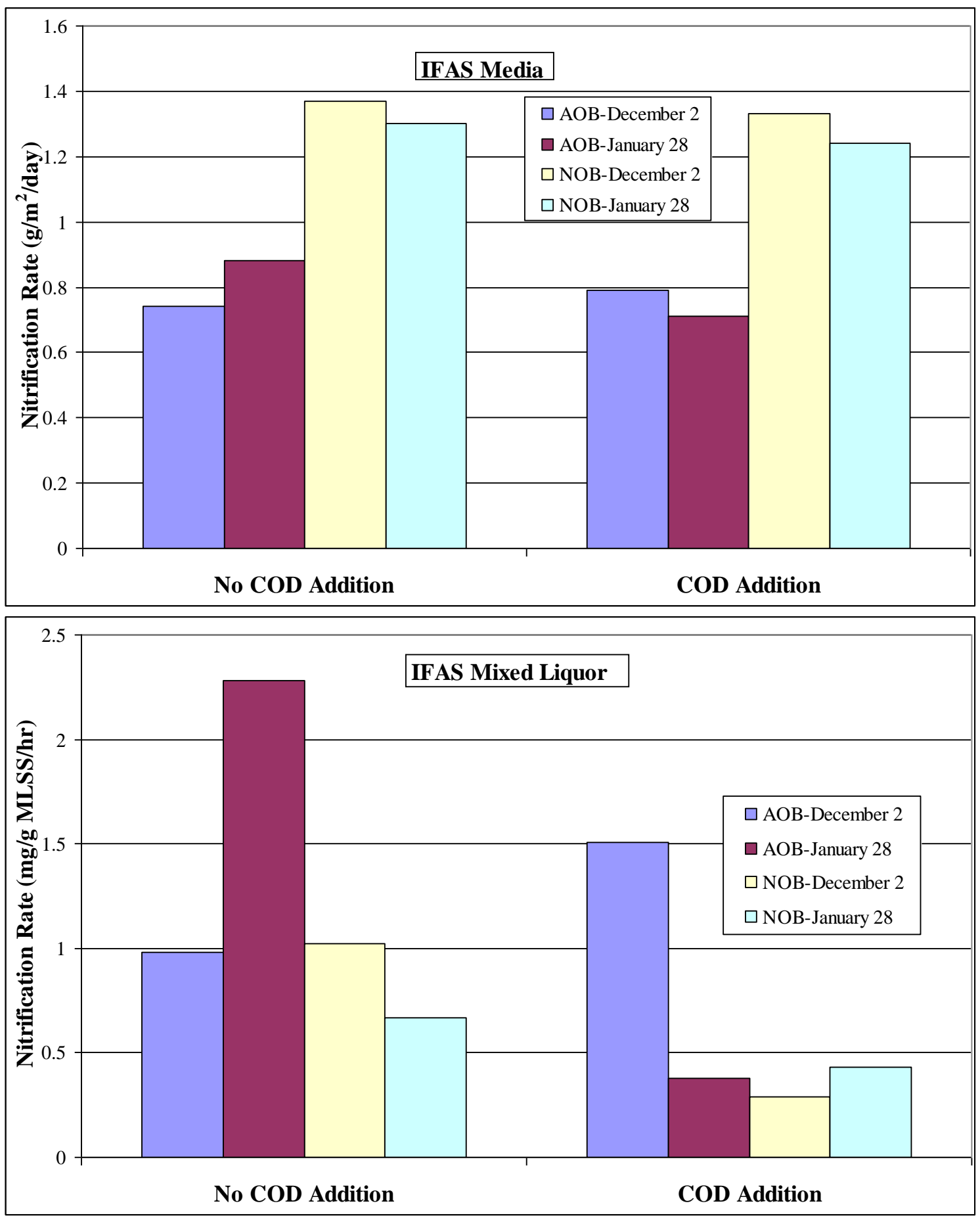

Figure 5-9. Effects of COD addition on Nitrification Rates on the IFAS Media

The addition of COD did impact nitrification rates in the IFAS mixed liquor (Figure 5-8), resulting in a reduction in maximum activity in the bench-scale reactors. The only experiment 
that did not reflect this trend was the AOB experiment conducted on December 2, 2008, which shows an increase in ammonia oxidation rate. This can be explained by a rapid increase in the reactor $\mathrm{pH}$ to values as high as 8.3 in all of the mixed liquor that received the COD spike ( $\mathrm{pH}$ controllers worked only with automatic addition of alkalinity, not acid). It is well known that increases in $\mathrm{pH}$ can be beneficial for AOB activity (Park et al. 2007), and this change could have been responsible for the unexpected AOB data on December 2. However, in other experiments conducted, both $\mathrm{AOB}$ and $\mathrm{NOB}$ nitrification rates declined as a result of the addition of COD to the mixed liquor.

\subsection{CONCLUSIONS}

The campaign experiments provided additional information about IFAS process kinetics. Mixing and DO both affect maximum nitrification rates on the biofilm carriers. Increasing mixing intensity in the IFAS process decreases the mass transfer boundary layer thickness which increases substrate accessibility to the biofilm and the maximum nitrification rate. The effect of mixing on the maximum nitrification rate on the carriers is much more profound at lower DO. Bulk liquid DO also affects nitrification kinetics in the IFAS process, and the relationship between DO and nitrification rate is roughly linear until the biofilm becomes saturated with oxygen. After oxygen saturation occurs, nitrification rates cease to increase. Oxygen saturation occurs at different bulk DO for AOB and NOB activity. Saturation occurs at about $6 \mathrm{mg} / \mathrm{L}$ for NOB activity which is clearly shown by Figure 5-2. For AOB activity, saturation does not occur until bulk DO rises above $8 \mathrm{mg} / \mathrm{L}$. This research did not investigate the effect of DO concentrations above $8 \mathrm{mg} / \mathrm{L}$, so it is unknown exactly when oxygen saturation occurs. This phenomenon contradicts much of the data collected indicating where AOB and 
NOB populations inhabit the biofilm. Because oxygen saturation happens at a lower DO for NOB populations, it appears that NOB activity is localized at the surface of the biofilm, and that AOB activity occurs deeper in the biofilm. However, despite this observation, there is overwhelming evidence that AOB activity is localized at the biofilm surface and that NOB activity remains deeper in the biofilm. Molecular work to be completed by Pinto et al. (2009) should help to answer these questions. Either way, as bulk liquid DO decreases, oxygen becomes a limiting substrate and ultimately controls the maximum nitrification rate on the carriers.

The data collected concerning the half saturation effects on the biofilm carriers suggests that $\mathrm{K}_{\mathrm{S}}$ values in the IFAS process can be modeled using Monod kinetics and were, as expected, higher than accepted $\mathrm{K}_{\mathrm{S}}$ values for mixed liquor. Modeled $\mathrm{NOB}$ effective $\mathrm{K}_{\mathrm{S}}$ values for the carriers were $2168 \%$ higher than what is typically considered for suspended growth. This indicates that nitrite accessibility in the biofilm is greatly limited by substrate diffusion. Limited nitrite diffusion, however, is not altogether unexpected. Nitrite has a lower diffusivity than ammonia or oxygen so it makes sense that the half saturation coefficient would be much higher in the biofilm application. It is also consistent with NOB localized deeper within the biofilm. $\mathrm{K}_{\mathrm{S}}$ for AOB activity was only $33 \%$ higher than what is accepted for suspended phase AOB activity, indicating that ammonia is more easily accessed by the biofilm. This also indicates that AOB populations inhabit the surface of the biofilm where substrate diffusion has less effect. $\mathrm{K}_{\mathrm{O}}$ for both $\mathrm{AOB}$ and $\mathrm{NOB}$ activity in the biofilm is higher than typical mixed liquor value because of the mass transport issues associated with the biofilm. For AOB, the measured $\mathrm{K}_{\mathrm{O}}$ on the media was $244 \%$ more than values listed by Envirosim (2008), and NOB $\mathrm{K}_{\mathrm{O}}$ on the media was 54\% higher for NOBs than Envirosim (2008) values. This trend, however, 
contradicts the diffusion coefficient for oxygen, which is higher than ammonia and nitrite. If $\mathrm{K}_{\mathrm{S}}$ values for $\mathrm{AOB}$ activity in the biofilm was close to $\mathrm{K}_{\mathrm{S}}$ values for mixed liquor, then it would seem that oxygen, having a higher diffusivity, would diffuse into the surface of the biofilm easily and not be much higher than mixed liquor $\mathrm{K}_{\mathrm{O}}$ values.

The data suggest two possible biofilm configurations as shown in Figure 5-10 below. The most likely scenario (Figure 5-10A) would appear to involve AOB at the surface of the biofilm and NOB located further within. This hypothesis is supported by effective Ks data and the observation of more significant $\mathrm{AOB}$ activity in the mixed liquor during colder periods (suggesting better bioaugmentation). However, it is also well accepted that suspended growth NOB are more susceptible than AOB to low DO concentrations (Ko for NOB is higher than AOB). This combined with the effective Ko data reported elsewhere (Thomas et al, 2009) suggests that NOB could be located at the surface of the biofilm (Figure 5-10B). Based on fullscale tank TN removal under DO-limited conditions, there did appear to be some degree of simultaneous nitrification-denitrification activity occurring, and this suggests a deep heterotrophic biofilm was also likely present. 


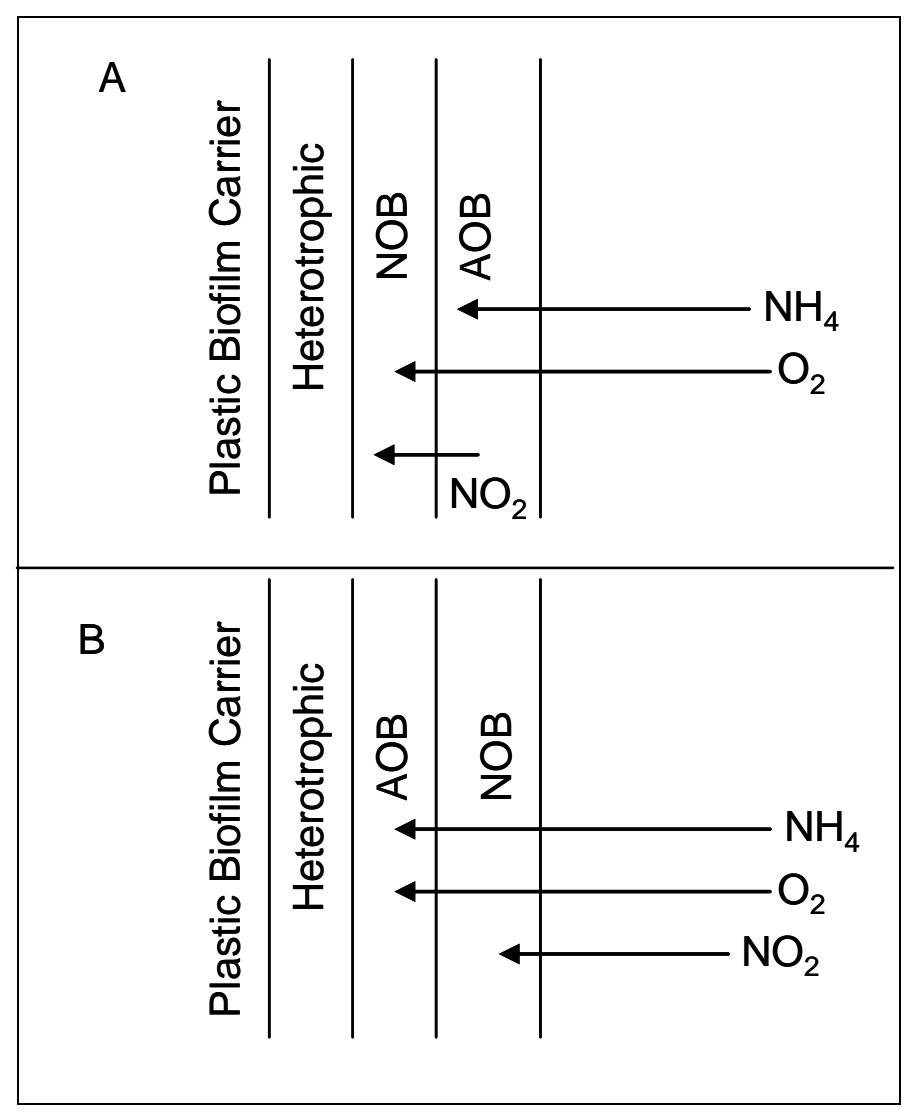

Figure 5-10. Possible Biofilm Configurations

The final observation from the data is that the presence of COD has little to no effect on nitrification rates on the biofilm carriers. In addition, COD uptake on the carriers is limited compared to the IFAS mixed liquor, indicating minimal heterotrophic growth on the IFAS media, suggesting that most of the biofilm is inhabited by autotrophic growth.

\subsection{References}

APHA, AWWA, WEF 1995. Standard methods for the examination of water and wastewater. Washington, D.C.: APHA.

Boltz, J., Daigger, G. 2009. Bulk-Liquid Hydrodynamics Provides Uncertainly In Biofilm Reactor Design. 
Envirosim, 2008. BioWin Version 3.0 Default parameters.

McQuarrie, J., Rutt, K., Seda, J., Haegh, M. Observations From The First Year of Full-Scale Operation - The IFAS/BNR Process At The Broomfield Wastewater Reclamation Facility, Broomfield, CO. Proceedings of the $77^{\text {th }}$ WEFTEC- National Conference of the Water Environment Federation. New Orleans, LA, October 2-6, 2004.

Ross, D., Fernandes, W., Briggs, T., Kim, N., Booth, G., Neely, D., Welp, J. Integrated Fixed Film Activated Sludge (IFAS) At The Lakeview WWTP: The Real Implementation Issues. Proceedings of the $77^{\text {th }}$ WEFTEC- National Conference of the Water Environment Federation. New Orleans, LA, October 2-6, 2004.

Thomas, W. 2009. Evaluation of Nitrification Kinetics for a 2.0 MGD IFAS Process

Demonstration. Civil and Environmental Engineering. Virginia Polytechnic Institute and State University, Blacksburg, VA.

Water Quality Management Planning Regulation. Chapter 720. 9 VAC 25-820-70.

Yerrell, K., Gobbie, M., Dold, P., Jones, R., Sickerdick, L. Full-Scale Demonstration Of A FreeMoving Media IFAS Process For Enhancing Nitrification Performance. Proceedings of the $74^{\text {th }}$ WEFTEC- National Conference of the Water Environment Federation. Atlanta, GA, October 1317,2001 


\section{ENGINEERING SIGNIFICANCE}

Nitrification rate testing has offered a great deal of insight into the performance of the IFAS process for a number of operating conditions and temperatures. Biofilm carrier content serves as a tool when assessing process health and changes according to temperature and process operation. Biofilm content measurements were homogeneous throughout the length of the IFAS zone which indicates that the IFAS zone is well mixed, despite being a plug flow reactor by nature. This trend is also consistent with nitrification activity. Nitrification rates, both $\mathrm{AOB}$ and $\mathrm{NOB}$, were constant on carriers throughout the length of the IFAS zone despite the decline substrate concentration, also suggesting that IFAS zone is well mixed with respect to biomass growth. As temperature changed seasonally, biomass moved on and off the carriers for a number of reasons. As water temperature increased higher than $23{ }^{\circ} \mathrm{C}$, carrier biomass content began to decline significantly, corresponding with a significant shift of AOB activity from the fixed film phase to the mixed liquor. This sloughing of biomass and shift of nitrification activity to the mixed liquor occurred when operating conditions, like process SRT, supported autotrophic growth in the suspended phase of the IFAS tank. Then, as temperature cooled in the basin in the late autumn and early winter, biomass content on the carriers steadily increased from about $3 \mathrm{~g}$ MLSS $/ \mathrm{m}^{2}$ to about $7 \mathrm{~g}$ MLSS $/ \mathrm{m}^{2}$. This shift on the carriers occurred for two reasons. One reason is that the IFAS basin began to approach washout conditions for nitrifiers. As a result, autotrophs moved to the fixed film phase where they could be exposed to a higher effective SRT. The second reason for the shift of biomass onto the carriers is probably a result of a reduction in mixing input to the tank. At low temperatures, less aeration is required to maintain DO in the tank, so the decreased aeration intensity likely also resulted in decreased agitation of the media and thus less sloughing of biomass. 
AOB and NOB activity localization is dependent on temperature and process SRT. AOB activity appears to inhabit the surface of the biofilm and smoothly transitions between the biofilm and suspended fraction as temperature and operating conditions, such as SRT, change. AOB activity in the mixed liquor represents half of the total AOB activity in the IFAS zone when temperatures reach and exceed $23^{\circ} \mathrm{C}$. When temperature dropped to below $20^{\circ} \mathrm{C}$, AOB activity on the media made up a maximum $75 \%$ of the total AOB activity in the IFAS tank. When temperature in the basin peaked, $\mathrm{AOB}$ activity in the basin was at its lowest, making up only $30 \%$ of the total AOB activity in the IFAS basin. The majority of NOB activity remains on the carriers year round and makes much less of a transition from the biofilm to the mixed liquor as temperatures and SRT increase and conditions that support autotrophic growth improve. NOB on the carriers never decreased to less than $60 \%$ of the total NOB activity in the tank, and NOB activity increased to over $90 \%$ of the total NOB activity in the tank during the colder wintertime temperatures. This phenomenon indicates that NOB activity also has a much higher affinity for the carriers and that NOB activity occurs deeper in the biofilm. This probably makes sense given the immediate availability of nitrite produced in the biofilm as a result of local AOB activity. However, AOB and NOB activity remains in the IFAS mixed liquor, even during washout conditions, due to "bio-augmentation" caused by sloughing of biomass off the carriers.

The campaign experiments provided additional information about IFAS process kinetics. Mixing and DO both affect maximum nitrification rates on the biofilm carriers. Increasing mixing intensity in the IFAS process decreases the mass transfer boundary layer thickness which increases substrate accessibility to the biofilm and the maximum nitrification rate. The effect of mixing on the maximum nitrification rate on the carriers is much more profound at 
lower DO. Bulk liquid DO also affects nitrification kinetics in the IFAS process, and the relationship between DO and nitrification rate is roughly linear until the biofilm becomes saturated with oxygen. After oxygen saturation occurs, nitrification rates cease to increase. Oxygen saturation occurs at different bulk DO for AOB and NOB activity. Saturation occurs at about $6 \mathrm{mg} / \mathrm{L}$ for NOB activity which is clearly shown by Figure 5-2. For AOB activity, saturation does not occur until bulk DO rises above $8 \mathrm{mg} / \mathrm{L}$. This research did not investigate the effect of DO concentrations above $8 \mathrm{mg} / \mathrm{L}$, so it is unknown exactly when oxygen saturation occurs. This phenomenon contradicts much of the data collected indicating where AOB and NOB populations inhabit the biofilm. Because oxygen saturation happens at a lower DO for NOB populations, it would appear that NOB activity is localized at the surface of the biofilm, and that $\mathrm{AOB}$ activity occurs deeper in the biofilm. However, despite this observation, there is overwhelming evidence that $\mathrm{AOB}$ activity is localized at the biofilm surface and that NOB activity remains deeper in the biofilm. Molecular work to be completed by Pinto et al (2009) should help to answer these questions. Either way, as bulk liquid DO decreases, oxygen becomes a limiting substrate and ultimately controls the maximum nitrification rate on the carriers.

The data collected concerning the half saturation effects on the biofilm carriers suggest that $\mathrm{K}_{\mathrm{S}}$ values in the IFAS process can be modeled using Monod kinetics and were, as expected, higher than accepted $\mathrm{K}_{\mathrm{S}}$ values for mixed liquor. Modeled $\mathrm{NOB}$ effective $\mathrm{K}_{\mathrm{S}}$ values for the carriers were $2168 \%$ higher than what is typically considered for suspended growth. This indicates that nitrite accessibility in the biofilm is greatly limited by substrate diffusion. Limited nitrite diffusion, however, is not altogether unexpected. Nitrite has a lower diffusivity than ammonia or oxygen so it makes sense that the half saturation coefficient would be much higher 
in the biofilm application. It is also consistent with NOB localized deeper within the biofilm. $\mathrm{K}_{\mathrm{S}}$ for AOB activity is only $33 \%$ higher than what is accepted for suspended phase AOB activity, indicating that ammonia is more easily accessed by the biofilm. This also indicates that AOB populations inhabit the surface of the biofilm where substrate diffusion has less effect.

$\mathrm{K}_{\mathrm{O}}$ for both $\mathrm{AOB}$ and NOB activity in the biofilm is higher than typical mixed liquor value because of the mass transport issues associated with the biofilm. FOR AOB, the measured $\mathrm{K}_{\mathrm{O}}$ on the media was $244 \%$ more than values listed by Envirosim (2008), and NOB $\mathrm{K}_{\mathrm{O}}$ on the media was $54 \%$ higher for NOBs than Envirosim (2008) values. This trend, however, contradicts the diffusion coefficient for oxygen, which is higher than ammonia and nitrite. If $\mathrm{K}_{\mathrm{S}}$ values for $\mathrm{AOB}$ activity in the biofilm is close to $\mathrm{K}_{\mathrm{S}}$ values for mixed liquor, then it would seem that oxygen, having a higher diffusivity, would diffuse into the surface of the biofilm easily and not be much higher than mixed liquor $\mathrm{K}_{\mathrm{O}}$ values.

The data suggest two possible biofilm configurations as shown in Figure 6-1 below. The most likely scenario (Figure 6-1A) would appear to involve AOB at the surface of the biofilm and NOB located further within. This hypothesis is supported by effective Ks data and the observation of more significant $\mathrm{AOB}$ activity in the mixed liquor during colder periods (suggesting better bioaugmentation). However, it is also well accepted that suspended growth NOB are more susceptible than AOB to low DO concentrations (Ko for NOB is higher than AOB). This combined with the effective Ko data reported elsewhere (Thomas et al, 2009 suggests that NOB could be located at the surface of the biofilm (Figure 6-1B). Based on fullscale tank TN removal under DO-limited conditions, there did appear to be some degree of simultaneous nitrification-denitrification activity occurring, and this suggests a deep heterotrophic biofilm was also likely present. 


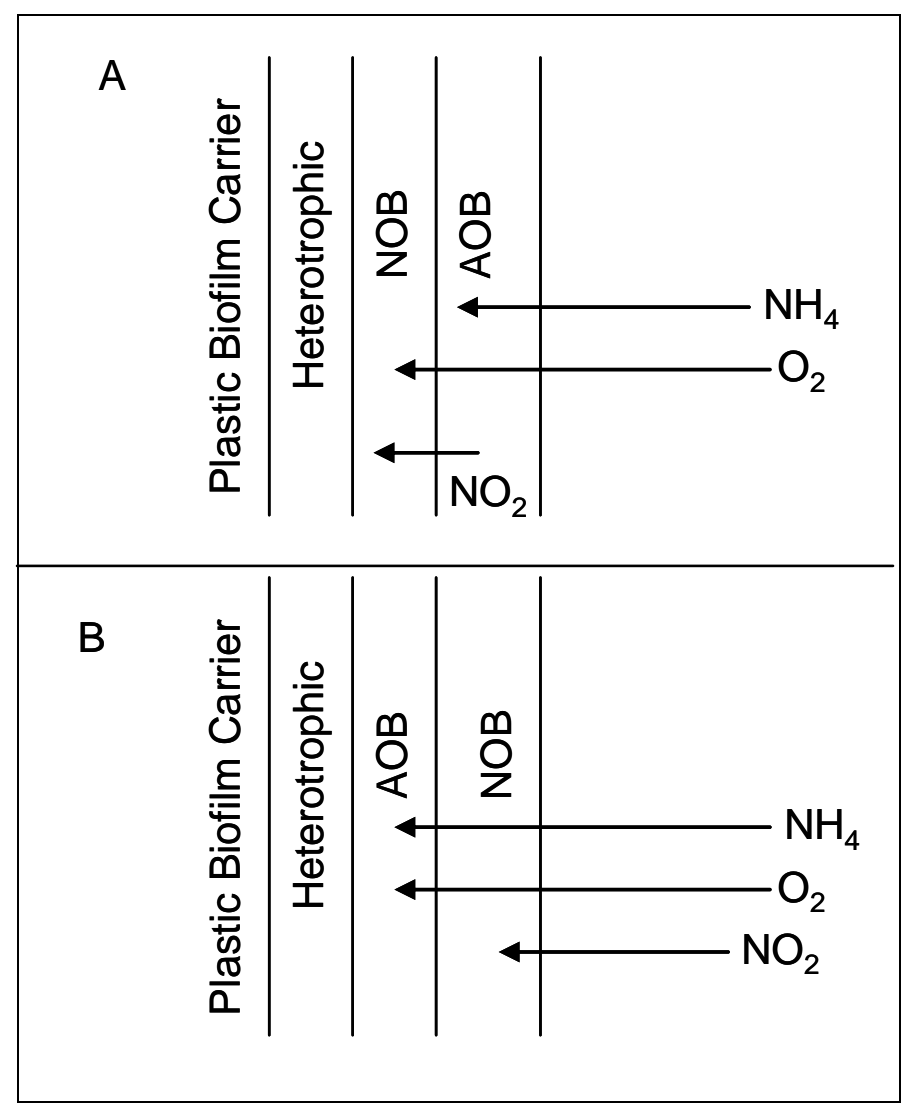

Figure 6-1. Possible Biofilm Configurations

The final observation from the data is that the presence of COD has little to no effect on nitrification rates on the biofilm carriers. In addition, COD uptake on the carriers is limited compared to the IFAS mixed liquor, indicating minimal heterotrophic growth on the IFAS media, suggesting that most of the biofilm is inhabited by autotrophic growth. 


\section{REFERENCES}

AEsoy, A., Odegaard, H., Haegh, M, Risla, F., Bentzen, G. Upgrading Wastewater Treatment Plants By The Use Of Biofilm Carriers, Oxygen Addition And Pre-treatment In The Sewer Network. Civil and Environmental Engineering. Aaiborg University.

APHA, AWWA, WEF 1995. Standard methods for the examination of water and wastewater. Washington, D.C.: APHA.

Boltz, J., Daigger, G. 2009. Bulk-Liquid Hydrodynamics Provides Uncertainly In Biofilm Reactor Design.

Chen, S., Ling, J., Blancheton, J. 2006. Nitrification Kinetics Of Biofilm As Affected By Water Quality Factors. Aquacultural Engineering: 34(3): 179-197.

Choi, N., Phillips, H., Johnson, T.L., Butler, R., Lauro, T. Pilot Testing Of MBBR And IFAS

Treatment Processes For Nitrification And Denitrification At The Mamaroneck WWTP.

Proceedings of the $80^{\text {th }}$ WEFTEC- National Conference of the Water Environment Federation, San Diego, CA. 80: October 13-17, 2007.

Envirosim, 2008. BioWin Version 3.0 Default parameters.

Germain, E., Bancroft, L., Dawson, A., Hinrichs, C., Fricker, L., Pearce, P. 2007. Evaluation Of Hybrid Processes For Nitrification By Comparing MBBR/AS And IFAS Configurations. Water Science and Technology: 55(8-9): 43-49.

Grady, C., Daigger, G., Lim, H. 1999. Biological Wastewater Treatment, Theory And Application. New York: Marcel Deker, Inc.

Head, M., Oleszkiewicz, J. 2005. Nitrifying Bacteria Addition Into Reactors Operating Near Washout Conditions For Nitrification. Journal of Environmental Engineering and Science: 4(4): 257-264.

Hubbell, S., Krichten, D. Demonstration And Full Scale Results Of A Plant Upgrade For BNR Using Integrated Fixed-Film Activated Sludge (IFAS) Technology. Proceedings of the $77^{\text {th }}$ WEFTEC- National Conference of the Water Environment Federation. New Orleans, LA, October 2-6, 2004.

Hubbell, S., McDowell, C. Cold Temperature BNR Using Integrated Fixed-Film Activated Sludge (IFAS) Hybrid Technology. Proceedings of the $76^{\text {th }}$ WEFTEC- National Conference of the Water Environment Federation. Los Angeles, CA, October 12-15, 2003.

Jackson, D., Ripley, L., Maurina, T., Hubbell, S. Conversion from Contact Stabilization To Nitrification Using Integrated Fixed Film Activated Sludge (IFAS) In The Colony, Texas. Proceedings of the $80^{\text {th }}$ WEFTEC- National Conference of the Water Environment Federation. San Diego, CA, October 13-17, 2007. 
Johnson, T., McQuarrie, J., Shaw, A. Integrated Fixed-Film Activated Sludge (IFAS): The New Choice For Nitrogen Removal Upgrades In The United States. Proceedings of the $77^{\text {th }}$ WEFTEC- National Conference of the Water Environment Federation. New Orleans, LA, October 2-6, 2004.

Johnson, T., Shaw, A. A Pilot-Scale Comparison of IFAS And MBBR To Achieve Very Low Total Nitrogen Concentrations. Proceedings of the $80^{\text {th }}$ WEFTEC- National Conference of the Water Environment Federation. San Diego, CA, October 13-17, 2007.

Jones, R., Sen, D., Lambert, R. 1998. Full Scale Evaluation Of Nitrification Performance In An Integrated Fixed Film Activated Sludge Process. Water Science and Technology: 38(1): 71-78.

Kaldate, A., Smedley, S., Turner, T. Evaluation Of IFAS Technology For TN Removal At Chesterfield County BNR Program. Proceedings of the $81^{\text {st }}$ WEFTEC- National Conference of the Water Environment Federation. Chicago, IL, October 18-22, 2008.

Liubicich, J., Pitt, P., Psaltakis, E., Zabinski, A., Lauro, T. Bench Scale Testing Of The IFAS Technology At The Mamaroneck WWTP. Proceedings of the $77^{\text {th }}$ WEFTEC- National Conference of the Water Environment Federation. New Orleans, LA, October 2-6, 2004.

Lyde, D. 1996. CRC Handbook of Chemistry And Physics. 77.

Maas, C., Parker, W., Legge, R. Detachment Of Solids And Nitrifiers In IFAS Systems. Proceedings of the $80^{\text {th }}$ WEFTEC- National Conference of the Water Environment Federation. San Diego, CA, October 13-17, 2007.

Masterson, T., Federico, J., Duerr, S. Upgrading For Total Nitrogen Removal With A Porous Media IFAS System. Proceedings of the $77^{\text {th }}$ WEFTEC- National Conference of the Water Environment Federation. New Orleans, LA, October 2-6, 2004.

Metcalf \& Eddy. 2003. Wastewater Engineering: Treatment and Reuse. Boston: McGraw-Hill, Inc.

McQuarrie, J., Rutt, K., Seda, J., Haegh, M. Observations From The First Year of Full-Scale Operation - The IFAS/BNR Process At The Broomfield Wastewater Reclamation Facility, Broomfield, $C O$. Proceedings of the $77^{\text {th }}$ WEFTEC- National Conference of the Water Environment Federation. New Orleans, LA, October 2-6, 2004.

Motsch, S., Fetherolf, D., Guhse, G., McGettigan, J., Wilson, T. MBBR and IFAS Pilot Program For Denitrification At Fairfax County's Norman Cole Pollution Control Plant. Proceedings of the WEF Nutrient Removal Conference (2007). Baltimore, MD, March 4-7, 2007.

Nazaroff, W., Alvarez-Cohen, L. 2001. Environmental Engineering Science. New York: John Wiley \& Sons, Inc. 
Nelson, D., Renner, T. Improving Performance Of A Conventional Activated Sludge WTF To Provide Nitrification Utilizing Integrated Fixed Film Activated Sludge (IFAS). Proceedings of the $80^{\text {th }}$ WEFTEC- National Conference of the Water Environment Federation. San Diego, CA, October 13-17, 2007.

Odegaard, H., Rusten, B., Siljudalen, J. The Development Of The Moving Bed Biofilm ProcessFrom Idea To Commercial Product.

Onnis-Hayden, A., Dair, D., Johnson, C., Schramm, A., Gu, A. Kinetics And Nitrifying Populations In Nitrogen Removal Processes At A Full-Scale Integrated Fixed-Film Activated Sludge (IFAS) Plant. Proceedings of the $80^{\text {th }}$ WEFTEC- National Conference of the Water Environment Federation. San Diego, CA, October 13-17, 2007.

Park, S., Bae, W., Chung, J., Baek, S. 2007. Empirical Model Of The pH Dependence Of The Maximum Specific Nitrification Rate. Process Biochemistry: 42(12): 1671-1676.

Psaltakis, E., Liubicich, J, Pitt, P., Antonio, P., Posada, S. Demonstration Of Integrated Fixed Film Activated Sludge Process For BNR At The Mamaroneck WWTP. Proceedings of the $76^{\text {th }}$ WEFTEC- National Conference of the Water Environment Federation. Los Angeles, CA, October 12-15, 2003.

Randall, C., Sen, D. 1996. Full-Scale Evaluation Of An Integrated Fixed-Film Activated Sludge (IFAS) Process For Enhanced Nitrogen Removal. Water Science and Technology: 33(12): $155-$ 162.

Randall, C., Sen, D. Improving The Aquifas (Unified) Computational Model For Activated Sludge, IFAS and MBBR Systems By Embedding A Multi-Layer Biofilm Diffusion Model Within A Multi-Cell Activated Sludge System. Proceedings of the WEF Nutrient Removal Conference (2007). Baltimore, MD, March 4-7, 2007.

Regmi, P. 2008. Biological Nutrient Removal Upgrade At The James River Wastewater Treatment Plant. Civil and Environmental Engineering. Old Dominion University, Norfolk, VA.

Ross, D., Fernandes, W., Briggs, T., Kim, N., Booth, G., Neely, D., Welp, J. Integrated Fixed Film Activated Sludge (IFAS) At The Lakeview WWTP: The Real Implementation Issues.

Proceedings of the $77^{\text {th }}$ WEFTEC- National Conference of the Water Environment Federation. New Orleans, LA, October 2-6, 2004.

Rusten, B., Hem, L., Odegaard, H. 1995. Nitrification Of Municipal Wastewater In Moving Bed Biofilm Reactors. Water Environment Research: 67: 75-86

Sen, D., Murthy, S., Phillips, H., Pattarkine, V., Copithorn, R., Randall, C., Schwinn, D., Banerjee, S. Minimizing Aerobic And Post Anoxic Volume Requirements In Tertiary Integrated Fixed-Film Activated Sludge (IFAS) And Moving Bed Biofilm Reactor (MBBR) systems Using The Aquifas Model. Proceedings of the $80^{\text {th }}$ WEFTEC- National Conference of the Water Environment Federation. San Diego, CA, October 13-17, 2007. 
Sen, D., Randall, C., Brink, W., Farren, G, Pehrson, D., Flournoy, W., Copithorn, R. Understanding The Importance Of Aerobic Mixing, Biofilm Thickness Control And Modeling On The Success Or Failure Of IFAS Systems For Biological Nutrient Removal. Proceedings of the WEF Nutrient Removal Conference (2007). Baltimore, MD, March 4-7, 2007.

Thomas, W. 2009. Evaluation of Nitrification Kinetics for a 2.0 MGD IFAS Process

Demonstration. Civil and Environmental Engineering. Virginia Polytechnic Institute and State University, Blacksburg, VA.

Water Quality Management Planning Regulation. Chapter 720. 9 VAC 25-820-70.

Yerrell, K., Gobbie, M., Dold, P., Jones, R., Sickerdick, L. Full-Scale Demonstration Of A FreeMoving Media IFAS Process For Enhancing Nitrification Performance. Proceedings of the $74^{\text {th }}$ WEFTEC- National Conference of the Water Environment Federation. Atlanta, GA, October 13$17,2001$.

Yongzhen, P., Zhu, G. 2006. Biological Nitrogen Removal With Nitrification And Denitrification Via Nitrite Pathway. Applied Microbiology Biotechnology: 73: 15-26.

Yu-Min, S., Makinia, J., Pagilla, K. Estimation Of The Maximum Specific Growth Rate Constant For Autotrophs-Experience From The Longterm Operation Of A Lab-Scale SBR System.

Proceedings of the WEF Nutrient Removal Conference (2007). Baltimore, MD, March 4-7, 2007.

Zhu, S., Chen, S. 2002. The Impact Of Temperature On Nitrification Rate In Fixed Film Biofilters. Aquacultural Engineering: 26(4): 221-237. 


\section{APPENDICES}

\subsection{Appendix A. Nitrification Rate Testing Results}

Table 8-1. Full Scale Plant Results

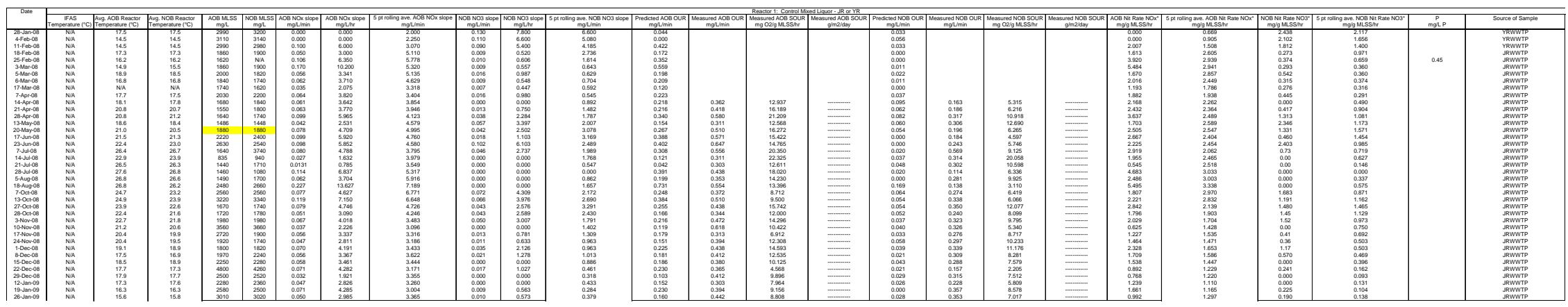

Table 8-2. IFAS Mixed Liquor Results

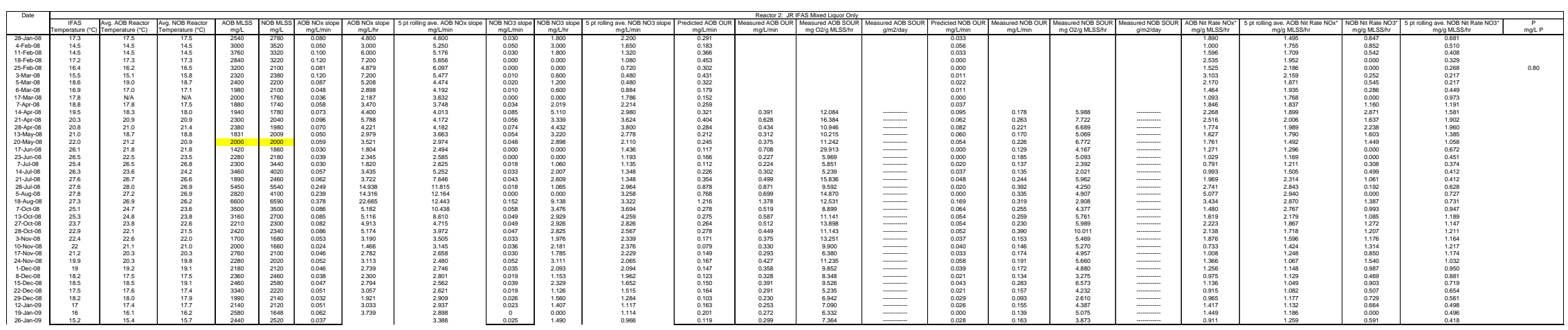


Table 8-3. IFAS Mixed Liquor with Media Results

\begin{tabular}{|c|c|c|c|c|c|c|c|c|c|c|c|c|c|c|c|c|c|c|c|c|c|c|c|c|c|c|c|c|c|c|c|c|}
\hline 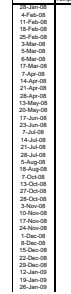 & 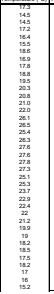 & 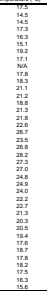 & 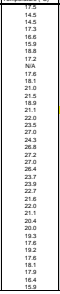 & 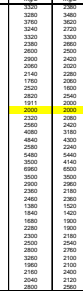 & 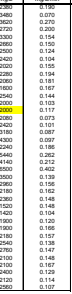 & 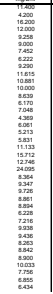 & 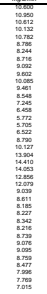 & 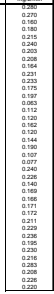 & 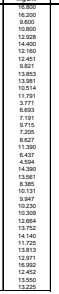 & 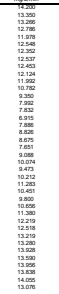 & 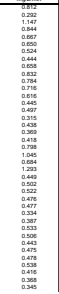 & 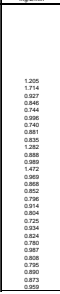 & 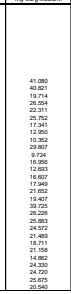 & 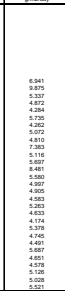 & 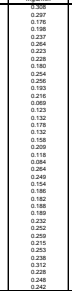 & 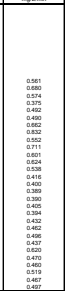 & 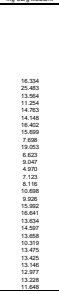 & 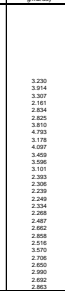 & 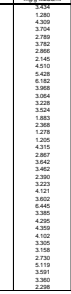 & 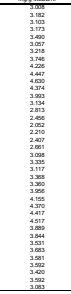 & 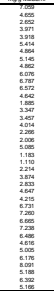 & 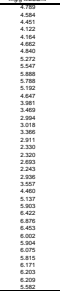 & 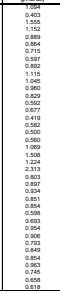 & 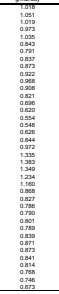 & 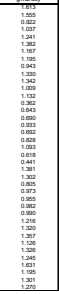 & 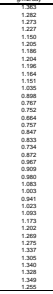 & 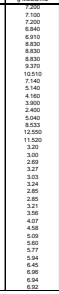 & 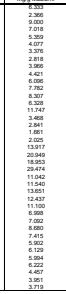 & 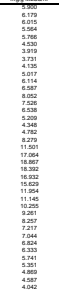 & 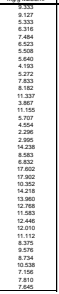 & 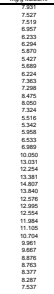 & \\
\hline
\end{tabular}

Table 8-4. IFAS Media Results

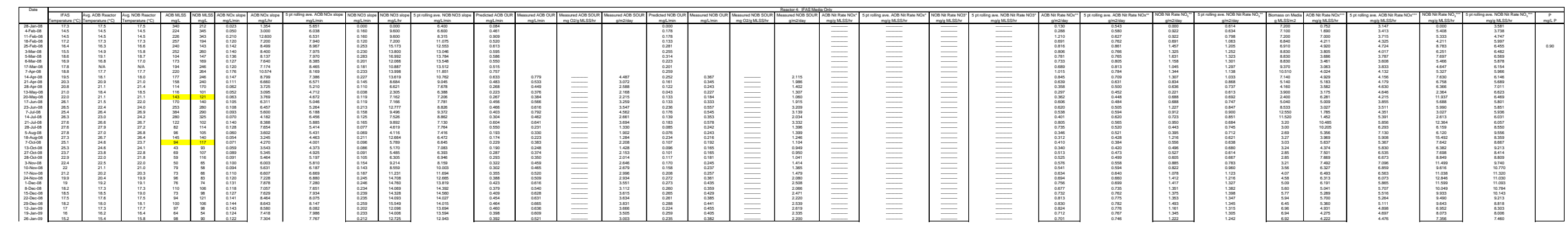


8.2 Appendix B. Sampling Location Results

Table 8-5. Sampling Location Results

\begin{tabular}{|c|c|c|cc|}
\hline $\begin{array}{c}\text { Nit Rate } \mathrm{NO}_{x}^{* *} \\
\mathrm{~g} / \mathrm{m}^{2} / \mathrm{day}\end{array}$ & $\begin{array}{c}\text { OUR } \\
\mathrm{mg} / \mathrm{L} / \mathrm{min}\end{array}$ & $\begin{array}{c}\text { SOUR } \\
\mathrm{mg} / \mathrm{L} / \mathrm{m}^{2} / \mathrm{min}\end{array}$ & $\begin{array}{c}\text { Avg. DO } \\
\mathrm{mg} / \mathrm{L}\end{array}$ & $\begin{array}{c}\mathrm{MLSS} \\
\mathrm{mg} / \mathrm{L}\end{array}$ \\
\hline 0.33 & 0.07 & 0.28 & 4.1 & 143 \\
0.323 & 0.06 & 0.238 & 3.8 & 170 \\
0.389 & 0.05 & 0.201 & 5.1 & 182 \\
0.365 & 0.055 & 0.222 & 4.7 & 146 \\
\hline \hline
\end{tabular}

\begin{tabular}{|c|c|c|cc|}
\hline \hline $\begin{array}{c}\text { Nit Rate } \mathrm{NO}_{3}{ }^{* *} \\
\mathrm{~g} / \mathrm{m}^{2} / \mathrm{day}\end{array}$ & $\begin{array}{c}\text { OUR } \\
\mathrm{mg} / \mathrm{L} / \mathrm{min}\end{array}$ & $\begin{array}{c}\text { SOUR } \\
\mathrm{mg} / \mathrm{L} / \mathrm{m}^{2} / \mathrm{min}\end{array}$ & $\begin{array}{c}\text { Avg. DO } \\
\mathrm{mg} / \mathrm{L}\end{array}$ & $\begin{array}{c}\mathrm{MLSS} \\
\mathrm{mg} / \mathrm{L}\end{array}$ \\
\hline 0.543 & 0.031 & 0.123 & 4.4 & 122 \\
0.521 & 0.028 & 0.112 & 3.9 & 102 \\
0.671 & 0.029 & 0.116 & 4.8 & 202 \\
0.595 & 0.035 & 0.139 & 4.9 & 122 \\
\hline
\end{tabular}




\subsection{Appendix C. $K_{O}$ Results}

Table 8-6. Media $\mathrm{K}_{\mathrm{O}}$ Data

\begin{tabular}{|c|c|c|c|c|c|}
\hline Date & $\begin{array}{l}\mathrm{DO} \\
\mathrm{mg} / \mathrm{L}\end{array}$ & $\begin{array}{l}\text { Max NOx Slope } \\
\mathrm{mg} / \mathrm{L} / \mathrm{min}\end{array}$ & $\begin{array}{l}\text { Max Nit Rate NOX*" } \\
\text { g/m²/day }\end{array}$ & $\begin{array}{l}\mathrm{MLSS} \\
\mathrm{mg} / \mathrm{L}\end{array}$ & $\begin{array}{c}\begin{array}{c}\text { Biomass on Media } \\
\mathrm{g} / \mathrm{m}^{2}\end{array} \\
\end{array}$ \\
\hline \multirow{3}{*}{ 19-May-08 } & 3.1 & 0.059 & 0.34 & 205 & 2.4 \\
\hline & 5.2 & 0.069 & 0.4 & 184 & 2.4 \\
\hline & $\begin{array}{l}.3 \\
9.1\end{array}$ & $\begin{array}{l}0.092 \\
0.092\end{array}$ & 0.53 & 142 & $\begin{array}{l}2.4 \\
2.4\end{array}$ \\
\hline \multirow{4}{*}{ 4-Jun-08 } & 3.1 & 0.098 & 0.57 & 158 & 3.46 \\
\hline & 5.1 & 0.143 & 0.82 & 112 & 3.46 \\
\hline & 7.1 & 0.17 & 0.98 & 142 & 3.46 \\
\hline & $\frac{9.1}{21}$ & 0.198 & 1.14 & 118 & $\begin{array}{l}3.46 \\
\end{array}$ \\
\hline \multirow{3}{*}{ 22-Jul-08 } & $\begin{array}{c}2.1 \\
4\end{array}$ & $\begin{array}{l}0.089 \\
0.125\end{array}$ & $\begin{array}{l}0.51 \\
0.72\end{array}$ & $\begin{array}{l}190 \\
220\end{array}$ & $\begin{array}{l}3.2 \\
3.2\end{array}$ \\
\hline & 6.5 & 0.162 & 0.93 & 193 & 3.2 \\
\hline & 8.1 & 0.159 & & 120 & \\
\hline
\end{tabular}

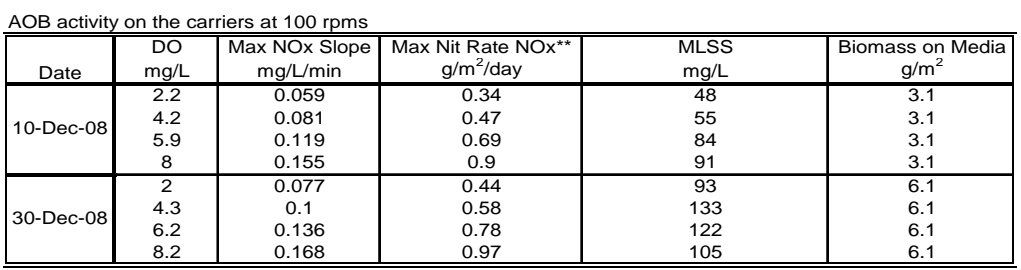

\begin{tabular}{|c|c|c|c|c|c|}
\hline Date & $\begin{array}{c}\mathrm{DO} \\
\mathrm{mg} / \mathrm{L}\end{array}$ & $\begin{array}{c}\mathrm{Max} \mathrm{NO}_{3} \text { Slope } \\
\mathrm{mg} / \mathrm{L} / \mathrm{min}\end{array}$ & $\begin{array}{c}\text { Max Nit Rate } \mathrm{NO}_{3}{ }^{* *} \\
\mathrm{~g} / \mathrm{m}^{2} / \text { day }\end{array}$ & $\begin{array}{c}\mathrm{MLSS} \\
\mathrm{mg} / \mathrm{L}\end{array}$ & \begin{tabular}{|c|} 
Biomass on Media \\
$\mathrm{g} / \mathrm{m}^{2}$
\end{tabular} \\
\hline \multirow{3}{*}{ 2-Jun-08 } & & 0.163 & 0.94 & 124 & 3.46 \\
\hline & $\begin{array}{l}5.7 \\
7.2\end{array}$ & $\begin{array}{c}0.168 \\
1.78\end{array}$ & $\begin{array}{l}0.97 \\
1.03\end{array}$ & $\begin{array}{c}112 \\
95\end{array}$ & $\begin{array}{l}.40 \\
3.46 \\
3.46\end{array}$ \\
\hline & & 0.173 & & 118 & $\begin{array}{l}3.40 \\
3.46 \\
\end{array}$ \\
\hline \multirow{4}{*}{ 24-Jun-08 } & 2.4 & 0.096 & 0.55 & 381 & 8.53 \\
\hline & & 0.168 & 0.97 & 365 & 8.53 \\
\hline & 6.1 & 0.202 & 1.16 & 273 & 8.53 \\
\hline & 8.4 & 0.209 & 1.2 & 258 & 8.53 \\
\hline \multirow{3}{*}{ 4-Nov-08 } & 2.1 & 0.157 & $\begin{array}{c}0.9 \\
1\end{array}$ & $\begin{array}{l}58 \\
75\end{array}$ & $\begin{array}{l}3 \\
3 \\
3\end{array}$ \\
\hline & $\begin{array}{l}4.8 \\
6.5\end{array}$ & 0.174 & $\begin{array}{l}1 \\
0.95\end{array}$ & $\begin{array}{l}75 \\
82\end{array}$ & $\begin{array}{l}3 \\
3\end{array}$ \\
\hline & $\begin{array}{c}6.5 \\
9\end{array}$ & $\begin{array}{l}0.165 \\
0.18\end{array}$ & $\begin{array}{l}0.95 \\
1.04\end{array}$ & $\begin{array}{l}82 \\
68\end{array}$ & 3 \\
\hline
\end{tabular}

\begin{tabular}{|c|c|c|c|c|c|}
\hline Date & $\begin{array}{c}\mathrm{DO} \\
\mathrm{mg} / \mathrm{L}\end{array}$ & $\begin{array}{c}\mathrm{Max} \mathrm{NO}_{3} \mathrm{Slope} \\
\mathrm{mg} / \mathrm{L} / \mathrm{min}\end{array}$ & $\begin{array}{c}\text { Max Nit Rate } \mathrm{NO}_{3}{ }^{* *} \\
\mathrm{~g} / \mathrm{m}^{2} / \text { day }\end{array}$ & $\begin{array}{c}\mathrm{MLSS} \\
\mathrm{mg} / \mathrm{L}\end{array}$ & $\begin{array}{c}\text { Biomass on Media } \\
\mathrm{g} / \mathrm{m}^{2}\end{array}$ \\
\hline \multirow{3}{*}{ 9-Dec-08 } & 2.1 & 0.116 & 0.67 & 48 & 5.6 \\
\hline & 4.1 & 0.126 & $\begin{array}{l}0.73 \\
1.16\end{array}$ & $\begin{array}{l}55 \\
84\end{array}$ & $\begin{array}{l}5.6 \\
5.6\end{array}$ \\
\hline & & $\begin{array}{l}0.2 \\
0.286\end{array}$ & $\begin{array}{l}1.16 \\
1.65\end{array}$ & $\begin{array}{l}84 \\
91\end{array}$ & $\begin{array}{l}5.6 \\
5.6\end{array}$ \\
\hline \multirow{3}{*}{ 27-Jan-09 } & 2.4 & 0.114 & 0.65 & & 6.92 \\
\hline & & & & ------ & \\
\hline & $\begin{array}{l}6.3 \\
85\end{array}$ & 0.167 & $\begin{array}{l}0.96 \\
12\end{array}$ & ------ & $\begin{array}{l}6.92 \\
6.92\end{array}$ \\
\hline
\end{tabular}


Table 8-7. Mixed Liquor $\mathrm{K}_{\mathrm{O}}$ Data.

AOB activity on the carriers at 175 rpms

\begin{tabular}{|c|c|c|c|c|}
\hline \hline Date & $\begin{array}{c}\text { DO } \\
\mathrm{mg} / \mathrm{L}\end{array}$ & $\begin{array}{c}\text { Max NOx Slope } \\
\mathrm{mg} / \mathrm{L} / \mathrm{min}\end{array}$ & $\begin{array}{c}\text { Max Nit Rate NOx } \\
\mathrm{mg} / \mathrm{g} \text { MLSS/hr }\end{array}$ & $\begin{array}{c}\text { MLSS } \\
\mathrm{mg} / \mathrm{L}\end{array}$ \\
\hline & 2 & 0.0662 & 15.81 & 1760 \\
12-Nov-08 & 4.2 & 0.0654 & 15.26 & 1800 \\
& 5.9 & 0.0601 & 14.5 & 1740 \\
& 8 & 0.0637 & 14.87 & 1800 \\
\hline \hline
\end{tabular}

NOB activity on the carriers at $175 \mathrm{rpms}$

\begin{tabular}{|c|c|c|c|c|}
\hline \hline Date & $\mathrm{DO}$ & $\begin{array}{c}\text { Max } \mathrm{NO}_{3} \text { Slope } \\
\mathrm{mg} / \mathrm{L} / \mathrm{min}\end{array}$ & $\begin{array}{c}\text { Max Nit Rate } \mathrm{NO}_{3}{ }^{* *} \\
\mathrm{mg} / \mathrm{g} \mathrm{MLSS} / \mathrm{hr}\end{array}$ & $\begin{array}{c}\mathrm{MLSS} \\
\mathrm{mg} / \mathrm{L}\end{array}$ \\
\hline & 2.2 & 0.0391 & 9.03 & 1820 \\
11-Nov-08 & 4.9 & 0.0406 & 9.37 & 1800 \\
& 6.5 & 0.0421 & 9.72 & 1680 \\
& 8.9 & 0.0379 & 8.75 & 1620 \\
\hline
\end{tabular}




\subsection{Appendix D. Mixing and DO Results}

Table 8-8. Mixing and DO Data

\begin{tabular}{|c|c|c|c|c|c|c|}
\hline $\begin{array}{c}A O B \text { activity on } \\
\text { Date }\end{array}$ & 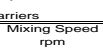 & $\frac{9}{89}$ & mor & 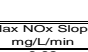 & 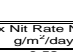 & 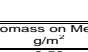 \\
\hline \multirow{3}{*}{ 18: Nov-0os } & 175 & 247 & 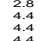 & \begin{tabular}{|l|l}
0.099 \\
0.19 \\
0.119
\end{tabular} & 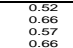 & 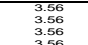 \\
\hline & 190 & 171 & $\begin{array}{l}17 \\
5= \\
5=7\end{array}$ & $\begin{array}{l}\text { o.o64 } \\
\text { o.1.198 } \\
0.1989\end{array}$ & 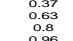 & 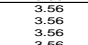 \\
\hline & 100 & 97 & 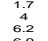 & 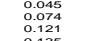 & $\begin{array}{l}0.26 \\
0.43 \\
0.7 \\
0.7\end{array}$ & $\begin{array}{l}3.56 \\
3.56 \\
3.565\end{array}$ \\
\hline \multirow{3}{*}{ 13-Jan-09 } & 175 & 253 & 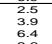 & 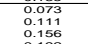 & $\begin{array}{l}0.42 \\
0.42 \\
0.94\end{array}$ & 6 \\
\hline & 190 & 178 & 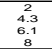 & 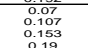 & $\begin{array}{l}0.4 \\
0.88 \\
0.88\end{array}$ & $\begin{array}{l}\text { s6 } \\
\text { s6 }\end{array}$ \\
\hline & 100 & 107 & $\begin{array}{l}5.9 \\
5.9 \\
8.1\end{array}$ & 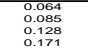 & 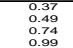 & \\
\hline
\end{tabular}

\begin{tabular}{|c|c|c|c|c|c|c|}
\hline $\begin{array}{l}\text { activity } \\
\text { Date }\end{array}$ & 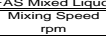 & a & $\begin{array}{l}\text { Do } \\
\text { mgh/ }\end{array}$ & $\begin{array}{l}\text { Max NOX Slope } \\
\text { malumin }\end{array}$ & 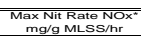 & \begin{tabular}{|l|l} 
MLSS \\
mglu
\end{tabular} \\
\hline \multirow{3}{*}{ 25-Nov-08 } & 175 & 154 & $\begin{array}{l}2.2 \\
4.9 \\
6.1 \\
6.1\end{array}$ & $\begin{array}{l}\text { o.0.099 } \\
\text { o.0.055 }\end{array}$ & 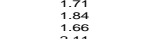 & $\begin{array}{l}1730 \\
1930 \\
1980\end{array}$ \\
\hline & 140 & 116 & $\begin{array}{l}4.1 \\
4.2 \\
6 \\
7\end{array}$ & $\begin{array}{l}0.063 \\
0.0559 \\
0.055\end{array}$ & $\begin{array}{l}\frac{2.13}{2.13} \\
1.5\end{array}$ & $\begin{array}{l}1800 \\
1800 \\
2160\end{array}$ \\
\hline & 100 & 76 & $\begin{array}{l}1.9 \\
5.9 \\
5.9\end{array}$ & $\begin{array}{l}0.052 \\
0.058 \\
0.0565\end{array}$ & 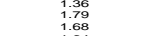 & $\begin{array}{l}2280 \\
19800 \\
2000\end{array}$ \\
\hline \multirow{3}{*}{ 16-Dec-08 } & 175 & 152 & 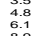 & $\begin{array}{lll}0.046 \\
\text { o. } 0.0453 \\
0.0438\end{array}$ & $\begin{array}{l}1.12 \\
1.12 \\
1.2\end{array}$ & 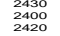 \\
\hline & 140 & 116 & $\begin{array}{c}2.9 \\
6.9 \\
6.1\end{array}$ & 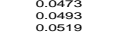 & $\begin{array}{l}1.19 \\
1.22 \\
1.21\end{array}$ & 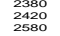 \\
\hline & 100 & 77 & $\begin{array}{l}2.6 \\
3.6 \\
6.4\end{array}$ & 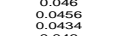 & $\begin{array}{l}1.13 \\
.098 \\
.094\end{array}$ & 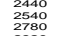 \\
\hline
\end{tabular}

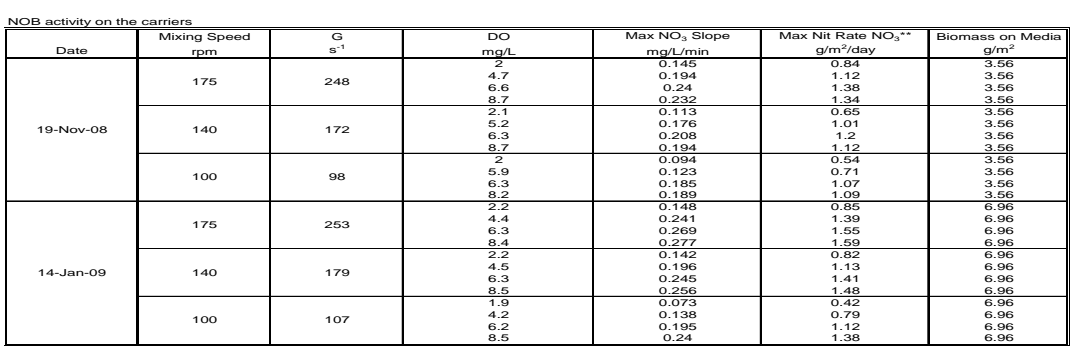

\begin{tabular}{|c|c|c|c|c|c|c|}
\hline $\begin{array}{l}\text { Bactiviy } \\
\text { Date }\end{array}$ & 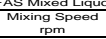 & $\frac{\mathrm{G}}{\mathrm{s}^{-1}}$ & $\begin{array}{l}\mathrm{DO} \\
\mathrm{mg} / \mathrm{h}\end{array}$ & $\begin{array}{l}\text { Max NOX Slope } \\
\text { mal/Lmin }\end{array}$ & $\begin{array}{c}\text { Max Nit Rate NOX } \\
\text { math MLSSThr }\end{array}$ & $\begin{array}{ll}\text { MLSS } \\
\text { mol }\end{array}$ \\
\hline \multirow{3}{*}{ 26-Nov-08 } & 175 & 153 & $\begin{array}{l}4.7 \\
6.6 \\
6.6\end{array}$ & $\begin{array}{l}0.0 .035 \\
0.037 \\
0.037\end{array}$ & $\begin{array}{l}1.22 \\
1.01 \\
1.12\end{array}$ & 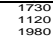 \\
\hline & 140 & 116 & $\begin{array}{l}2.1 \\
5.2 \\
6.3\end{array}$ & $\begin{array}{l}0.0 .054 \\
0.045 \\
0.045\end{array}$ & $\begin{array}{l}1.8 \\
1.24\end{array}$ & 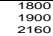 \\
\hline & 100 & 77 & $\begin{array}{l}5.9 \\
5.9 \\
6.3\end{array}$ & 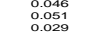 & 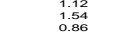 & 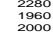 \\
\hline \multirow{4}{*}{ 17-Dec-.08 } & 175 & 151 & $\begin{array}{l}4.9 \\
6.3\end{array}$ & 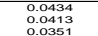 & $\begin{array}{l}1.09 \\
\text { i. } \\
0.75\end{array}$ & 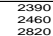 \\
\hline & & & & & & \\
\hline & 140 & 116 & $\begin{array}{l}6.7 \\
9.3 \\
\end{array}$ & $\begin{array}{l}0.021 \\
0.05 \\
0.051\end{array}$ & $\begin{array}{l}0.21 \\
1.28 \\
1.28 \\
\end{array}$ & 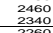 \\
\hline & 100 & 77 & $\begin{array}{l}4.5 \\
6.4 \\
8.4\end{array}$ & $\begin{array}{l}0.0558 \\
0.0506 \\
0.0592\end{array}$ & $\begin{array}{l}1.52 \\
1.39 \\
161\end{array}$ & $\begin{array}{l}2200 \\
2180 \\
2200\end{array}$ \\
\hline
\end{tabular}




\subsection{Appendix E. COD Addition Results}

Table 8-9. COD Addition Data

$A O B$ activity the coriers at 175

\begin{tabular}{|c|c|c|c|c|c|c|c|c|c|c|c|}
\hline Date & $\begin{array}{c}\begin{array}{c}\text { Max NOx Slope } \\
\mathrm{mg} / \mathrm{L} / \mathrm{min}\end{array} \\
\end{array}$ & $\begin{array}{c}\text { Max Nit Rate NOx } \\
\text { mg/g MLSS/hr }\end{array}$ & $\begin{array}{c}\text { Max Nit Rate NOx } x^{\star \star} \\
\mathrm{g} / \mathrm{m}^{2} / \text { day }\end{array}$ & $\begin{array}{c}\text { COD Uptake } \\
\mathrm{mg} / \mathrm{L} / \mathrm{min}\end{array}$ & $\begin{array}{l}\text { COD Uptake* } \\
\mathrm{mg} / \mathrm{g} \mathrm{MLSS} / \mathrm{hr}\end{array}$ & 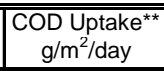 & $\begin{array}{c}\text { OUR } \\
\mathrm{mg} / \mathrm{L} / \mathrm{min}\end{array}$ & \begin{tabular}{|c|} 
SOUR \\
$\mathrm{mg} / \mathrm{g}$ MLSS/hr
\end{tabular} & $\begin{array}{c}\text { SOUR } \\
\mathrm{g} / \mathrm{m}^{2} / \text { day }\end{array}$ & $\begin{array}{c}\mathrm{MLSS} \\
\mathrm{mg} / \mathrm{L}\end{array}$ & $\begin{array}{c}\text { Biomass on Media } \\
\mathrm{g} / \mathrm{m}^{2}\end{array}$ \\
\hline \multirow{4}{*}{ 2-Dec-08 } & 0.036 & 0.98 & --------- & 2.88 & 1.32 & --------- & 0.352 & 0.16 & -------- & 2180 & -------- \\
\hline & 0.06 & 1.51 & --------. & 205.2 & 86.23 & --------- & 0.739 & 0.31 & -------. & 2380 & ------- \\
\hline & 0.128 & - & 0.74 & 1.2 & - - - - & 0.12 & 0.651 & - & 2.6 & 78 & 5.4 \\
\hline & 0.137 & 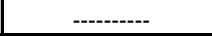 & 0.79 & 4.38 & --.---.-- & 0.42 & 0.677 & -.-. & 2.71 & 79 & 5.4 \\
\hline \multirow{4}{*}{ 28-Jan-09 } & 0.04 & 2.28 & -------- & 1.92 & 0.81 & 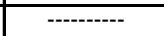 & 0.25 & 0.11 & & 2360 & --.-- \\
\hline & 0.012 & 0.38 & ------- & 127.8 & 47.61 & --.-- & 0.93 & 0.35 & -.---.-. & 2680 & - \\
\hline & 0.237 & -------- & 0.88 & 3.6 & -------- & 0.35 & 0.69 & -------- & 2.74 & 100 & 6.9 \\
\hline & 0.231 & --.---.-- & 0.71 & 14.22 & --.---.-- & 1.37 & 0.71 & --------- & 2.85 & 110 & 6.9 \\
\hline
\end{tabular}

NOB activity on the carriers at $175 \mathrm{rpms}$

\begin{tabular}{|c|c|c|c|c|c|c|c|c|c|c|c|}
\hline Date & $\begin{array}{c}\mathrm{Max} \mathrm{NO}_{3} \text { Slope } \\
\mathrm{mg} / \mathrm{L} / \mathrm{min}\end{array}$ & $\begin{array}{c}\text { Max Nit Rate } \mathrm{NO}_{3}{ }^{*} \\
\mathrm{mg} / \mathrm{g} \mathrm{MLSS} / \mathrm{hr}\end{array}$ & \begin{tabular}{|c|} 
Max Nit Rate $\mathrm{NO}_{3}{ }^{* *}$ \\
$\mathrm{~g} / \mathrm{m}^{2} /$ day
\end{tabular} & $\begin{array}{c}\text { COD Uptake } \\
\mathrm{mg} / \mathrm{L} / \mathrm{min}\end{array}$ & $\begin{array}{l}\text { COD Uptake* } \\
\mathrm{mg} / \mathrm{g} \text { MLSS/hr }\end{array}$ & $\begin{array}{l}\text { COD Uptake }{ }^{\star *} \\
\mathrm{~g} / \mathrm{m}^{2} / \text { day }\end{array}$ & $\begin{array}{c}\text { OUR } \\
\mathrm{mg} / \mathrm{L} / \mathrm{min}\end{array}$ & \begin{tabular}{|c|} 
SOUR \\
$\mathrm{mg} / \mathrm{g}$ MLSS/hr
\end{tabular} & $\begin{array}{c}\text { SOUR } \\
\mathrm{g} / \mathrm{m}^{2} / \text { day }\end{array}$ & $\begin{array}{c}\mathrm{MLSS} \\
\mathrm{mg} / \mathrm{L}\end{array}$ & $\begin{array}{c}\text { Biomass on Media } \\
\mathrm{g} / \mathrm{m}^{2}\end{array}$ \\
\hline \multirow{4}{*}{ 2-Dec-08 } & 0.04 & 1.02 & --------- & 16.02 & 6.8 & --------- & 0.14 & 0.059 & --------- & 2360 & 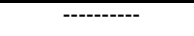 \\
\hline & 0.012 & 0.29 & --------- & 106.8 & 43.5 & --------- & 0.651 & 0.265 & --------- & 2460 & - \\
\hline & 0.237 & ------- & 1.37 & 14.52 & -------- & 1.4 & 0.319 & -..--- & 1.28 & 79 & 5.4 \\
\hline & 0.231 & - & 1.33 & 31.56 & --.---.-- & 3.03 & 0.375 & & 1.5 & 94 & 5.4 \\
\hline \multirow{4}{*}{ 28-Jan-09 } & 0.027 & 0.67 & --------- & 2.13 & 0.87 & -------- & 0.144 & 0.059 & -----י & 2440 & \\
\hline & 0.019 & 0.43 & -------.- & 92.4 & 33.72 & --------. & 0.817 & 0.3 & ---------- & 2740 & \\
\hline & 0.225 & --------- & 1.3 & 18.24 & --------- & 1.75 & 0.411 & --------- & 1.65 & 84 & 6.9 \\
\hline & 0.215 & ---------- & 1.24 & 25.8 & --------- & 2.48 & 0.47 & --o- & 1.88 & 108 & 6.9 \\
\hline
\end{tabular}

